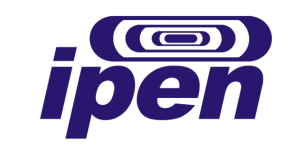

AUTARQUIA ASSOCIADA À UNIVERSIDADE DE SÃO PAULO

\title{
DETERMINAÇÃO DE ISÓTOPOS DE URÂNIO E TÓRIO E POLÔNIO EM PERFÍS DE SEDIMENTO DA BAIXADA SANTISTA, SP
}

\section{GUILHERME DA FRANCA RAMOS}

Dissertação apresentada como parte dos requisitos para a obtenção do grau de mestre em Ciências na área de Tecnologia Nuclear - Aplicações

Orientadora: Barbara Paci Mazzilli

São Paulo 2010 


\section{AGRADECIMENTOS}

À Profa ${ }^{a}{ }^{2} r^{a}$ Barbara Paci Mazzilli pelas orientações e todo suporte para o desenvolvimento do trabalho.

À minha esposa Rita e filha Maria Thereza pelo amor, carinho e suporte durante esta etapa.

Aos meus pais Paulo e Ana Maria.

Aos meus irmãos Ana Paula e Ricardo

Ao Prof. Dr. Paulo Sergio Cardoso da Silva pela inestimável ajuda e companheirismo.

Aos meus colegas do L.R.A., especialmente a $\mathrm{Dr}^{\mathrm{a}}$ Sandra Regina Damatto, $\mathrm{Dr}^{\mathrm{a}}$ Márcia Pires Campos, Fernanda Melo Le Bourlegat, Fábio Vitorino Sussa, Fabiola Pedroso Amaral, Dr. Marcelo Maduar, Marcelo Bessa Nisti.

À CETESB pela coleta das amostras

Aos meus amigos e colegas 
"Qualquer pessoa que tenha experiência com o trabalho científico sabe que aqueles que se recusam a ir além dos fatos raramente chegam aos fatos em si"

Thomas Huxley

"A música exprime a mais alta filosofia numa linguagem que a razão não compreende."

Arthur Schopenhauer

"Let my soul smile through my heart and my heart smile through my eyes, that I may scatter rich smiles in sad hearts." ParamahansaYogananda 


\section{DETERMINAÇÃO DE ISÓTOPOS DE URÂNIO E TÓRIO E POLÔNIO EM PERFÍS DE SEDIMENTO DA BAIXADA SANTISTA, SP}

\section{Guilherme da Franca Ramos}

RESUMO

O objetivo do presente trabalho é determinar a concentração de atividade de isótopos de ocorrência natural de urânio e tório e o polônio em perfis de sedimento marinho da Baixada Santista. A Baixada Santista é uma região populosa e abrange os municípios de Bertioga, Guarujá, Santos, São Vicente, Cubatão, Praia Grande, Mongaguá, Itanhaém e Peruíbe. Esta é uma das mais importantes regiões industriais do Brasil, dado ao grande número de indústrias, como as de fertilizantes, petroquímicas e do aço. A grande atividade industrial, juntamente com a grande população da região, exerce forte pressão sobre a biota marinha.

O presente trabalho analisou 10 perfis de sedimentos marinhos extraídos da região. Foram coletados perfis com tamanhos variando de 41 a $98 \mathrm{~cm}$, na região de Santos, Cubatão, São Vicente e Bertioga. Os perfis foram fatiados a cada $2 \mathrm{~cm}$ e passaram por um pré-tratamento físico e químico. Para a dissolução total e digestão foram utilizados ataques com ácidos fortes. As técnicas radioquímicas utilizadas para a separação dos radionuclídeos e preparação das fontes radioativas, para a contagem alfa, foram separação por cromatografia de troca iônica e eletrodeposição para urânio e tório e deposição espontânea para o polônio.

Os resultados obtidos para as concentrações de atividade dos radionuclídeos são semelhantes aos de sedimentos marinhos em regiões não contaminadas, exceto em alguns pontos amostrados, nos quais foi possível identificar influência antrópica. 


\title{
DETERMINATION OF URANIUM AND THORIUM ISOTOPES AND POLONIUM IN SEDIMENT PROFILES FROM BAIXADA SANTISTA, SP
}

\section{Guilherme da Franca Ramos}

\begin{abstract}
The objective of the present work is to determine the activity concentration of uranium and thorium isotopes and polonium in estuarine sediments from BaixadaSantista. The area comprehends nine cities in the Brazilian coast (Bertioga, Guarujá, Santos, São Vicente, Cubatão, Praia Grande, Mongaguá, Itanhaém and Peruíbe). It is one of the most important industrial areas in Brazil due to the large number of industries operating in Cubatão, such as steel, petrochemical and fertilizer industries. That, together with a large population, causes a negative impact on the marine biota. In the present work 10 profiles of sediment cores, with depth varying from 41 to $98 \mathrm{~cm}$, were analyzed. The cores were obtained from Santos, Cubatão, São Vicente and Bertioga. The cores were sliced every $2 \mathrm{~cm}$ and were treated with both physical and chemical processes, including drying, grinding and sieving. The samples were dissolved by acid digestion, till total dissolution and destruction of organic matter. After the acid digestion, the samples were filtered and evaporated till dryness. The radiochemical techniques used to separate the radionuclides and to prepare the final source for alpha counting were ion exchange chromatography and spontaneous deposition for polonium and electrodeposition for $\mathrm{U}$ and $\mathrm{Th}$. The final sources were counted in a surface barrier alpha spectrometer.

Values obtained for the radionuclides analyzed were similar to the activity concentrations of sediments in non polluted areas, with the exception of a few samples that showed anthropic influence.
\end{abstract}




\section{SUMÁRIO}

1. INTRODUÇÃO

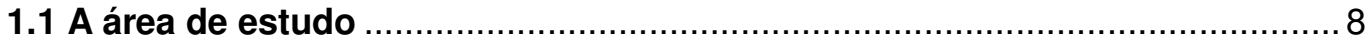

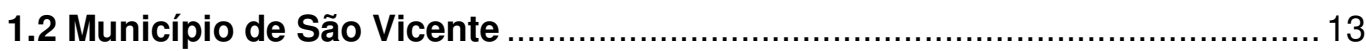

1.3 Município de Cubatão .............................................................................. 13

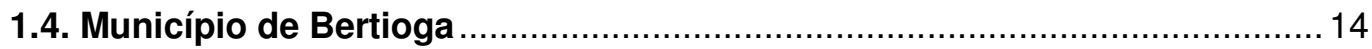

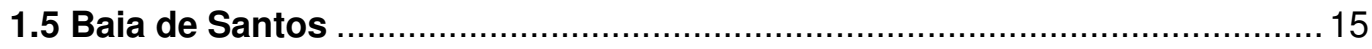

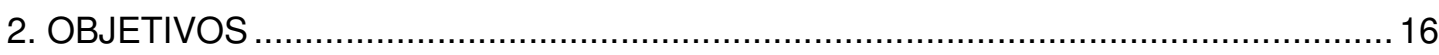

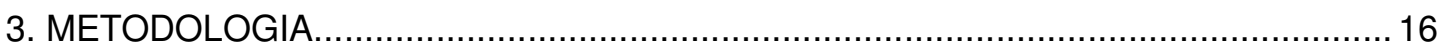

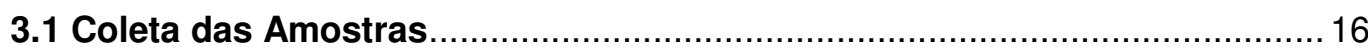

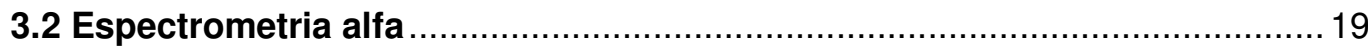

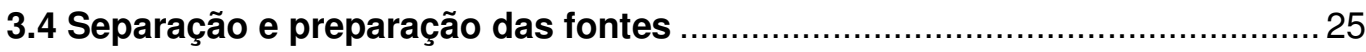

3.5 Determinação da Eficiência e calibração das energias dos detectores alfa.27 3.6 Determinação da radiação de fundo e limite inferior de detecção (LID) .......30 3.7 Validação da metodologia para a determinação do U, Th e Po ......................31

3.8 Cálculo do rendimento químico e da concentração de atividade dos

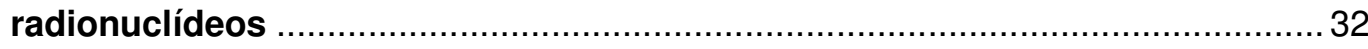

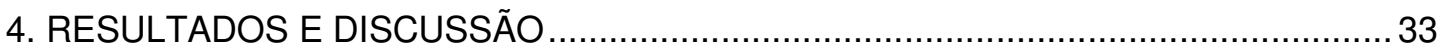

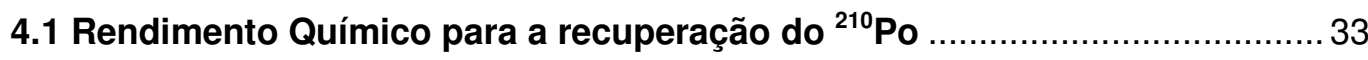

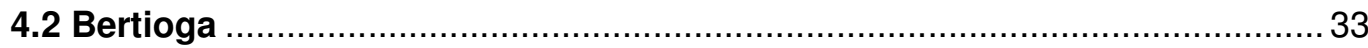

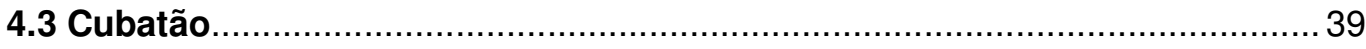

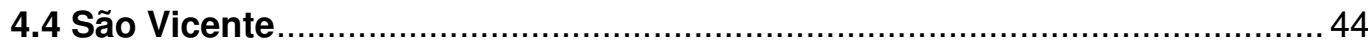

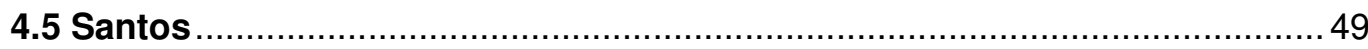

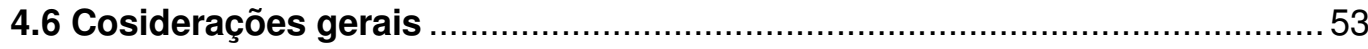

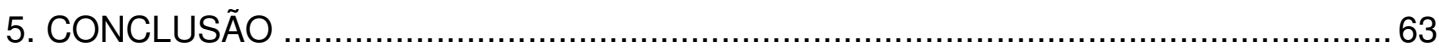

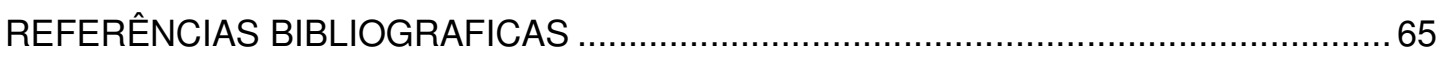




\section{LISTA DE FIGURAS}

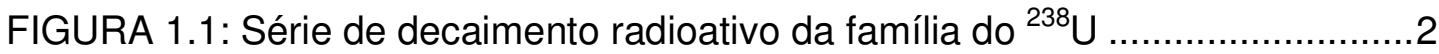

FIGURA 1.2: Série de decaimento radioativo da família do ${ }^{232} \mathrm{Th}$...........................2

FIGURA 1.3: Região da Baixada Santista e seus municípios ...............................10

FIGURA 3.1: Amostrador tipo piston corer. Disponível em www.mnhn. ...............17

FIGURA 3.2: Localização dos pontos de coleta na área de estudo ......................19

FIGURA 3.3: Esquema de um detector de partículas alfa (espectrômetro alfa) ...20

FIGURA 3.4: Espectro típico de urânio por espectrometria alfa. Ressaltando em

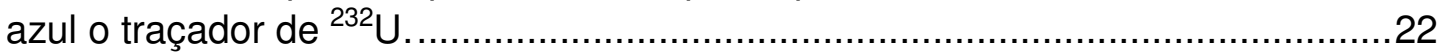

FIGURA 3.5: Espectro típico de tório por espectrometria alfa. Ressaltando em

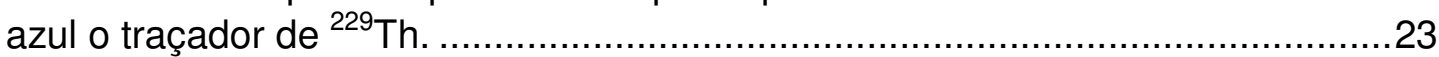

FIGURA 3.6: Espectro típico de polônio por espectrometria alfa. Ressaltando em

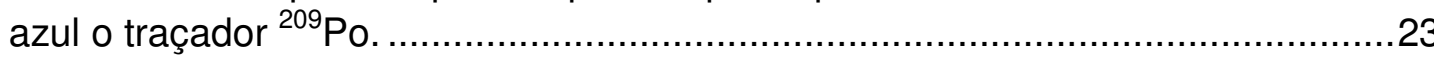

FIGURA 3.7: Arranjo experimental para a eletrodeposição ..................................26

FIGURA 3.8: Suporte para a deposição do polônio e arranjo experimental para a

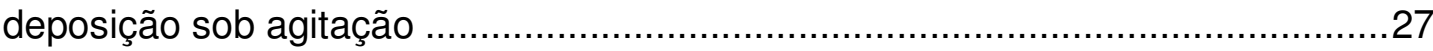

FIGURA 3.9: Espectrômetro alfa e detalhe da câmara com detector ....................28

FIGURA 3.10: Curva de Calibração do detector alfa .........................................29

FIGURA 4.1 Concentrações de atividade dos radionuclídeos $\left(\mathrm{Bq} \mathrm{kg}^{-1}\right)$ e fração fina no testemunho BE1 coletado na região de Bertioga ...................................36

FIGURA 4.2: Concentrações de atividade dos radionuclídeos $\left(\mathrm{Bq} \mathrm{kg}^{-1}\right)$ e fração fina no testemunho BE2 coletado na região de Bertioga ....................................37

FIGURA 4.3: Concentrações de atividade dos radionuclídeos $\left(\mathrm{Bq} \mathrm{kg}^{-1}\right)$ e fração fina no testemunho BE3 coletado na região de Bertioga .....................................37

FIGURA 4.4: Box plot com as concetrações de atividade média dos radionuclídeos estudados nos testemunhos coletados na região de Bertioga (BE1, BE2 e BE3), mostrando erro padrão (EP) e desvio padrão (DP) .38

FIGURA 4.5: Concentrações de atividade dos radionuclídeos $\left(\mathrm{Bq} \mathrm{kg}^{-1}\right)$ e fração

fina no testemunho CB1 coletado na região de Cubatão. 41

FIGURA 4.6: Concentrações de atividade dos radionuclídeos $\left(\mathrm{Bq} \mathrm{kg}^{-1}\right)$ e fração fina no testemunho CB2 coletado na região de Cubatão.

FIGURA 4.7:Box plotcom as concetrações de atividade média dos radionuclídeos estudados nos testemunhos coletados na região de Cubatão (CB1 e CB2), mostrando erro padrão (EP) e desvio padrão (DP) .43

FIGURA 4.8: Concentrações de atividade dos radionuclídeos $\left(\mathrm{Bq} \mathrm{kg}^{-1}\right)$ e fração fina no testemunho SV1 coletado na região de São Vicente, SP..........................46 FIGURA 4.9: Concentrações de atividade dos radionuclídeos $\left(\mathrm{Bq} \mathrm{kg}^{-1}\right)$ e fração fina no testemunho SV2 coletado na região de São Vicente, SP..... 46 FIGURA 4.10: Concentrações de atividade dos radionuclídeos $\left(\mathrm{Bq} \mathrm{kg}^{-1}\right)$ e fração fina no testemunho SV3 coletado na região de São Vicente, SP. 
FIGURA 4.11 Box plot do testemunho SV1 coletado na região de São Vicente, $\mathrm{SP}$, mostrando as médias, erro padrão (EP) e desvio padrão (DP) para os radionuclídeos estudados. 48

FIGURA 4.12: Concentrações de atividade dos radionuclídeos $\left(\mathrm{Bq} \mathrm{kg}^{-1}\right)$ e fração fina no testemunho SA1 coletado na região de Santos, SP. 50 FIGURA 4.13: Concentrações de atividade dos radionuclídeos $\left(\mathrm{Bq} \mathrm{kg}^{-1}\right)$ e fração fina no testemunho SA2 coletado na região de Santos, SP. 51 FIGURA 4.14: Box plot do testemunho SA1 coletado na região de Santos, SP, mostrando as médias, erro padrão (EP) e desvio padrão (DP) para os radionuclídeos estudados.

FIGURA 4.15: Box plot com as médias, erro padrão e desvio padrão das concentrações de atividade do ${ }^{238} \mathrm{U}$ nos dez testemunhos coletados, a linha azul representa o valor médioglobal para solos e as vermelhas a variação típica esperada(UNSCEAR, 1988)

FIGURA 4.16: Box plot com as médias, erro padrão e desvio padrão das concentrações de atividade do ${ }^{234} \mathrm{U}$ nos dez testemunhos coletados. 54

FIGURA 4.17: Box plot com as médias, erro padrão e desvio padrão das concentrações de atividade do ${ }^{230} \mathrm{Th}$ nos dez testemunhos coletados. 56

FIGURA 4.18: Box plot com as médias, erro padrão e desvio padrão das concentrações de atividade do ${ }^{232}$ Th nos dez testemunhos coletados, a linha azul representa o valor médio global para solos e as vermelhas a variação típica esperada (UNSCEAR, 1988)

FIGURA 4.19: Box plot com as médias, erro padrão e desvio padrão das concentrações de atividade do ${ }^{210} \mathrm{Po}$ nos dez testemunhos coletados, a linha vermelha representa o valor médio para solos (Argonne, 2005)

FIGURA 4.20: Box plot com as médias, erro padrão e desvio padrão das concentrações de atividade do ${ }^{210} \mathrm{Po}$ nos dez testemunhos coletados, as linhas azuis representam os valores máximos e mínimos para sedimentos marinhos da Antartica (Saito, 1996) 


\section{LISTA DE TABELAS}

TABELA 3.1.: Identificação dos pontos de coleta ..............................................18

TABELA 3.2: Meias-vidas e energia dos emissores alfa de interesse neste

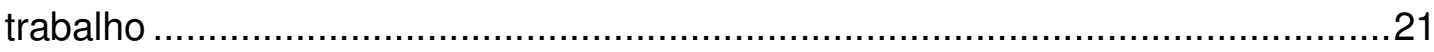

TABELA 3.3: Valores médios das Eficiências dos detectores alfa em $2 \pi$............29

TABELA 3.4:Concentração de atividade em amostras de material de referência, de sedimentos marinhos do Mar Báltico (IAEA 300).

TABELA 4.1 Concentrações de atividade dos radionuclídeos $\left(\mathrm{Bq} \mathrm{kg}^{-1}\right)$ no testemunho BE1 em Bertioga

TABELA 4.2 Concentrações de atividade dos radionuclídeos $\left(\mathrm{Bq} \mathrm{kg}^{-1}\right)$ no testemunho BE2 em Bertioga

TABELA 4.3 Concentrações de atividade dos radionuclídeos $\left(\mathrm{Bq} \mathrm{kg}^{-1}\right)$ no testemunho BE3 em Bertioga

TABELA 4.4: Concentrações de atividade dos radionuclídeos $\left(\mathrm{Bq} \mathrm{kg}^{-1}\right)$ no testemunho CB1 em Cubatão 40

TABELA 4.5: Concentrações de atividade dos radionuclídeos $\left(\mathrm{Bq} \mathrm{kg}^{-1}\right)$ no testemunho CB2 em Cubatão 40

TABELA 4.6: Concentrações de atividade dos radionuclídeos $\left(\mathrm{Bq} \mathrm{kg}^{-1}\right)$ no testemunho SV1 em São Vicente.

TABELA 4.7: Concentrações de atividade dos radionuclídeos $\left(\mathrm{Bq} \mathrm{kg}^{-1}\right)$ no testemunho SV2 em São Vicente

TABELA 4.8: Concentrações de atividade dos radionuclídeos $\left(\mathrm{Bq} \mathrm{kg}^{-1}\right)$ no testemunho SV3 em São Vicente

TABELA 4.9: Concentrações de atividade dos radionuclídeos $\left(\mathrm{Bq} \mathrm{kg}^{-1}\right)$ no testemunho SA 1 em Santos

TABELA 4.10: Concentrações de atividade dos radionuclídeos $\left(\mathrm{Bq} \mathrm{kg}^{-1}\right)$ no testemunho SA 2 em Santos. 


\section{INTRODUÇÃO}

Existe um interesse cada vez maior no estudo dos ambientes marinhos e na determinação e quantificação de contaminantes provenientes das atividades antrópicas. Em particular, há interesse na determinação de radionuclídeos, tendo em vista aspectos relativos à radioproteção e aos efeitos ecotoxicológicos (Sirelkhatim et al., 2008).

O estudo de testemunhos de sedimento marinho fornece uma série temporal do aporte destes elementos, permitindo que ao analisar as camadas mais profundas, seja possível inferir valores relativos às concentrações naturais dos elementos presentes no ambiente, incluindo os radionuclídeos, e desta forma estabelecer o grau de contaminação dos sedimentos mais recentes (ValetteSilver, 1993; Turner, 2000; Aloupi \& Angelidis, 2001; Belzunce et al., 2001;).

Os radionuclídeos podem ser de origem natural e artificial. O segundo grupo compõe-se daqueles que são originados de reações nucleares e da fissão do urânio e devido ao fallout diretamente relacionado às explosões nucleares na atmosfera (Katherin, 1984 in Figueira, 2000).

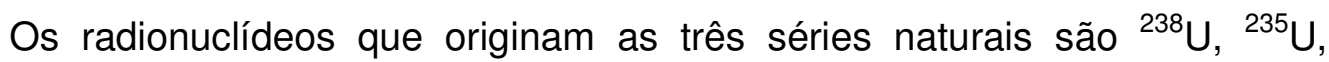
${ }^{232}$ Th. Nas FIGURAS 1.1 e 1.2 são apresentadas as séries de decaimento do ${ }^{238} \mathrm{U}$ e ${ }^{232} \mathrm{Th}$. Estes nuclídeos sofrem sucessivos decaimentos e produzem outros radionuclídeos, até transformarem-se por fim nos três isótopos estáveis do chumbo $\left({ }^{206} \mathrm{~Pb},{ }^{207} \mathrm{~Pb}\right.$ e ${ }^{208} \mathrm{~Pb}$, respectivamente). Nestas séries de decaimento, há radionuclídeos com meia-vida muito curta e outros cuja meia vida é da ordem de grandeza da origem do sistema solar, como é o caso do ${ }^{238} \mathrm{U}$ (meia-vida de $4,5 \times 10^{9}$ anos), ${ }^{235} \mathrm{U}$ (meia-vida de $7 \times 10^{9}$ anos) $\mathrm{e}^{232} \mathrm{Th}\left(1,39 \times 10^{10}\right.$ anos) (Nudat $\mathrm{v}$. $2.5,2005)$.

O urânio é o elemento de ocorrência natural com maior massa atômica. Pode ser encontrado em pequenas concentrações (da ordem de $\mathrm{mg} \mathrm{kg}^{-1}$ ) em solos e rochas, na água superficial e subterrânea e no ar. 
O isótopo do urânio com maior abundância é o ${ }^{238} \mathrm{U}$, presente na natureza com uma fração isotópica de 99,2\%, o restante é composto pelo outro isótopo de ocorrência natural o ${ }^{235} U(0,72 \%)$ e uma fração muito pequena por ${ }^{234} U(0,005 \%)$.

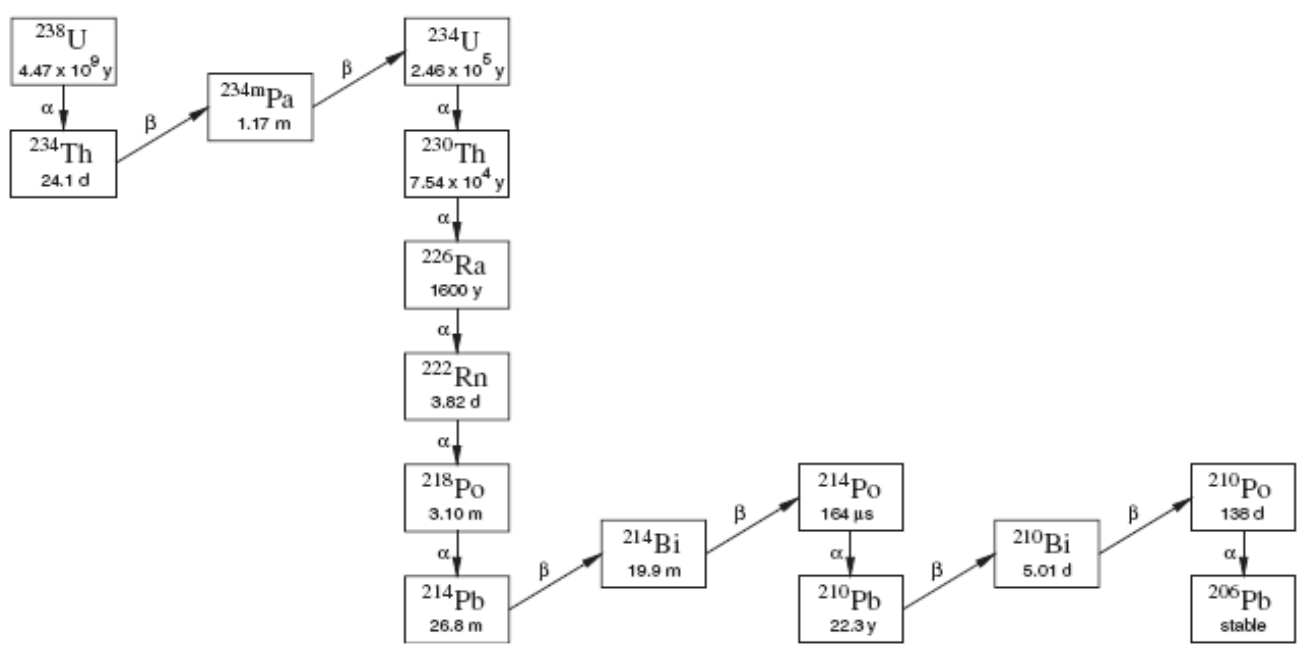

FIGURA 1.1: Série de decaimento radioativo da família do ${ }^{238} \mathrm{U}$

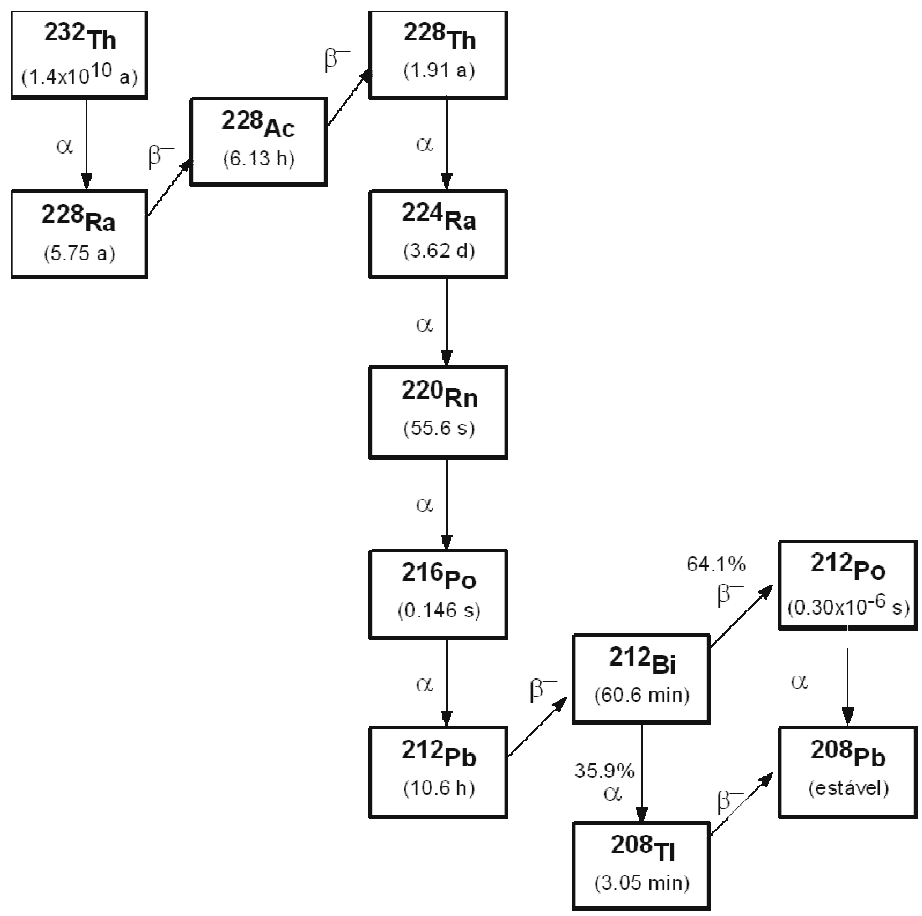

e decaimento radioativo da família do ${ }^{232} \mathrm{Th}$ 
Já o tório é encontrado em quantidades maiores na natureza, mas ainda assim da ordem de $10 \mathrm{ppm}$. Em sua forma pura apresenta-se como um metal prateado com densidade semelhante à do chumbo. Pode-se considerar que o único isótopo natural do tório é o ${ }^{232} \mathrm{Th}$.

A fonte mais comum para a mineração deste elemento são os depósitos de monazita, que é um ortofosfato de terras raras com urânio e tório. Na monazita brasileira a quantidade de óxido urânio é de aproximadamente 0,3\% e de óxido de tório é aproximadamente 6\% (Lauria \& Rochedo, 2005).

Em sistemas fechados, ou seja, naqueles que não há trocas entre os vários compartimentos, os elementos componentes das séries radioativas, com o passar do tempo, tendem a entrar em equilíbrio. Isto significa que a taxa de formação dos nuclídeos filhos é igual a sua taxa de decaimento. Neste caso temos o chamado equilíbrio secular, no qual a atividade do nuclídeo filho é a mesma do pai. Este pode ser expresso pela equação abaixo:

$\mathrm{N}_{1} \lambda_{1}=\mathrm{N}_{2} \lambda_{2}=\mathrm{N}_{3} \lambda_{3} \ldots$

Onde $\mathrm{N}$ é o número de átomos e $\lambda$ é a constante de decaimento, os índices $1,2 \mathrm{e}$ 3 representam os radionuclídeos pai, filho, neto e assim por diante (Keller, 1981).

Em sistemas fechados para que se atinja $98,5 \%$ do equilíbrio é necessário que se passe seis vezes o valor da meia-vida do radionuclídeo com maior meiavida (Ketcham, 1996). A partir do exposto pode-se considerar em equilíbrio a série do ${ }^{238} \mathrm{U}$ passados 1,5 milhões de anos, já para o ${ }^{232} \mathrm{Th}$ isso ocorre em 40 anos.

Os ambientes marinhos e estuarinos não podem ser considerados ambientes fechados já que permitem múltiplas e complexas interações entre os diversos compartimentos ambientais como a atmosfera, hidrosfera, litosfera e biosfera. Por isso as séries radioativas sofrem perturbações no equilíbrio devido a aportes ou remoções de radionuclídeos.

Os processos geológicos como intemperismo, sedimentação e transporte, mobilizam os elementos diferentemente (Silva, 1998). Fatores como solubilidade, formação de colóides, entre outros, afetam o transporte, a deposição e a remobilização dos radionuclídeos. Os sedimentos marinhos podem apresentar 
perturbações no equilíbrio por aportes exógenos ou por remoção, mas uma vez que o sistema se torna fechado novamente pela contínua deposição sedimentar, o equilíbrio pode ser restabelecido.

O aporte atmosférico de elementos radioativos para o sedimento marinho e dos estuários provém principalmente do decaimento do ${ }^{222} \mathrm{Rn}$ que, por ser um gás difunde-se com facilidade a partir do local de onde é emanado (Matthews et al., 2007).

Além da contribuição via decaimento do ${ }^{222} \mathrm{Rn}$, as diferenças de solubilidade entre os elementos pode fazer com que sejam transportados pelos corpos d'água com maior ou menor facilidade, desde que possuam meia-vida suficientemente grande para que a solubilidade afete significativamente o seu transporte.

Os elementos radioativos distribuem-se comumente por toda a crosta terrestre, nos oceanos e na atmosfera, mas diversas atividades humanas podem aumentar o risco de exposição a estes elementos. Quando nos referimos aos elementos radioativos há os materiais radioativos de ocorrência natural (NORM), e os radionuclídeos naturais que são tecnologicamente aumentados - (materiais radioativos de ocorrência natural tecnologicamente aumentados - TENORM).

Diversas atividades humanas contribuem para o aumento do risco de exposição radioativa, como por exemplo, o ciclo do combustível nuclear desde a mineração do urânio, seu beneficiamento, transporte, armazenamento, fissão e estocagem do rejeito gerado. Não somente as instalações nucleares são fontes de preocupação quanto ao aumento da exposição à radiação (Baxter, 1996; Paschoa \& Godoy, 2002), mas também outras atividades humanas como a mineração, a indústria de fertilizantes, as usinas termelétricas movidas a carvão e a indústria petroquímica.

Os radionuclídeos pertencentes às famílias do ${ }^{238} \mathrm{U}$ e ${ }^{232} \mathrm{Th}$ podem ser liberados para o ambiente devido a diversos processos industriais, como no caso do processamento da rocha fosfática para a produção de ácido fosfórico, processos da indústria petroquímica, mineração, siderurgia, entre outros processos (NCRP, 1987; Kvasnicka, 1996; Mishra, 2001). 
A exposição à radiação ionizante pode causar efeitos adversos à saúde. Os isótopos naturais de urânio, tório e polônio são emissores alfa, e estas partículas têm um alcance muito curto e por isso a contaminação interna é, mais comumente, motivo para preocupação com relação aos prejuízos à saúde humana.

A contaminação interna com materiais radioativos se dá principalmente pela ingestão de alimentos e de água contaminada e pela inalação. Uma fração do que é ingerido pode ser absorvida pelos intestinos e passar a circular pela corrente sanguínea. Da quantidade que foi efetivamente absorvida, parte pode ainda ser excretada pelos rins, o que pode ocorrer de forma mais rápida ou mais lenta dependendo de como o elemento interage com o metabolismo humano. $\mathrm{O}$ que o metabolismo não consegue excretar passa a ser acumulado preferencialmente em alguns órgãos, de acordo com o elemento.

O Argonne National Laboratory, ligado à Environmental Science Division divisão de ciências ambientais dos EUA, elaborou um relatório sobre a toxicidade de diversos elementos e sobre seu metabolismo pelos seres humanos (Argonne, 2005).

Para os isótopos do urânio, a maior parte da contaminação interna provém da ingestão de alimentos e de água contaminada. Já em regiões onde há mineração e beneficiamento do urânio para a produção de combustível nuclear, este elemento pode fazer parte da poeira suspendida, tornando-se um material respirável. Nesta situação, o urânio é absorvido mais rapidamente, pois não precisará ser transportado até os intestinos onde ocorre maior absorção. Nos pulmões a absorção se dá diretamente dos alvéolos pulmonares para a circulação.

No caso da ingestão, a maior parte não é absorvida pela circulação sanguínea e por isso é eliminada pelas fezes em alguns dias. Apenas de 0,2 a $0,5 \%$ do que é ingerido passa para o sangue e se deposita preferencialmente nos ossos (22\%), nos rins (12\%) e nos tecidos de forma geral. O restante do urânio é excretado. A parcela que se deposita nos ossos torna-se fator de risco para o desenvolvimento de câncer ósseo como resultado da radiação ionizante emitida pelos produtos de decaimento do urânio. Mas a principal fonte de preocupação é 
o efeito renal pela passagem de compostos solúveis de urânio pelos rins, o que pode causar danos a este órgão. Os danos podem ser reversíveis dependendo do grau de exposição.

Para o tório também a principal fonte de preocupação é a contaminação interna. No caso deste elemento, uma fração muito menor, quando comparada ao urânio, é absorvida pelo trato digestório, apenas de 0,02 a 0,05\%. Da parcela absorvida, 70\% fixa-se na porção mineral da matriz do endósteo e se distribui para todo o tecido ósseo com uma meia-vida biológica de 22 anos. Por isso é fonte de preocupação quanto ao surgimento de câncer ósseo.

O restante do tório absorvido acumula-se no fígado (4\%) e nos demais tecidos (16\%), com uma meia-vida biológica de 700 dias. Os 10\% restantes são diretamente excretados pelos rins.

Com atividade específica muito mais alta do que os isótopos de urânio e tório, os isótopos de polônio apresentam os seguintes valores - 6,7 × $10^{11} \mathrm{~Bq} \mathrm{~g}^{-1}$ para o ${ }^{209} \mathrm{Po}$ e $1665 \times 10^{11} \mathrm{~Bq} \mathrm{~g}^{-1}$ para o ${ }^{210} \mathrm{Po}$. Por este motivo os isótopos de polônio podem ser muito mais problemáticos para a saúde humana do que o tório e o urânio quando em mesma concentração. Existem vinte e cinco isótopos conhecidos de polônio, todos radioativos. Destes apenas três têm meias-vida maiores que dias. Estes são o ${ }^{208} \mathrm{Po}$ com meia-vida de $2.898 \pm 2$ anos, ${ }^{209} \mathrm{Po}$, com meia-vida de $102 \pm 5$ anos e ${ }^{210}$ Po com meia-vida de 138,376 $\pm 0,002$ dias (Nudat v. $2.5,2005)$.

Os isótopos de polônio são emissores alfa de ocorrência natural. Foram primeiramente descobertos por Marie Currie em 1898 através da purificação e separação deste elemento presente no mineral pitchblenda. Este elemento foi primeiramente batizado de rádio $\mathrm{F}$ e posteriormente recebeu o nome de polônio em homenagem à Polônia, terra natal de Marrie Currie.

Normalmente este elemento ocorre na natureza em concentrações muito baixas. Como os demais radionuclídeos de interesse no trabalho, pode ser fonte de contaminação interna quando presente na água, no alimento ou quando inalado. A deposição atmosférica de ${ }^{210} \mathrm{Po}$ em folhas de tabaco (Nicotiana 
tabacum) faz com que a fumaça do cigarro contenha quantidades maiores deste elemento, do que as encontradas na natureza.

Como para os demais radionuclídeos citados, parte (50 a 90\%) do polônio ingerido é eliminada pelas fezes. A fração remanescente acumula-se preferencialmente nos rins e no baço em proporções maiores do que em outros tecidos humanos. Outro tecido que acumula polônio é o parênquima pulmonar, que pode sofrer deposição de formas insolúveis de polônio. Por este motivo notam-se concentrações maiores deste elemento nos pulmões e arcos costais de fumantes. De acordo com o relatório do laboratório Argonne, há um aumento de $30 \%$ na exposição óssea em fumantes em relação a não fumantes (Argonne, 2005).

O ${ }^{210} \mathrm{Po}$ é um dos nuclídeos radioativos de maior importância para estudos ecotoxicológicos porque se acumula na cadeia alimentar. Este efeito bioacumulativo faz com que o consumo de alimentos de origem marinha seja uma fonte de aumento de dose em seres humanos (Cherryl \& Shannon apud Hernandez et al., 2002).

Os radionuclídeos são transportados aos ambientes estuarinos pelos rios, pelas águas subterrâneas e pela atmosfera, neste caso, na forma de gás ou aerossóis. Seu comportamento no ambiente estuarino pode ser dividido em dois grandes grupos: aquele que se mantém dissolvido e o que é retirado da solução (scavenging) pelo material particulado, por processos químicos ou biológicos. Por exemplo, os isótopos do urânio são mais solúveis, mantendo-se, portanto, em solução. Já os do tório são menos solúveis, sendo mais facilmente arrastados para o sedimento (Ivanovitch apud Emerson \& Young, 1995)

Os estuários são locais onde os rios deságuam no mar e nesta mistura de águas doce e salgada, a floculação e a sedimentação fazem com que haja uma contínua deposição de materiais orgânicos e inorgânicos formando um sedimento lamoso. O sedimento tem uma determinada capacidade de reter compostos, incluindo os materiais radioativos, já que estes são adsorvidos pelos grãos de aluminosilicatos, especialmente a fração fina. 
O ambiente químico dos estuários influencia a capacidade do sedimento de reter compostos e por isso, mudanças de $\mathrm{pH}$, salinidade, e na quantidade de matéria orgânica podem remobilizar estes componentes (Fukumoto, 2007). Além dos fatores químicos, já citados, há também agentes biológicos e físicos. Animais bentônicos escavadores revolvem o sedimento carregando os elementos e potencialmente remobilizando materiais para a água, em um fenômeno conhecido como bioturbação.

Os agentes físicos que modificam a distribuição das camadas de sedimento podem ser: alterações nos regimes de marés, tsunamis, terremotos, formações de bolhas devido à atividade de decomposição da matéria orgânica ou movimentações das camadas de sedimento de origem antrópica como na dragagem.

Em resumo, os sedimentos nos estuários têm a capacidade de reter elementos radioativos que chegam a este ecossistema. Mudanças no ambiente podem alterar a capacidade de retenção dos sedimentos e possivelmente liberar novamente os radionuclídeos. Por isso o estudo de perfis de sedimento reproduz o histórico de deposição e pode dar indícios de possíveis eventos de contaminação.

\subsection{A área de estudo}

A Baixada Santista foi classificada pelo grupo de Avaliação e Ações Prioritárias para a Conservação da Biodiversidade das Zonas Costeiras e Marinhas como uma região de alta biodiversidade e sob alta pressão antrópica (MMA, 2007).

Inúmeros estudos de qualidade ambiental foram realizados na Baixada Santista, já que com a instalação do pólo industrial de Cubatão a região recebeu diversas indústrias, principalmente siderúrgicas, indústria petroquímica e de fertilizantes.

Outras fontes de preocupação quanto à qualidade ambiental são: a operação do porto de Santos e do sistema de disposição de esgotos. O porto de Santos, de acordo com a Companhia de Docas do Estado de São Paulo 
(CODESP), é atualmente o maior porto brasileiro, movimentando mais de 70 toneladas de produtos por ano.

O sistema de deposição de esgoto de Santos/São Vicente opera desde 1978 à vazão máxima de $7000 \mathrm{~L} \mathrm{~s}^{-1}$ (Fukumoto, 2007). O sistema é composto por uma estação de pré-condicionamento e um emissário submarino. A maior parte do esgoto doméstico de Santos e São Vicente é lançada ao mar pelo emissário submarino, mas há um aporte de esgoto clandestino e de materiais provenientes de ocupações irregulares ao longo da orla marinha (Abessa, 2002 in Fukumoto, 2007).

A Baixada Santista é uma região populosa e abrange os municípios de Bertioga, Guarujá, Santos, São Vicente, Cubatão, Praia Grande, Mongaguá, Itanhaém e Peruíbe, sendo uma das mais importantes regiões industriais do Estado de São Paulo (FIGURA 1.3). Nesta região, destacam-se Santos (com uma área de $725 \mathrm{~km}^{2}$, com uma população de 418.288 habitantes), São Vicente (com área de $131 \mathrm{~km}^{2}$, com uma população de 323.599 habitantes) e Cubatão (ocupando $160 \mathrm{~km}^{2}$, com uma população de 120.271 habitantes) (IBGE, 2007). 
A localização destes municípios populosos na região costeira de São Paulo, juntamente as atividades portuárias e industriais exerce forte pressão aos ecossistemas aquáticos.

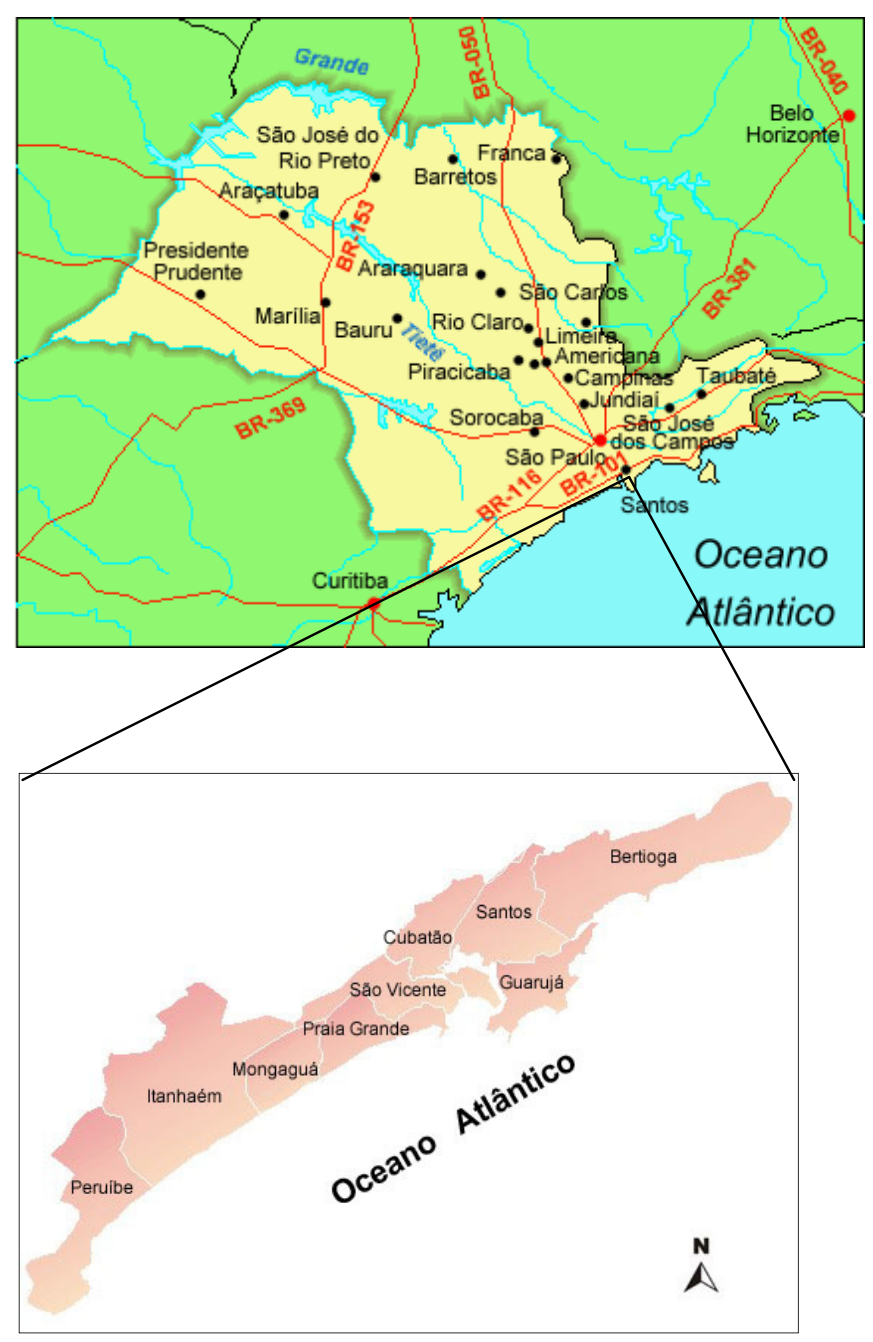

FIGURA 1.3: Região da Baixada Santista e seus municípios

O canal de Bertioga, conhecido também como Rio Bertioga, tem 30 quilômetros de extensão e ainda hoje é o responsável pela economia informal da Cidade.

$\mathrm{Na}$ Ilha de Santo Amaro encontra-se o município de Guarujá (23⒌ $59^{\prime}$ de latitude Sul e $46^{\circ} 15^{\prime}$ de longitude Ocidental) com $137 \mathrm{Km}^{2}$. A terceira maior ilha do litoral do Estado de São Paulo faz limite ao norte, com o Canal de Bertioga que separa Santos e Guarujá, a oeste, com o Canal do estuário de Santos e ao sul e a leste, com o Oceano Atlântico. Situado na zona de contato da borda escarpada do 
Planalto Atlântico com a Planície litorânea (Baixada Santista), o município de

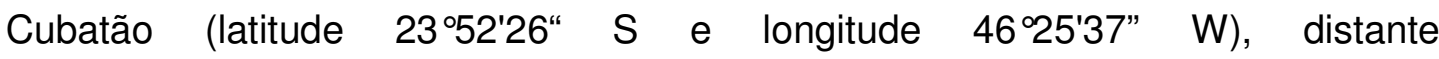
aproximadamente $60 \mathrm{~km}$ da Capital Paulista, possui entre 8 a $9 \mathrm{~km}$ de largura. Dos seus $160 \mathrm{~km}^{2}$ de área, apenas $18 \%$ são planícies, sendo o restante composto por serras, morros e manguezais.

$\mathrm{Na}$ Baixada Santista a geometria da costa apresenta amplas planícies de deposição marinha. $O$ preenchimento por sedimentos dessas antigas Baías se deu durante períodos em que o mar esteve mais alto do que o presente sendo que as ilhas, neste setor da costa, são predominantemente sedimentares. De acordo com a Secretaria do Meio Ambiente do Estado de São Paulo (1989), há um total de 29 ilhas na Baixada Santista (incluindo as duas grandes ilhas de Santo Amaro e São Vicente), além de três ilhotas e seis lajes (destacando a Laje de Santos).

Os diversos rios que compõem a bacia hidrográfica santista podem ser agrupados em dois tipos: O primeiro é constituído pelos rios cujas nascentes estão localizadas no alto da serra, tendo características torrenciais neste trecho, porém, formam meandros furados e manguezais no seu trecho inferior, sendo responsáveis pela intensa sedimentação fluvial que ocorre na região, dificultando o escoamento das águas. Dentro deste tipo incluem-se os rios Cubatão, Mogi, Piaçagüera, Perequê, Quilombo, Jurubatuba e rio da Onça. O segundo tipo seria o que apresenta rios com cursos pequenos, praticamente de planície, que apresenta somente parte de sedimentação e formação de lagamares e, duas vezes por dia, entram em contato direto com a água salobra, devido ao movimento das marés. Encontram-se nestas condições os rios Casqueiro, Boturoca ou Branco, rio Iriri, Santo Amaro, Cascalho e Saboó.

A Baía de Santos divide-se em duas áreas de sedimentação distintas, uma é influenciada por um fluxo unidirecional que provém do estuário saindo pelo canal do porto, enquanto que a outra é dominada pela maré oriunda da plataforma continental adjacente (Ponçano \& Fúlfaro, 1976).

Os sedimentos, a água, o ar e a biota da área estuarina entre as cidades de Cubatão e Santos têm sido considerados contaminados, especialmente por alguns metais pesados apresentando um histórico de intensa contaminação 
industrial multi-elementar, oriunda do maior complexo metal-petroquímico da América Latina. A cidade de Cubatão abriga um importante pólo industrial do Brasil, contendo mais de 100 indústrias, que são as principais responsáveis pela origem da poluição. As incontroláveis emissões de sólidos, líquidos e substâncias gasosas de indústrias químicas, petroquímicas, de fertilizantes, além de uma grande siderúrgica, colocaram a cidade de Cubatão, especialmente na década de 1980, no cenário das discussões ambientais mundiais. O ecossistema aquático das áreas adjacentes ao setor industrial tem sofrido, além da ação das intensas descargas de efluentes industriais, despejos domésticos, os quais têm acarretado profundas transformações no meio ambiente (CETESB, 1978).

A localização dos pólos e distritos industriais de Cubatão deve-se, em parte, à facilidade para liberação dos efluentes no mar e pela proximidade de Cubatão dos centros urbanos de comercialização e consumo, o que facilita a exportação de materiais e importação de insumos.

Os efluentes e resíduos transportados e armazenados na região impactam diretamente o estuário de Santos - São Vicente. As principais formas de poluição são as emissões de gases sulforados, fluorados e hidrocarbonetos, além de particulados sólidos de origem fosfática, carvão e minérios.

Efluentes líquidos orgânicos e inorgânicos, alguns com altos teores de acidez, metais pesados e material radioativo, são lançados diretamente sem tratamento nos corpos d'água, poluindo estuários, baías e mar, ou em bacias de decantação, comprometendo os lençóis freáticos. Também os rejeitos sólidos, tóxicos ou não, ainda constituem problemas em muitos complexos industriais.

Foi somente a partir de meados da década de oitenta que o crescimento descontrolado das fontes poluidoras começou a ser revertido. A região, que já foi conhecido como o Vale da Morte, ganhou notoriedade internacional devido aos efeitos da poluição nas populações residentes em Cubatão.

Em 1983, a CETESB (Companhia de Engenharia e Meio Ambiente) iniciou em Cubatão o "Plano de Controle de Poluição Ambiental em Cubatão". Este plano baseava-se em três linhas de ação - no controle da poluição, na pesquisa e elaboração de estudos que servissem de suporte para as ações na região, e na 
educação ambiental com foco nas lideranças políticas locais. O programa investiu cerca de U\$ 800 milhões para recuperar ar, água e solos contaminados.

Estas ações resultaram em uma redução considerável das emissões e dos efluentes industriais. De acordo com a Secretaria de Meio Ambiente do Estado de São Paulo o programa resultou até o ano de 2008 em uma redução da emissão de material particulado de 98,8\% (SMA, 2008).

\subsection{Município de São Vicente}

O município de São Vicente localiza-se a $71 \mathrm{~km}$ da Capital entre os municípios de Santos, Cubatão e Praia Grande, tendo ao sul o Oceano Atlântico. São Vicente é considerado a primeira vila portuguesa nas Américas. Foi fundada oficialmente em 22 de janeiro de 1532 por Martim Afonso de Souza e já era conhecida, na Europa, como ponto de parada para reabastecimento de mantimentos e tráfico de escravos índios. Em 1700 foi elevada à condição de Município e em 1895, foi passou à categoria de cidade.

A maior parte do território de São Vicente era originalmente coberta pela Mata Atlântica, representando $52 \%$ do total do município. As matas de restinga representavam $24 \%$ e os manguezais $16 \%$, sendo os $8 \%$ restantes constituídos de rios e canais.

\subsection{Município de Cubatão}

A região de Cubatão iniciou sua formação a partir de 1530, como parada de descanso para os viajantes que percorriam o trecho entre o Planalto e a cidade de Santos. Nos três primeiros séculos após o descobrimento não havia ligação por terra entre Santos e este local no sopé, sendo utilizadas canoas entre o Porto de Santos e um porto fluvial indígena situado na margem do Rio Mogi, chamado de "Piassaguera".

Nos primeiros anos do século XX Cubatão iniciou o seu crescimento com a chegada das primeiras indústrias. Com a construção da Usina Henry Borden em 
1926, fornecendo eletricidade e água em abundância, as condições para instalação de novas indústrias cresceram e a cidade entrou em nova fase.

A instalação da Refinaria Presidente Bernardes, em 1950, impulsionou a transformação da cidade em pólo petroquímico. Após o início das suas atividades, instalaram-se, entre 1956 e 1959, a Companhia Brasileira de Estireno, Union Carbide do Brasil, Coperbrás e Alba Química; em 1963 foi construída a COSIPA, atraindo outras indústrias como a Carbocloro, Rhodia, Cimento Votorantim, Cargil, White Martins, entre outras (Silva, 2007).

Como já foi dito anteriormente, a cidade ficou conhecida nos anos 80 como "Vale da Morte". Isso se deve ao fato de que a geomorfologia da região contribui para o agravamento da poluição atmosférica, devido à dificuldade de dispersão dos poluentes atmosféricos.

A Serra do Mar neste trecho específico tem a forma de uma "ferradura", de modo que a parte da planície de Cubatão, onde está assentado o parque industrial está dentro de uma "cratera", dificultando a circulação do ar e a dispersão dos poluentes.

Embora na década de 80 tenha sido implantado um trabalho de recuperação ambiental e deste apresentar resultados positivos na qualidade ambiental da região, estudos sobre o controle da poluição são ainda de extrema importância.

\subsection{Município de Bertioga}

O município de Bertioga é delimitado pelo continente e pela llha de Santo Amaro ao longo de seus $24 \mathrm{~km}$ de extensão (FIGURA 1.3). Sua desembocadura sul se liga ao complexo estuarino de Santos e ao mar aberto por sua desembocadura norte, conhecido como Barra de Bertioga. Segundo Miranda et al. (1998) a desembocadura norte do canal é quase uma segunda conexão entre o oceano e o complexo estuarino de Santos.

O Canal de Bertioga atinge até $1 \mathrm{~km}$ de largura na sua região central, conhecido como Largo do Candinho, onde duas correntes de maré divergentes 
(proveniente da desembocadura sul e da desembocadura norte) se encontram. Assim, as características de dupla desembocadura desse canal fazem dessa área um local de deposição de material em suspensão (IPT 1974).

O Canal de Bertioga e adjacências também têm grande importância social, econômica e ambiental. Em suas imediações encontra-se o Porto de Santos e o complexo industrial de Cubatão. Além disto, o próprio canal é utilizado para fins recreativos, turísticos e para pesca.

A principal atividade econômica de Bertioga é o turismo, e de acordo com a SEADE - Sistema Estadual de Analise de Dados, sua população aumenta de aproximadamente 40.000 para 60.000 habitantes nos meses de verão.

\subsection{Baia de Santos}

A Baía de Santos está localizada na porção central do litoral do estado de

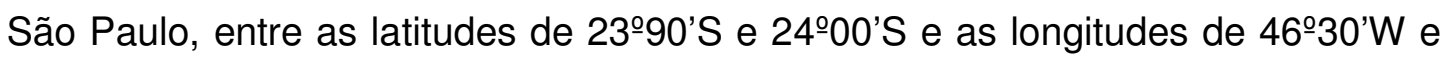
4650"W. Santos é o maior e mais populoso município litorâneo do estado de São Paulo, localizado na região denominada Baixada Santista. Possui infra-estrutura de serviços e potencial turístico podendo atender até 300 mil turistas nas temporadas de verão (Abessa et al., 2005). Os efluentes domésticos são coletados e encaminhados para uma estação de pré-condicionamento. O efluente resultante do tratamento é encaminhado para disposição final na Baía de Santos, via emissário submarino, na Praia José Menino. Este emissário entrou em operação em 1979 e tem saída a 4 km da costa, na porção central Baía de Santos (CETESB, 1997).

Ainda, uma grande carga de esgotos in natura chega ao estuário, proveniente de ocupações existentes nas margens e de ligações clandestinas, além do descarte das docas e navios que operam no Porto de Santos, podendo alcançar a Baía de Santos. 


\section{OBJETIVOS}

O presente trabalho de mestrado está inserido em um projeto maior, com fomento da Fundação de Amparo a Pesquisa do Estado de São Paulo (FAPESP), que visa determinar as concentrações de metais, terras raras e radionuclídeos naturais em perfis de sedimentos marinhos da Baixada Santista.

Dentre os radionuclídeos naturais estudados no já referido projeto este trabalho tem o objetivo de quantificar as concentrações de ${ }^{238} \mathrm{U},{ }^{234} \mathrm{U},{ }^{230} \mathrm{Th},{ }^{210} \mathrm{Po}$ $\mathrm{e}^{232} \mathrm{Th}$.

Outro objetivo global do projeto é auxiliar à CETESB quanto ao estabelecimento de valores de base, para os elementos estudados, de maneira a possibilitar a classificação da qualidade dos sedimentos do litoral do Estado de São Paulo e eventualmente determinar valores de contaminação.

Também foi realizada a comparação das concentrações dos radionuclídeos com as porcentagens de finos (silte+argila), resultados obtidos por outros pesquisadores dentro do projeto.

\section{METODOLOGIA}

\subsection{Coleta das Amostras}

As amostras utilizadas neste estudo foram coletadas nos meses de maio e junho de 2007 com o auxílio da CETESB. Para a coleta foi estabelecido um protocolo e um plano de amostragem no qual se procurou contemplar a representatividade dos vários ambientes, segundo os regimes de erosão/deposição.

Foram coletados 10 perfis de sedimento em quatro cidades da baixada Santista: Cubatão, São Vicente, Bertioga e Santos, com amostrador de testemunhos tipo Piston - Corer. A FIGURA 3.1 apresenta um esquema do equipamento perfurando o sedimento. Na FIGURA 3.1 é ilustrado o Piston - Corer após o lançamento da embarcação e, na sequência, o peso tocando primeiro o fundo e acionando o mecanismo que libera o amostrador. Devido à sua massa, o 
instrumento penetra no sedimento ( 3 e 4 ) e forma-se vácuo que permite a coleta do perfil de sedimento.

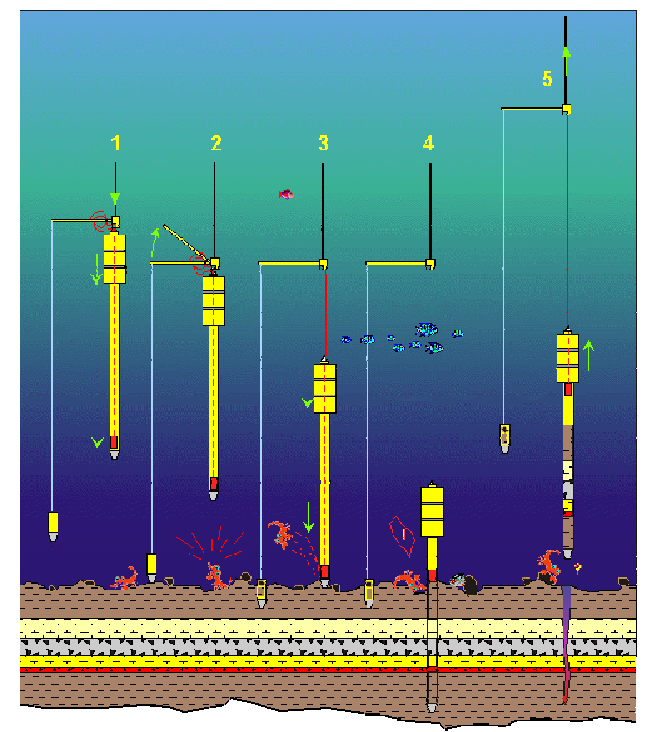

FIGURA 3.1: Amostrador tipo piston corer. Disponível em www.mnhn.

Os perfis coletados tiveram comprimentos variando de 41 a $98 \mathrm{~cm}$. Para as análises estes perfis foram seccionados a cada $2 \mathrm{~cm}$, gerando, desta forma, um total de 162 amostras. Foi então estabelecido um critério de redução do número de amostras para otimizar o trabalho (diminuindo o número de análises, tempo e consumo de reagentes).

A escolha das fatias que foram analisadas teve como base a similaridade entre as camadas, estabelecida pela análise dos resultados obtidos da análise por ativação com nêutrons realizada nestes testemunhos (relatório FAPESP n: 2006/05686-4). A TABELA 3.1 apresenta a localização dos pontos de coleta por cidade e a FIGURA 3.2 apresenta a localização dos mesmos. 
TABELA3.1.: Identificação dos pontos de coleta

\begin{tabular}{|c|c|c|c|c|}
\hline Local & Ponto & Data da coleta & Coordenadas & $\begin{array}{l}\text { Profundidade } \\
(\mathrm{m})\end{array}$ \\
\hline \multirow{4}{*}{ Cubatão } & \multirow{2}{*}{ CB1 - Rio da onça } & \multirow{2}{*}{$22 / 05 / 2007$} & S 23을 $75.3^{\prime \prime}$ & \multirow[b]{2}{*}{2,8} \\
\hline & & & W 46을 $21^{\prime} 40.2 "$ & \\
\hline & \multirow{2}{*}{$\begin{array}{l}\text { CB2 - Rio das onças } \\
\text { (próximo à Cosipa) }\end{array}$} & \multirow{2}{*}{$22 / 05 / 2007$} & S 23ํ5' $13.6^{\prime \prime}$ & \\
\hline & & & W 46을' $14.8^{\prime \prime}$ & 2,3 \\
\hline \multirow{4}{*}{ São Vicente } & \multirow{2}{*}{ SV1-Rio Boturoca } & \multirow{2}{*}{$23 / 05 / 2007$} & S 23오' $55^{\prime} 93.7^{\prime \prime}$ & \multirow{2}{*}{2,2} \\
\hline & & & W 46을 $27^{\prime} 52.5^{\prime \prime}$ & \\
\hline & \multirow{2}{*}{ SV2 - Largo de São } & \multirow{2}{*}{$23 / 05 / 2007$} & S 23ํ 57' 14.4"' & \multirow[b]{2}{*}{0,6} \\
\hline & & & W 46을 $25^{\prime} 48.3^{\prime \prime}$ & \\
\hline \multirow{8}{*}{ Bertioga } & \multirow{2}{*}{$\begin{array}{l}\text { SV3 - Largo do } \\
\text { Pompeba }\end{array}$} & \multirow{2}{*}{$23 / 05 / 2007$} & S 23은 $56^{\prime} 0.6^{\prime \prime}$ & \multirow[b]{2}{*}{1,0} \\
\hline & & & W 46을 $25^{\prime} 12^{\prime \prime}$ & \\
\hline & \multirow{2}{*}{ BE 1 - Rio Itapanhaú } & \multirow{2}{*}{ 29/05/2007 } & S 23ํ 51' 61.8"' & \multirow{2}{*}{1,5} \\
\hline & & & W 46웅' $45.9^{\prime \prime}$ & \\
\hline & \multirow{2}{*}{ BE 2 - Rio Iriri } & \multirow{2}{*}{ 29/05/2007 } & S 23ํ5' 63.8”' & \multirow{2}{*}{2,0} \\
\hline & & & W 46우 11' $86.3^{\prime \prime}$ & \\
\hline & \multirow{2}{*}{$\begin{array}{l}\text { BE } 3 \text { - Largo do } \\
\text { Candinho }\end{array}$} & \multirow{2}{*}{$29 / 05 / 2007$} & 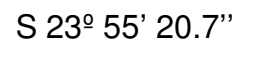 & \\
\hline & & & W 46ㅇ 14' $28.8^{\prime \prime}$ & 2,5 \\
\hline \multirow{4}{*}{ Santos } & \multirow{2}{*}{$\begin{array}{l}\text { SA } 1 \text { - Emissário } \\
\text { submarino }\end{array}$} & \multirow{2}{*}{$12 / 06 / 2007$} & S 24응' $20.7^{\prime \prime}$ & \multirow[b]{2}{*}{11,0} \\
\hline & & & W 46을 $20^{\prime} 98.8^{\prime \prime}$ & \\
\hline & \multirow{2}{*}{$\begin{array}{l}\text { SA } 2 \text { - Ilha } \\
\text { Palmas }\end{array}$} & \multirow{2}{*}{$12 / 06 / 2007$} & $S 24^{\circ} 00^{\prime} 64.0^{\prime \prime}$ & \\
\hline & & & W 46 19' $49.6^{\prime \prime}$ & 10,0 \\
\hline
\end{tabular}




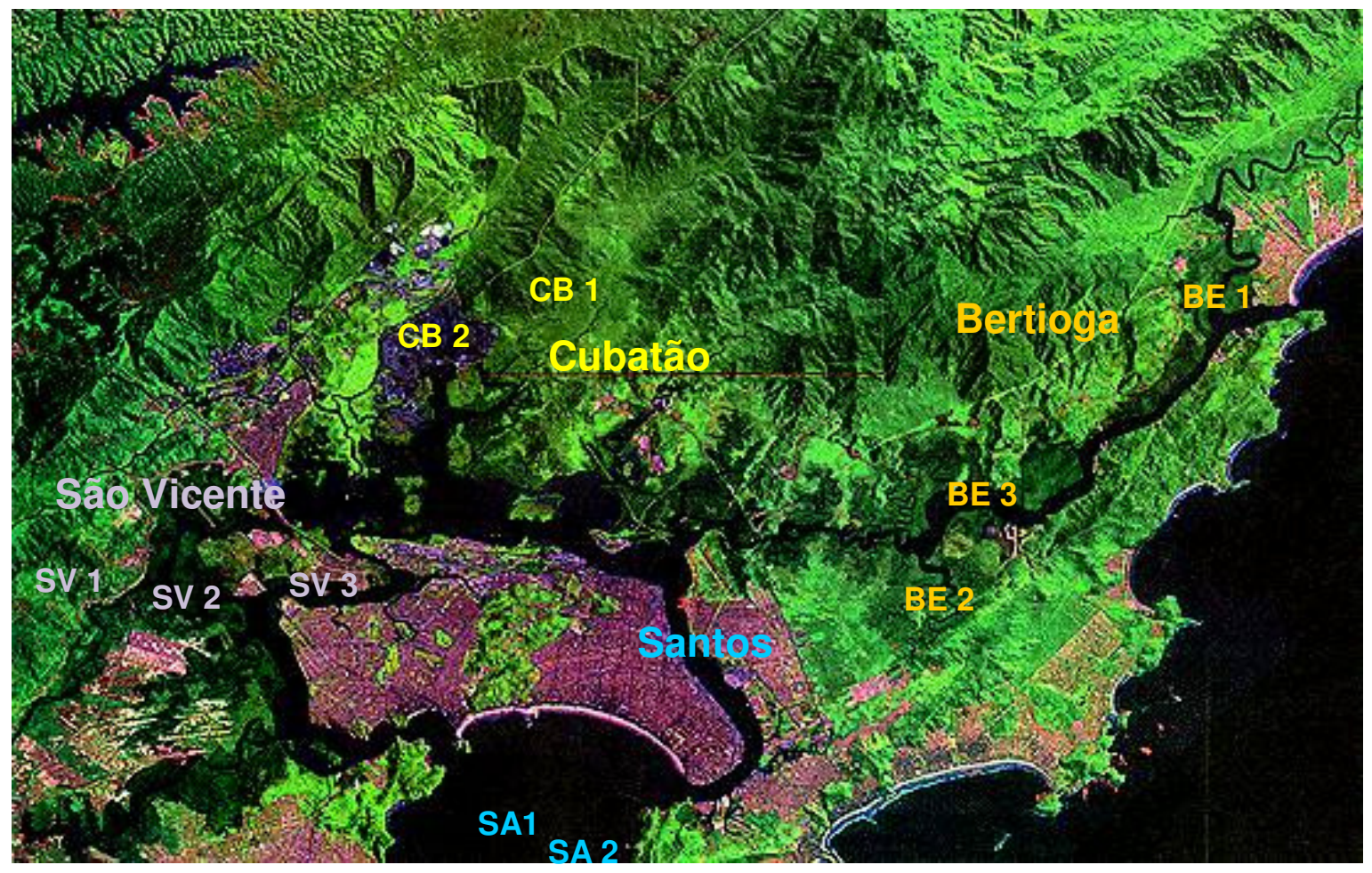

FIGURA 3.2: Localização dos pontos de coleta na área de estudo

\subsection{Espectrometria alfa}

A técnica de espectrometria alfa consiste na detecção de partículas alfa emitidas por um radionuclídeo presente na amostra analisada. Partículas alfa são núcleos de átomos de hélio e, portanto possuem dois prótons e dois nêutrons, desta forma toda vez que um nuclídeo emitir uma partícula alfa sua massa diminuirá em quatro unidades e o número atômico em duas (Keller, 1981).

Existem diversos tipos de detectores capazes de medir radiação alfa, como câmaras de ionização, contadores proporcionais, detectores de cintilação líquida e detectores semicondutores, entre outros. Dentre os detectores semicondutores os de barreira de superfície de silício são amplamente usados para análise de amostras ambientais e de rejeitos nucleares por apresentarem uma excelente resolução de energia e boa eficiência (Hou \& Roos, 2007).

Estes detectores alfa são compostos resumidamente por uma lâmina de silício em uma câmara mantida sob vácuo e um arranjo eletrônico para amplificação e conversão do sinal que é transformado em contagens. Um esquema do detector utilizado é apresentado na FIGURA 3.3. 


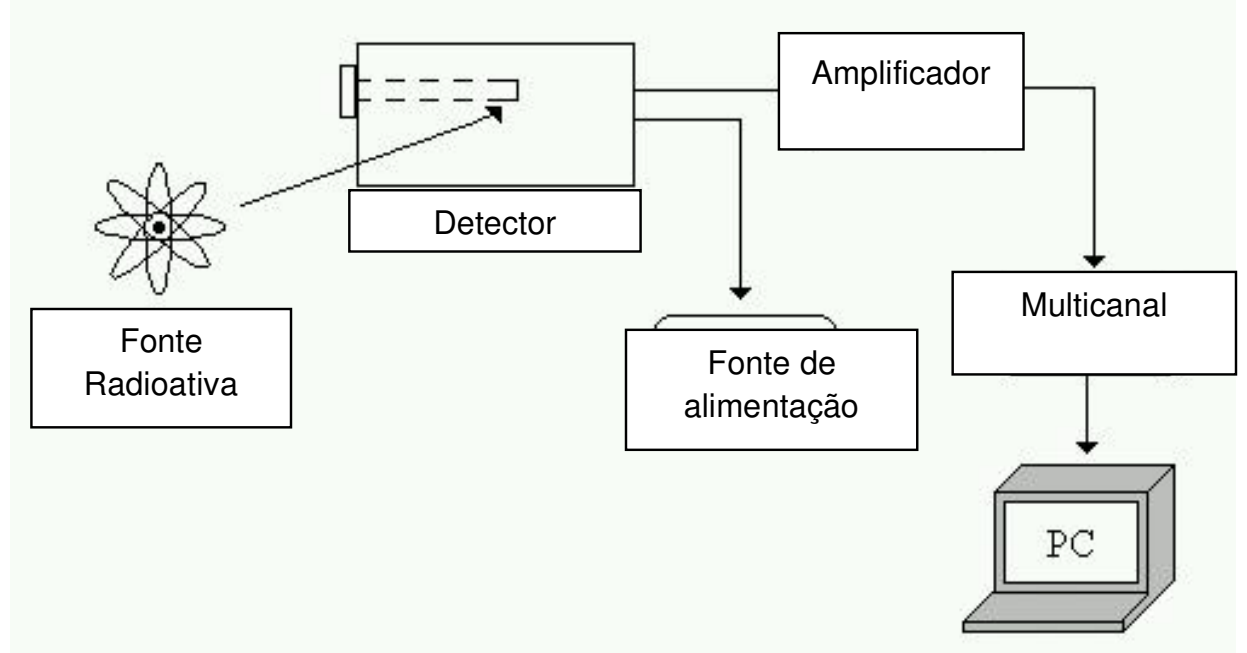

FIGURA 3.3: Esquema de um detector de partículas alfa (espectrômetro alfa)

A preparação de amostras para a contagem de emissões alfa requer a preparação de fontes com finos depósitos com o elemento de interesse para evitar auto absorção e interferências devido a outros radionuclídeos com energia de decaimento alfa semelhante à dele. Para a preparação destes depósitos é necessário utilizar procedimentos químicos de separação como a cromatografia de troca iônica. Além disto, os detectores são mantidos sob vácuo para evitar choques das partículas alfa com elementos presentes no ar.

Os radionuclídeos analisados no presente estudo apresentam um ou mais decaimentos alfa. As energias e meias-vidas destes nuclídeos são apresentadas na TABELA 3.2. 
TABELA 3.2: Meias-vidas e energia dos emissores alfa de interesse neste trabalho

\begin{tabular}{lll}
\hline Nuclídeo & Meia-vida & Energia (MeV) \\
${ }^{238} \mathrm{U}$ & $4,5 \times 10^{9}$ anos & $4,19(77 \%)$ \\
${ }^{234} \mathrm{U}$ & $2,48 \times 10^{5}$ anos & $4,77(72,5 \%)$ \\
& & $4,72(27,5 \%)$ \\
${ }^{232} \mathrm{U}$ & 72 anos & $5,32(68 \%)$ \\
& & $5,26(23 \%)$ \\
${ }^{209} \mathrm{Po}$ & 102 anos & $4,89(99,54 \%)$ \\
${ }^{210} \mathrm{Po}$ & 138.376 dias & $5,31(100 \%)$ \\
${ }^{232} \mathrm{Th}$ & $1,39 \times 10^{10}$ anos & $4,00(77 \%)$ \\
& & $3,95(23 \%)$ \\
${ }^{230} \mathrm{Th}$ & $8,0 \times 10^{4}$ anos & $4,68(73,3 \%)$ \\
& & $4,62(23,4 \%)$ \\
${ }^{229} \mathrm{Th}$ & 7340 anos & $4,85(52,2 \%)$ \\
& & $4,90(10,8 \%)$ \\
& & $4,81(8,4 \%)$ \\
& & $5,42(73 \%)$ \\
& & $5,34(26,7 \%)$ \\
& &
\end{tabular}

Para estimar as perdas durante o processo analítico, são usados traçadores radioativos. O ideal é que estes radionuclídeos não estejam presentes na amostra a ser analisada; as energias alfa do traçador e do radionuclídeo a ser quantificado devem ser suficientemente discriminadas para não haver interferências (Santos, 2001).

Para quantificar as perdas, os traçadores devem ser incorporados nos estágios iniciais do procedimento analítico. Neste trabalho foram utilizados como traçadores os seguintes isótopos: ${ }^{232} \mathrm{U}$ (com atividade de $0,5024 \mathrm{~Bq} \mathrm{~g}{ }^{-1}$ ), ${ }^{229} \mathrm{Th}$ (com atividade de $1,5727 \mathrm{~Bq} \mathrm{~g}^{-1}$ ) e ${ }^{209} \mathrm{Po}$ (com atividade de 2,1715 $\mathrm{Bq} \mathrm{g}^{-1}$ ). 
As FIGURAS 3.4, 3.5 e 3.6 apresentam espectros dos radionuclídeos determinados e dos traçadores, estes estão marcados em cor azul na figura.

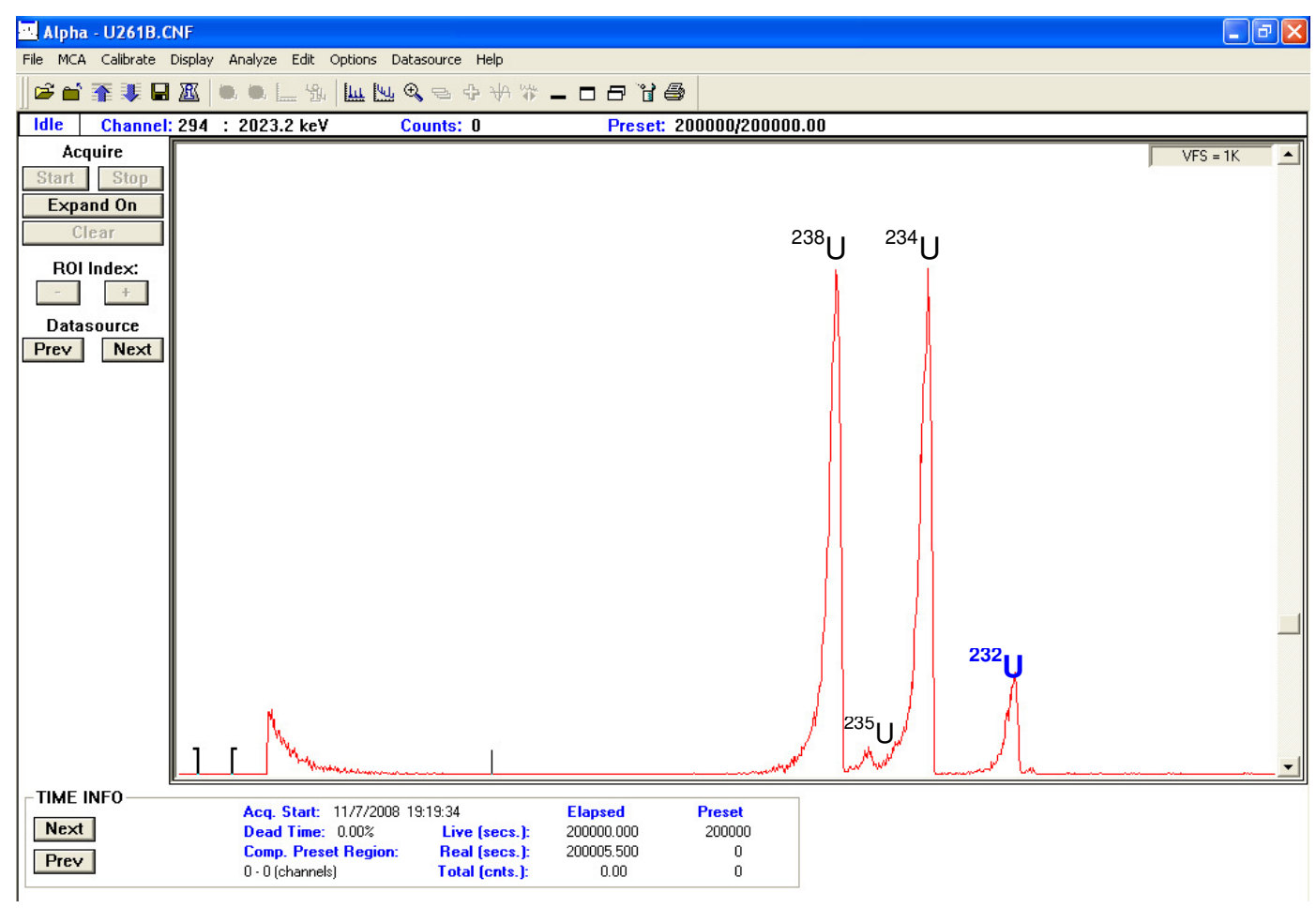

FIGURA 3.4: Espectro típico de urânio por espectrometria alfa. Ressaltando em azul o traçador de ${ }^{232} U$. 
Alpha - Th257A.CNF

File MCA Calibrate Display Analyze Edit Options Datasource Help

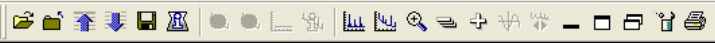

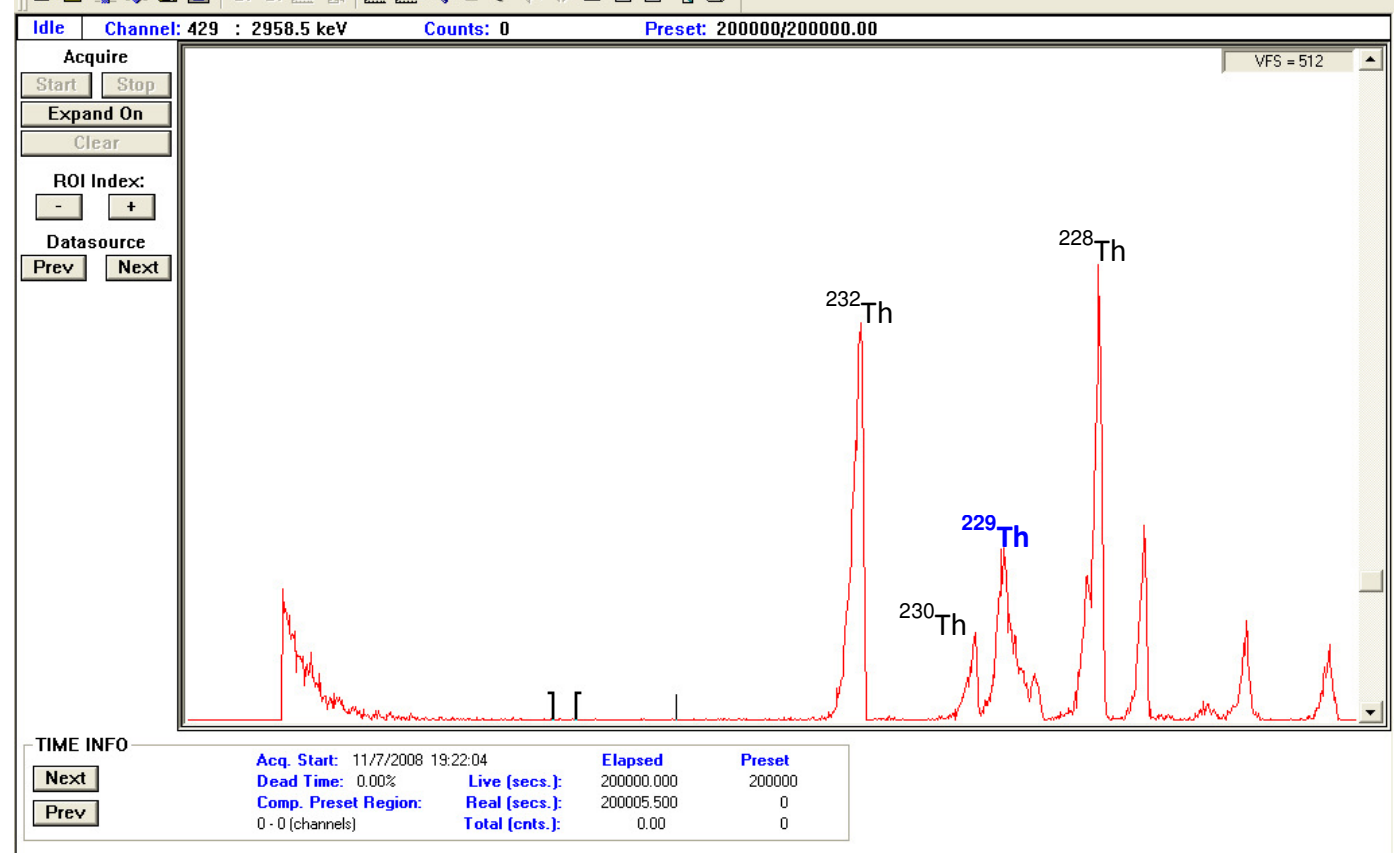

FIGURA 3.5: Espectro típico de tório por espectrometria alfa. Ressaltando em azul o traçador de ${ }^{229} \mathrm{Th}$.

Alpha - A2Po.CNF*

0

File MCA Calbrate Display Analyze Edit Options Datasource Help

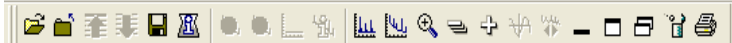

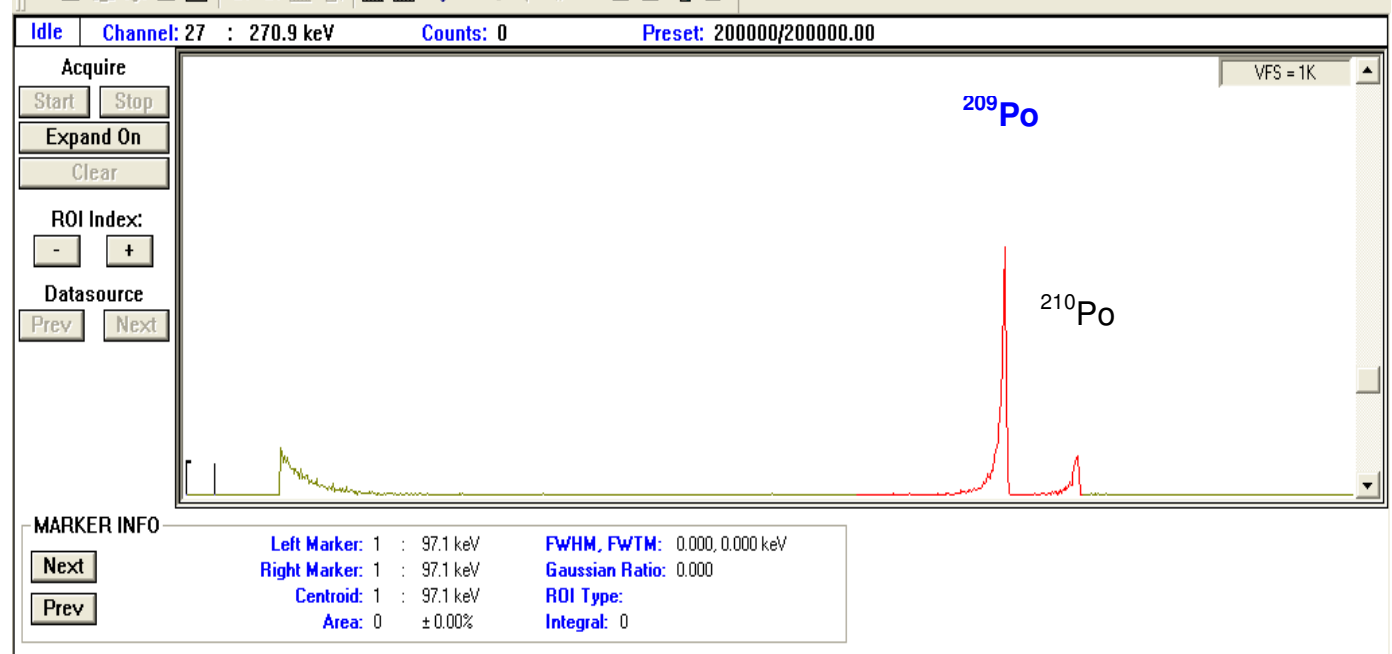

FIGURA 3.6: Espectro típico de polônio por espectrometria alfa. Ressaltando em azul o traçador ${ }^{209} \mathrm{Po}$. 


\subsection{Pré-tratamento físico e químico das amostras}

No Laboratório de Radiometria Ambiental (LRA), procedeu-se o prétratamento das amostras dos perfis.

Os perfis de sedimento foram guardados em freezer até o momento da abertura. Estes foram abertos com auxílio de uma serra elétrica obtendo-se duas meias calhas de sedimento. Foi observado se o perfil estava intacto, ou seja, sem fragmentos de vegetação ou qualquer tipo de resíduo que não fosse sedimento efetuando-se em seguida, a sua medida em comprimento.

Após a medida, o perfil foi seccionado a cada $2 \mathrm{~cm}$. As amostras foram então secas em estufa por 24 horas para eliminação de umidade. A temperatura foi mantida em $60^{\circ} \mathrm{C}$ para evitar perdas de elementos por volatilidade, como no caso do polônio. Após a secagem as amostras foram maceradas, pulverizadas em almofariz e pistilo de porcelana, homogeneizadas e acondicionadas em frascos de polietileno.

Para a análise foi utilizado 0,5 grama de sedimento, ao qual se adicionou $100 \mu \mathrm{g}$ de solução de cada um dos traçadores de ${ }^{232} \mathrm{U}$ (com atividade de 0,5024 $\mathrm{Bq} \mathrm{g}^{-1}$ ), ${ }^{229} \mathrm{Th}$ (com atividade de 1,5727 $\mathrm{Bq} \mathrm{g}^{-1}$ ) e ${ }^{209} \mathrm{Po}$ (com atividade de 2,1715 $\mathrm{Bq}^{-1}$ ) de maneira a poder se estimar as perdas relacionadas aos processos de dissolução, separação e deposição.

A amostra foi submetida a uma série de ataques ácidos com água régia (1 parte de ácido nítrico para 3 de ácido clorídrico) e HF a $90^{\circ} \mathrm{C}$ até sua total dissolução.

Foi adicionado à solução, $\mathrm{NH}_{4} \mathrm{OH}$ para precipitar principalmente hidróxidos de ferro e alumínio, já que é comum a presença de $\mathrm{Fe}$ e Al em amostras de sedimento. Os hidróxidos têm uma grande capacidade de adsorver elementos, servindo como carreadores para arrastar urânio, tório e polônio.

Após a formação do precipitado, este foi deixado por um dia em repouso para decantar e em seguida filtrado com papel Whatman. O precipitado foi então lavado com uma solução diluída de $\mathrm{NH}_{4} \mathrm{OH}$ e dissolvido com ácido clorídrico 
concentrado. A solução obtida foi levada a quase secura e avolumada até $100 \mathrm{~mL}$ com $\mathrm{HCl} 9 \mathrm{~mol} \mathrm{~L}^{-1}$.

\subsection{Separação e preparação das fontes}

O urânio, tório e polônio presentes na amostra foram separados por cromatografia de troca iônica com resina aniônica AG1-X8 (100 a 200 mesh) na forma clorídrica. A amostra contendo $U$, Th e Po foi percolada pela resina condicionada com $\mathrm{HCl} 9 \mathrm{~mol} \mathrm{~L}^{-1}$ para a retenção do U, Fe e Po e separação do Th na fração eluída. Foi utlizado $\mathrm{HNO}_{3} 1 \mathrm{~mol} \mathrm{~L}^{-1}$ para eluir o $\mathrm{Po}, \mathrm{HNO}_{3} 8 \mathrm{~mol} \mathrm{~L}^{-1}$ para eluir o $\mathrm{Fe}$ e $\mathrm{HCl} 0,1 \mathrm{~mol} \mathrm{~L}^{-1}$ para $\mathrm{U}$. A eliminação do ferro é necessária devido ao fato deste ser o principal interferente na eletrodeposição do U (Silva, 1998).

A solução contendo Th, separada na primeira etapa da cromatografia, foi então evaporada até uma gota, ressuspendida com $\mathrm{HNO}_{3} 8 \mathrm{~mol} \mathrm{~L}^{-1}$ e passada pela coluna que foi previamente condicionada com $\mathrm{HNO}_{3} 8 \mathrm{~mol} \mathrm{~L}^{-1}$. Posteriormente o Th foi eluido com $\mathrm{HCl} 0,1 \mathrm{~mol} \mathrm{~L}^{-1}$.

As soluções contendo $U$ e Th obtidas, foram evaporadas à secura, e tratadas três vezes com alíquotas de $1 \mathrm{~mL}$ de $\mathrm{HNO}_{3}$ concentrado, sendo que na última, foi adicionado $1 \mathrm{~mL}$ de $\mathrm{H}_{2} \mathrm{O}_{2}$ e evaporadas até uma gota.

O procedimento para eletrodeposição do urânio e tório, extraído das amostras deste estudo consiste em uma reação de óxido-redução induzida pelo estabelecimento de uma corrente elétrica entre dois eletrodos, mantidos em contato por solução de $\mathrm{NH}_{4} \mathrm{Cl}$ em pH 1. A solução é mantida sob uma corrente de $1,2 \mathrm{~A}$ e diferença de potencial de $7 \mathrm{~V}$, durante 1 hora.

A FIGURA 3.7 apresenta o arranjo experimental para a eletrodeposição de urânio e de tório com a fonte de tensão, eletrodos e a célula de eletrodeposição feita de um tipo de acrílico (polimetilmetacrilato) com base metálica. 

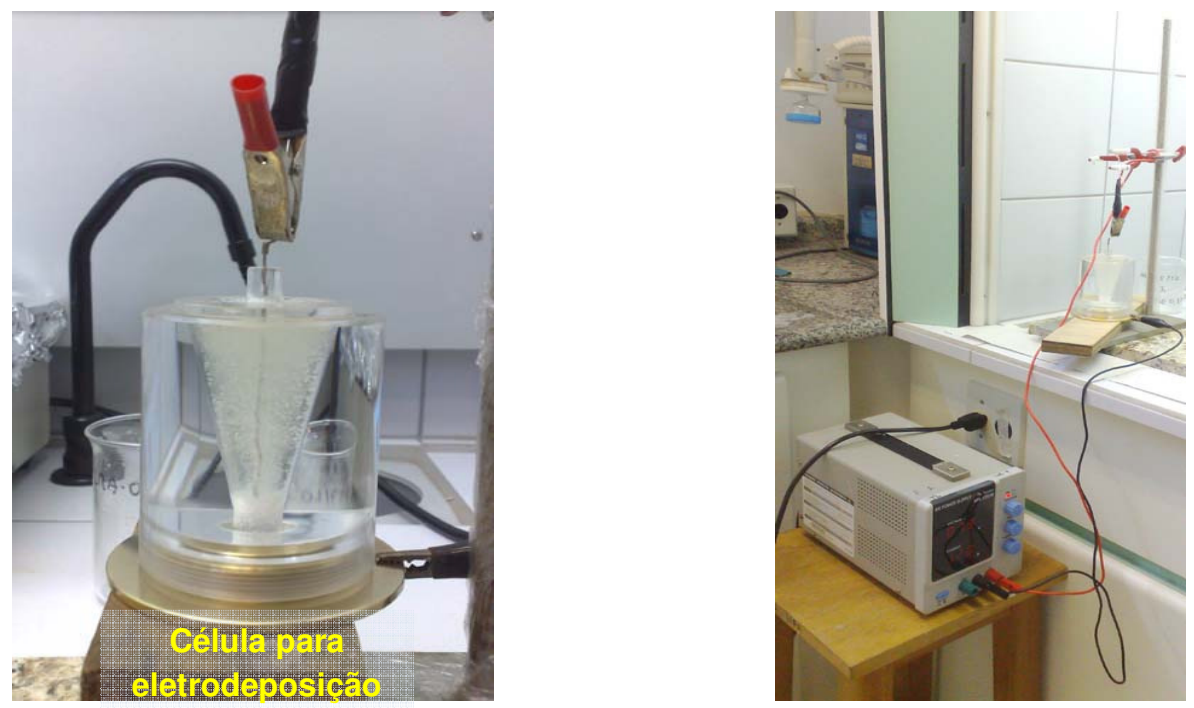

FIGURA 3.7: Arranjo experimental para a eletrodeposição

Para realizar a preparação da fonte contendo polônio utilizou-se uma adaptação do método elaborado por Flynn (1968) que consiste na deposição espontânea do polônio em discos de prata em uma solução de $\mathrm{HCl}$ a aproximadamente $90^{\circ} \mathrm{C}$ (Matthews et al., 2007).

A amostra contendo polônio, que foi eluida da coluna cromatográfica, foi levada à quase secura por três vezes com $10 \mathrm{~mL}$ de $\mathrm{HCl}$ concentrado para a eliminação do ácido nítrico e então foi adicionado $\mathrm{HCl} 6,25 \mathrm{~mol} \mathrm{~L}^{-1}$, posteriormente a amostra foi filtrada em filtro millipore 0,1 micra.

À amostra filtrada foi adicionado $10 \mathrm{~mL}$ de cloridrato de hidroxilamina $20 \%$ e $10 \mathrm{~mL}$ de solução de citrato de sódio $25 \%$, que são agentes complexantes utilizados para eliminar a interferência do $\mathrm{Fe}^{3+} \mathrm{e}$ do $\mathrm{Cr}^{6+}$ na deposição do polônio. Por fim adicionou-se $0,2 \mathrm{~mL}$ de carreador de $\mathrm{Bi}^{+3} 50 \mathrm{~g} \mathrm{~L}^{-1}$.

$\mathrm{O} \mathrm{pH}$ foi ajustado para $1,5 \mathrm{com} \mathrm{HCl} 1,5 \mathrm{~mol} \mathrm{~L}^{-1}$ e solução de hidróxido de amônio concentrado. A amostra foi avolumada para um máximo de $100 \mathrm{~mL}$, colocada em banho com temperatura controlada de 90 graus Celsius sob agitação para a deposição do polônio em plaquetas de prata por 2 horas. A FIGURA 3.3 apresenta 0 arranjo experimental para a deposição do polônio. 

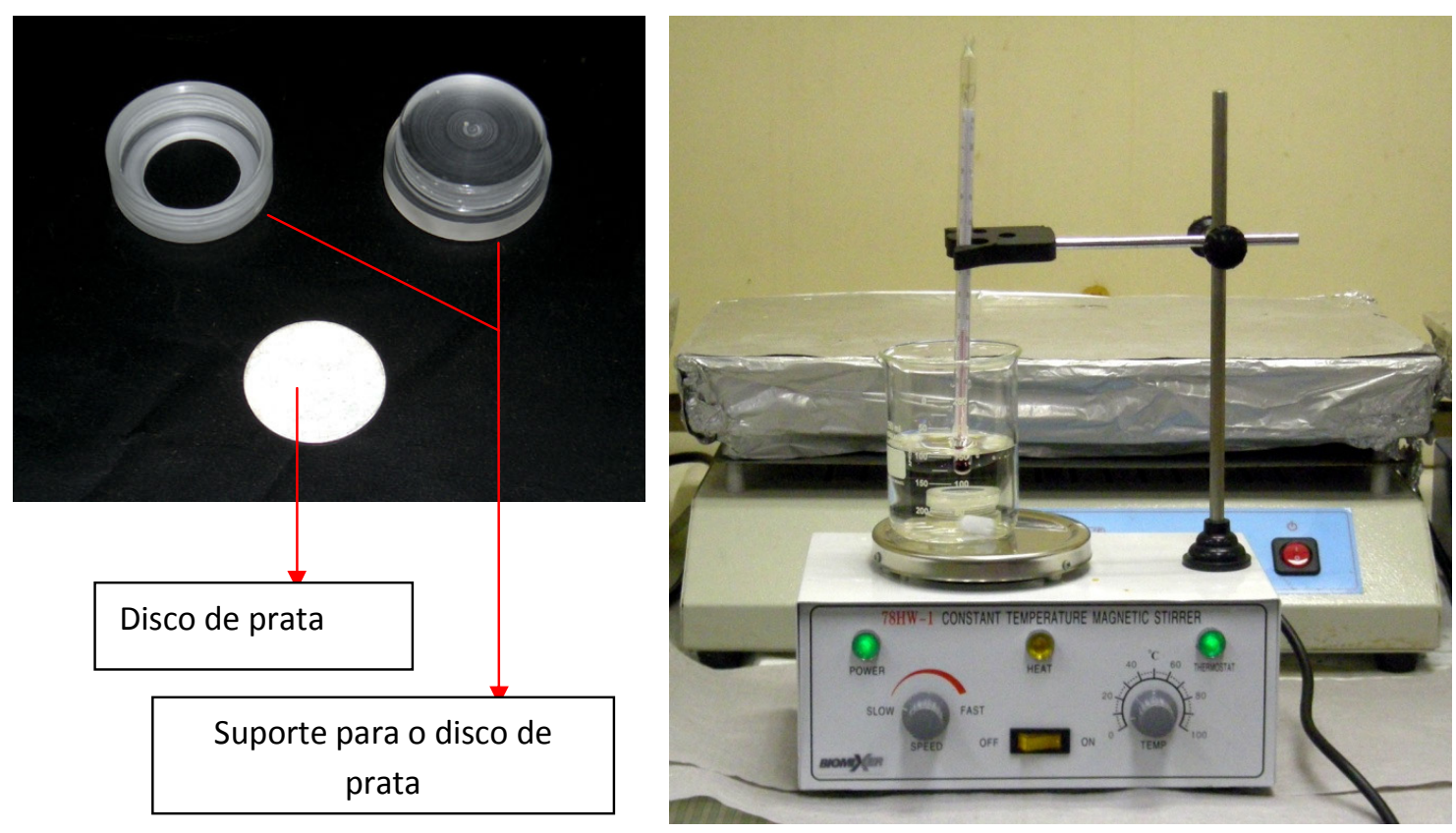

FIGURA 3.8: Suporte para a deposição do polônio e arranjo experimental para a deposição sob agitação

Após a deposição, a plaqueta foi lavada com água deionizada e álcool etílico $95 \%$ e posteriormente seca. A concentração de atividade das amostras foi determinada pela contagem no espectrômetro alfa de barreira de superfície, por 200.000 a 300.000 segundos.

\subsection{Determinação da Eficiência e calibração das energias dos} detectores alfa.

O detector utilizado no presente trabalho foi um detector de barreira de superfície de silício modelo Alpha Analyst da Camberra com oito câmaras (FIGURA 3.9). O software utilizado foi o Genie 2000 Alpha Aquisition \& Analysis v. 3.1. 


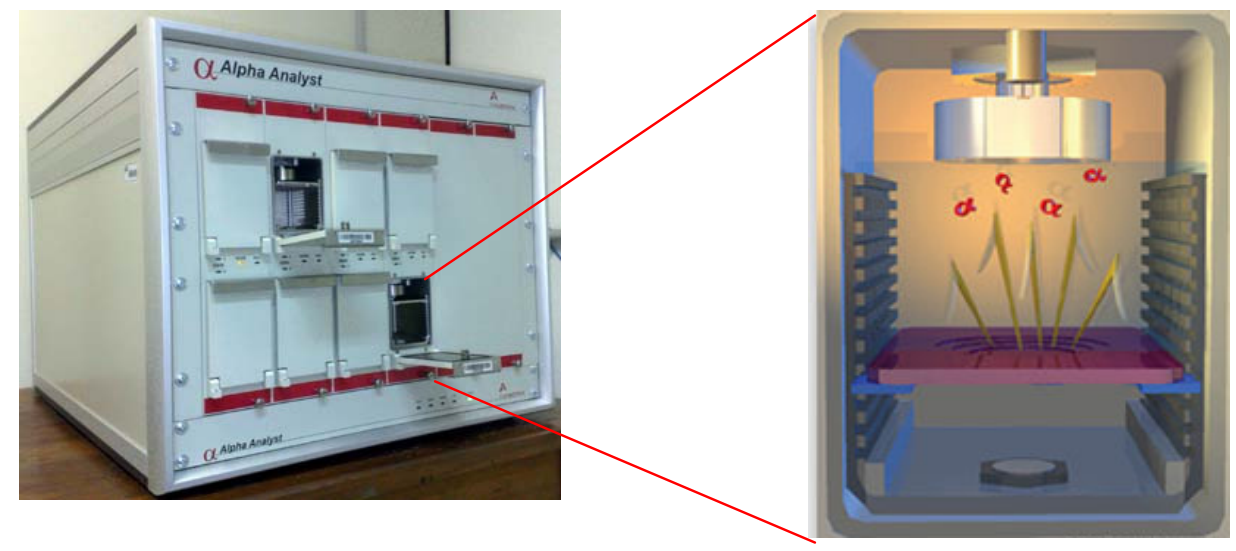

FIGURA 3.9: Espectrômetro alfa e detalhe da câmara com detector

Para a determinação da eficiência dos detectores foi utilizada uma fonte de ${ }^{241} \mathrm{Am}, \mathrm{AMR}-23$ da Amersham com atividade de $1,56 \times 10^{5} \mathrm{dpm}$ em 2 п, o que corresponde a $2600 \mathrm{~Bq}$. A fonte foi contada por 100 segundos por três vezes em cada uma das câmeras. Abaixo é apresentada a fórmula para o cálculo da eficiência e os resultados obtidos são apresentados na TABELA 3.3.

$$
E \boldsymbol{E}=\frac{\boldsymbol{C f}}{\boldsymbol{A f}} \quad \text { (equação 1) }
$$

onde:

$E f=$ eficiência de contagem $\left(\operatorname{cps~dps}^{-1}\right)$

$\mathrm{Cf}=$ contagem $\mathrm{da}$ fonte $(\mathrm{cps})$

$A f=$ atividade da fonte $(\mathrm{dps})$ 
TABELA 3.3: Valores médios das eficiências dos detectores alfa em $2 \pi$

\begin{tabular}{|l|l|}
\hline Câmara & Eficiência \\
\hline $1 A$ & $45,7 \%$ \\
\hline $1 B$ & $46,7 \%$ \\
\hline $2 A$ & $53,7 \%$ \\
\hline $2 B$ & $49,3 \%$ \\
\hline $3 A$ & $45,6 \%$ \\
\hline $3 B$ & $31,4 \%$ \\
\hline $4 A$ & $46,6 \%$ \\
\hline $4 B$ & $46,6 \%$ \\
\hline
\end{tabular}

Para a calibração das energias utilizou-se uma fonte tríplice da Amersham International contendo, ${ }^{239} \mathrm{Pu}(5,156 \mathrm{MeV}),{ }^{241} \mathrm{Am}(5,485 \mathrm{MeV})$ e ${ }^{244} \mathrm{Cm}(5,804$ $\mathrm{MeV}$ ). A fonte foi contada por 100 segundos e a curva de calibração para a câmara 1A é apresentada na FIGURA 3.10. A calibração das demais câmaras seguiu o mesmo procedimento.

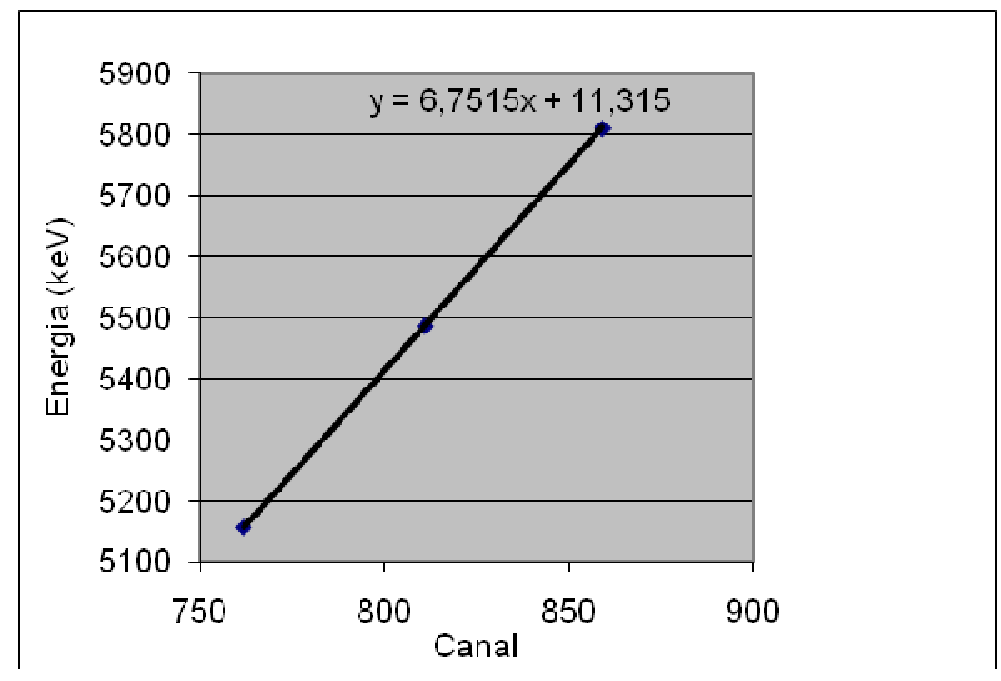

FIGURA 3.10: Curva de Calibração do detector alfa 
3.6 Determinação da radiação de fundo e limite inferior de detecção (LID)

A radiação de fundo foi medida contando-se por 200.000 segundos as câmaras vazias. Os valores obtidos para a radiação de fundo (BG) para os isótopos do urânio variaram de 0 a $6 \times 10^{-5}$ contagens por segundo, na região de interesse. Para os isótopos do tório os valores variaram de 0 a $210 \times 10^{-5}$ contagens por segundo, na região de interesse. Para o ${ }^{210} \mathrm{Po}$ foram obtidos valores de 0 a $5,0 \times 10^{-5}$ contagens por segundo na região de interesse.

O limite inferior de detecção representa a sensibilidade do método analítico empregado e foi determinada pela análise de água Milli-Q processada com a mesma metodologia empregada para a produção da fonte a partir das amostras.

O cálculo do limite inferior de detecção foi efetuado utilizando-se a seguinte fórmula:

$$
L I D=\frac{4,66 \times S_{b}}{t \times E f \times \gamma \times m} \quad \text { (equação 2) }
$$

onde,

LID= limite inferior de detecção

$\mathrm{S}_{\mathrm{b}}=$ desvio padrão da contagem da radiação de fundo (cps)

$\mathrm{t}=$ tempo de medida $(\mathrm{s})$

Ef = eficiência $\left(c p s \mathrm{dps}^{-1}\right)$

$Y=$ intensidade do pico (\%)

$\mathrm{m}=$ massa da amostra $(\mathrm{L})$

4,66 = representa o risco pré-estabelecido de seja medida alguma atividade na amostra que na verdade não exista ou que não seja medida uma atividade existente, considerando-se um nível de confiança de 95\%.

O valor encontrado para o polônio foi de $1,8 \times 10^{-11} \mathrm{~Bq} \mathrm{~kg}^{-1}$ 


\subsection{Validação da metodologia para a determinação do ${ }^{210} \mathrm{Po}$}

Para a validação da metodologia para a determinação de polônio foi utilizado um material de referência de sedimento marinho da Agência Internacional de Energia Atômica (IAEA - 300).

Foram preparadas 5 amostras de material de referência com a massa precisamente determinada, todas com valores próximos a $0,3 \mathrm{~g}$. À amostra acrescentou-se $0,1 \mu \mathrm{g}$ de solução de traçador de ${ }^{209} \mathrm{Po}$ (com atividade de 2,1715

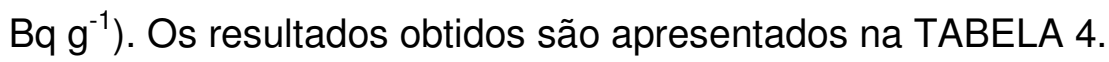

TABELA 3.4:Concentração de atividade em amostras de material de referência, de sedimentos marinhos do Mar Báltico (IAEA 300).

\begin{tabular}{cc}
\hline Amostra & $\begin{array}{c}\text { Concentração de atividade } \\
\left(\mathrm{Bq} \mathrm{kg}^{-1}\right)\end{array}$ \\
\hline $\mathbf{1}$ & 418,1 \\
$\mathbf{3}$ & 338,7 \\
$\mathbf{4}$ & 346,9 \\
$\mathbf{5}$ & 410,5 \\
\hline $\begin{array}{c}\text { Média e desvio } \\
\text { padrão }\end{array}$ & 388,1 \\
\hline $\begin{array}{c}\text { Valor certificado } \\
\text { Intervalo de } \\
\text { confiança } \\
\text { (Data de referência: } \\
\text { 01/01/1993 }\end{array}$ & $380,5 \pm 36,2$ \\
\hline $\begin{array}{c}\text { Desvio padrão } \\
\text { relativo }\end{array}$ & 360 \\
\hline $\begin{array}{c}\text { Erro relativo } \\
\end{array}$ & \\
\hline
\end{tabular}

Os resultados obtidos na análise de material de referência apresentaram um desvio padrão relativo abaixo de $10 \%$, o que demonstra boa precisão do método e o erro relativo de $5,7 \%$ mostra que a metodologia empregada tem boa exatidão. 


\subsection{Cálculo do rendimento químico e da concentração de atividade dos radionuclídeos}

O cálculo do rendimento foi efetuado de acordo com a seguinte fórmula:

$$
R q=\left(\frac{C s}{E f \times M s \times A s}\right) \times 100 \quad \text { (equação 3) }
$$

onde:

$\mathrm{Rq}=$ rendimento químico $(\%)$

Cs =contagem do traçador $(\mathrm{cps})$

As $=$ Atividade do traçador (dps)

Ms= Massa da solução do padrão

Ef $=$ Eficiência do detector $\left(\mathrm{cps} \mathrm{dps}^{-1}\right)$

O cálculo da concentração de atividade dos radionuclídeos por espectrometria alfa foi realizado utilizando a seguinte expressão:

$$
C a=A t \cdot \frac{\text { Cont.a }}{\text { Cont.s }} \cdot \frac{m s}{m a} \cdot 1000 \quad \text { (equação 4) }
$$

onde:

$\mathrm{Ca}=$ concentração de atividade na amostra $\left(\mathrm{Bq} \mathrm{kg}^{-1}\right)$.

$\mathrm{At}=$ Atividade do traçador $\left(\mathrm{Bq} \mathrm{g}^{-1}\right)$

Cont.a $=$ taxa de contagem na região do isótopo de interesse $(\mathrm{cps})$

Cont.s= taxa de contagem do traçador na região de interesse $(\mathrm{cps})$

$\mathrm{ms}=$ massa do traçador

$\mathrm{ma}=$ Massa da amostra 


\section{RESULTADOS E DISCUSSÃO}

\subsection{Rendimento Químico para a recuperação do ${ }^{210} \mathrm{Po}$}

As amostras de sedimento apresentaram-se bastantes resistentes ao ataque químico para a dissolução, as sucessivas adições de ácido sob aquecimento podem ter custado, no caso do polônio, em perdas por volatilização.

O maior valor obtido para o rendimento químico da análise foi 95,4\%, mas em média obteve-se um valor de 32,2\%. Saito (1996) obteve para a análise de material de referência para sedimento marinho (IAEA - 300) valores médios de $48,3 \%$ e quando analisou sedimentos marinhos da Antártica obteve média de $73,7 \%$.

As perdas na recuperação do polônio foram corrigidas pelo cálculo das perdas dos respectivos traçadores.

\subsection{Bertioga}

As concentrações elementares obtidas na análise de testemunhos coletados em ambiente estuarino são influenciadas por diversos fatores, tais como comportamento químico dos elementos, diferenças no aporte destes para o sedimento, potencial de redução, interações químicas, bioturbação, liberação e ressuspensão. Todos esses fatores podem alterar as concentrações dos radionuclídeos nos sedimentos. Para ambientes estuarinos e marinhos a salinidade e pH estão entre os principais fatores podem alterar o comportamento do elemento produzindo mudanças em sua solubilidade (Salbu \& Oughton, 1995).

Os resultados das concentrações de atividade dos radionuclídeos porcentagem de fração fina (incluindo média, desvio padrão e intervalo) para esta região são apresentados nas TABELAS 4.1, 4.2, e 4.3. Os dados de granulometria utilizados neste trabalho foram extraídos de Damatto (2010). A incerteza associada às medidas refere-se à propagação de erro, a não ser quando especificado diferentemente. 
TABELA 4.1: Concentrações de atividade dos radionuclídeos $\left(\mathrm{Bq} \mathrm{kg}^{-1}\right)$ e porcentagem de fração fina no testemunho BE1 em Bertioga

\begin{tabular}{|c|c|c|c|c|c|c|}
\hline Prof. (cm) & ${ }^{238} \mathrm{U}$ & ${ }^{234} \mathrm{U}$ & ${ }^{230} \mathrm{Th}$ & ${ }^{232} \mathrm{Th}$ & ${ }^{210} \mathrm{Po}$ & $F F(\%)$ \\
\hline 2 & $15 \pm 1$ & ND & ND & $18 \pm 1$ & $21 \pm 9$ & 3 \\
\hline 14 & $32 \pm 5$ & $42 \pm 2$ & $22 \pm 3$ & $25 \pm 1$ & $20 \pm 9$ & 28 \\
\hline 38 & $28 \pm 4$ & $45 \pm 3$ & $31 \pm 1$ & $26 \pm 1$ & $30 \pm 12$ & 34 \\
\hline 74 & $22 \pm 3$ & $24 \pm 1$ & $26 \pm 1$ & $25 \pm 1$ & ND & 31 \\
\hline 78 & $13 \pm 3$ & $15 \pm 1$ & $22 \pm 2$ & $20 \pm 1$ & $29 \pm 9$ & 31 \\
\hline média* & $22 \pm 8$ & $32 \pm 14$ & $25 \pm 4$ & $23 \pm 4$ & $25 \pm 5$ & $25 \pm 12$ \\
\hline$d p r^{\star \star}$ & 37 & 46 & 17 & 16 & 21 & 49 \\
\hline intervalo & $13-32$ & $15-45$ & $22-31$ & $18-26$ & $20-30$ & 3 a 34 \\
\hline
\end{tabular}

$\mathrm{ND}=$ não determinado

* representa média e desvio padrão

${ }^{* *}$ representa o desvio padrão relativo

TABELA 4.2: Concentrações de atividade dos radionuclídeos $\left(\mathrm{Bq} \mathrm{kg}^{-1}\right)$ e porcentagem de fração fina no testemunho BE2 em Bertioga

\begin{tabular}{|c|c|c|c|c|c|c|}
\hline Prof. (cm) & ${ }^{238} \mathrm{U}$ & ${ }^{234} \mathrm{U}$ & ${ }^{230} \mathrm{Th}$ & ${ }^{232} \mathrm{Th}$ & ${ }^{210} \mathrm{Po}$ & $\begin{array}{l}F(\%) \\
\end{array}$ \\
\hline 2 & $\begin{array}{ll}60 \pm 3 \\
\end{array}$ & $63 \pm 4$ & $51 \pm 2$ & $72 \pm 2$ & $62 \pm 8$ & 78 \\
\hline 6 & $88 \pm 3$ & $92 \pm 5$ & $53 \pm 2$ & $75 \pm 2$ & $34 \pm 2$ & 89 \\
\hline 10 & $92 \pm 3$ & $96 \pm 5$ & $72 \pm 5$ & $65 \pm 2$ & $79 \pm 2$ & 91 \\
\hline 14 & $67 \pm 1$ & $85 \pm 5$ & $68 \pm 3$ & $61 \pm 2$ & $80 \pm 3$ & 94 \\
\hline 26 & $73 \pm 2$ & $93 \pm 3$ & $79 \pm 2$ & $61 \pm 2$ & $95 \pm 2$ & 97 \\
\hline 38 & $81 \pm 2$ & $103 \pm 6$ & $72 \pm 3$ & $63 \pm 2$ & $89 \pm 2$ & 95 \\
\hline 46 & $62 \pm 2$ & $75 \pm 3$ & $88 \pm 3$ & $77 \pm 3$ & $19 \pm 1$ & 63 \\
\hline 50 & $42 \pm 1$ & $51 \pm 2$ & $43 \pm 1$ & $84 \pm 3$ & $95 \pm 3$ & 23 \\
\hline média* & $71 \pm 16$ & $82 \pm 18$ & $66 \pm 15$ & $70 \pm 9$ & $69 \pm 29$ & $79 \pm 25$ \\
\hline$d p r^{\star \star}$ & 23 & 22 & 23 & 12 & 41 & 32 \\
\hline intervalo & 42 a 92 & 51 a 103 & 43 a 88 & 61 a 84 & 19 a 95 & 23 a 97 \\
\hline
\end{tabular}

* representa média e desvio padrão

${ }^{* *}$ representa o desvio padrão relativo 
TABELA 4.3: Concentrações de atividade dos radionuclídeos $\left(\mathrm{Bq} \mathrm{kg}^{-1}\right)$ no testemunho BE3 em Bertioga

\begin{tabular}{|c|c|c|c|c|c|c|c|c|}
\hline $\begin{array}{l}\text { Prof. } \\
\text { (cm) }\end{array}$ & ${ }^{238} U$ & & ${ }^{234} \mathrm{U}$ & & ${ }^{230} \mathrm{Th}$ & ${ }^{232} \mathrm{Th}$ & ${ }^{210} \mathrm{Po}$ & FF(\%) \\
\hline 2 & 130 & \pm 5 & 177 & \pm 6 & $59 \pm 3$ & $52 \pm 2$ & $31 \pm 2$ & 85 \\
\hline 10 & 143 & \pm 5 & 211 & \pm 7 & $71 \pm 3$ & $62 \pm 2$ & $\mathrm{ND} \pm 8$ & 91 \\
\hline 18 & 118 & \pm 4 & 213 & \pm 6 & $70 \pm 3$ & $47 \pm 2$ & $26 \pm 2$ & 92 \\
\hline 26 & 102 & \pm 4 & 124 & \pm 5 & $47 \pm 2$ & $46 \pm 2$ & $50 \pm 2$ & 95 \\
\hline 38 & 137 & \pm 4 & 143 & \pm 5 & $47 \pm 2$ & $43 \pm 2$ & $24 \pm 2$ & 92 \\
\hline 46 & 118 & \pm 4 & 127 & \pm 5 & $56 \pm 3$ & $38 \pm 2$ & $27 \pm 1$ & 94 \\
\hline 54 & 132 & \pm 4 & 151 & \pm 3 & $119 \pm 5$ & $80 \pm 2$ & $22 \pm 1$ & 93 \\
\hline 66 & 259 & \pm 6 & 305 & \pm 6 & $190 \pm 5$ & $148 \pm 4$ & $24 \pm 1$ & 87 \\
\hline 70 & 262 & \pm 7 & 293 & \pm 8 & $228 \pm 5$ & $152 \pm 4$ & $34 \pm 2$ & 90 \\
\hline média* & 156 & \pm 61 & 194 & \pm 68 & $99 \pm 67$ & $74 \pm 45$ & $30 \pm 9$ & $91 \pm 3$ \\
\hline$d p r^{\star \star}$ & 39 & & 35 & & 68 & 60 & 31 & 4 \\
\hline intervalo & 102 a 262 & & 124 a 305 & & 47 a 228 & 38 a 152 & 22 a 50 & 85 a 95 \\
\hline
\end{tabular}

$\mathrm{ND}=$ não determinado

* representa média e desvio padrão

${ }^{* *}$ representa o desvio padrão relativo

O radionuclídeo que apresentou a maior concentração média de atividade,por perfil, foi $0{ }^{234} \mathrm{U}\left(194 \mathrm{~Bq} \mathrm{~kg}{ }^{-1}\right)$, já $0{ }^{210} \mathrm{Po}$ foi o que apresentou a menor concentração média, $25 \mathrm{~Bq} \mathrm{~kg}^{-1}$.

Nas FIGURAS 4.1, 4.2 e 4.3 são apresentadas as concentrações de atividade dos radionuclídeos e a porcentagem de fração fina (grãos menores que $63 \mu \mathrm{m})$ em função da profundidade.

Na FIGURA 4.4 são mostrados os box plots contendo as médias das atividades dos radionuclídeos analisados, o erro padrão e o desvio padrão para os testemunhos BE1, BE2 e BE3.

O perfil BE1 (coletado no rio Itapanhaú) é composto principalmente por areia como pode ser observado na FIGURA 4.1 apresentando uma quantidade de fração fina variando de 3 a 34\%. O inverso ocorre com o perfil BE3 que tem uma alta quantidade de finos e não apresenta uma variação grande com relação à porcentagem de fração fina (desvio padrão relativo igual a 4). Neste testemunho, a variação da quantidade de silte e argila é de 85 a 95\%. Já o perfil BE2 apresenta variações na granulometria ao longo do perfil com um alto teor de finos 
nos primeiros $40 \mathrm{~cm}$ (78 a 97\%) e uma porcentagem maior de areia nas fatias mais profundas.

O perfil BE1 (coletado no rio Itapanhaú) foi o que apresentou os menores valores de concentração de atividade e as menores variações para todos os radionuclídeos estudados (FIGURA 4.4). Aparentemente, neste perfil os elementos de uma mesma série radioativa natural apresentam-se em equilíbrio. As menores concentrações observadas para o perfil BE1 podem ser explicadas pelo fato deste testemunho ter também apresentado as menores quantidades de fração fina (FIGURA 4.1). O perfil BE2 também apresentou valores de concentração muito próximos entre si e pequena variação, indicando provável equilíbrio radioativo (FIGURA 4.4). O testemunho BE3 foi o que apresentou os maiores valores de concentração e maiores variações para todos os radionuclídeos, exceto o polônio (FIGURA 4.4). Há também, neste testemunho (BE3), uma tendência de aumento dos valores ao longo do perfil (FIGURA 4.3), o que pode estar relacionado à interferência antrópica, em um possível evento de contaminação no passado.

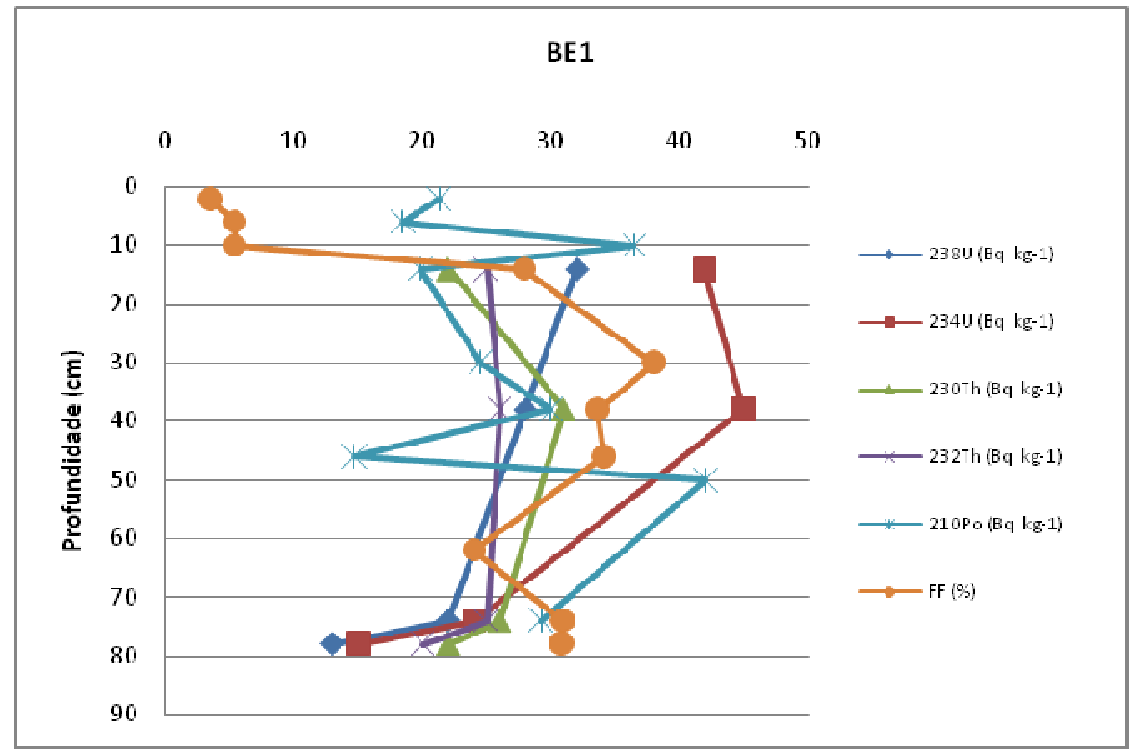

FIGURA 4.1 Concentrações de atividade dos radionuclídeos (Bq $\mathrm{kg}^{-1}$ ) e fração fina no testemunho BE1 coletado na região de Bertioga 


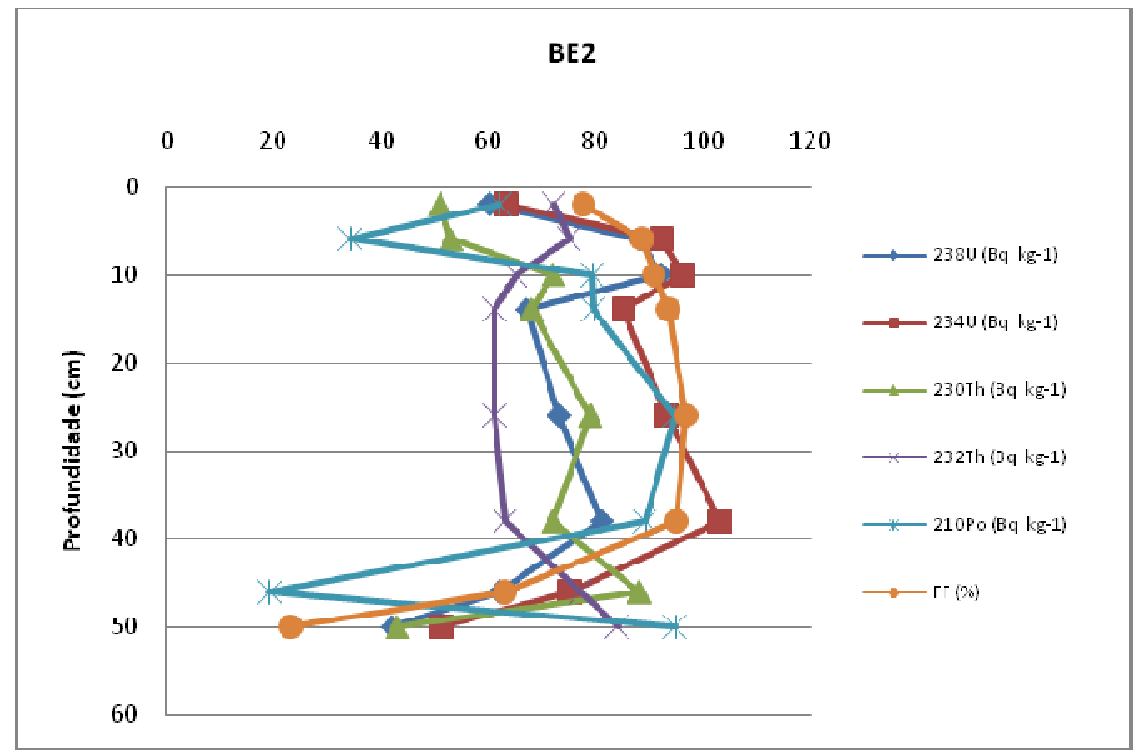

FIGURA 4.2: Concentrações de atividade dos radionuclídeos $\left(\mathrm{Bq} \mathrm{kg}^{-1}\right)$ e fração fina no testemunho BE2 coletado na região de Bertioga

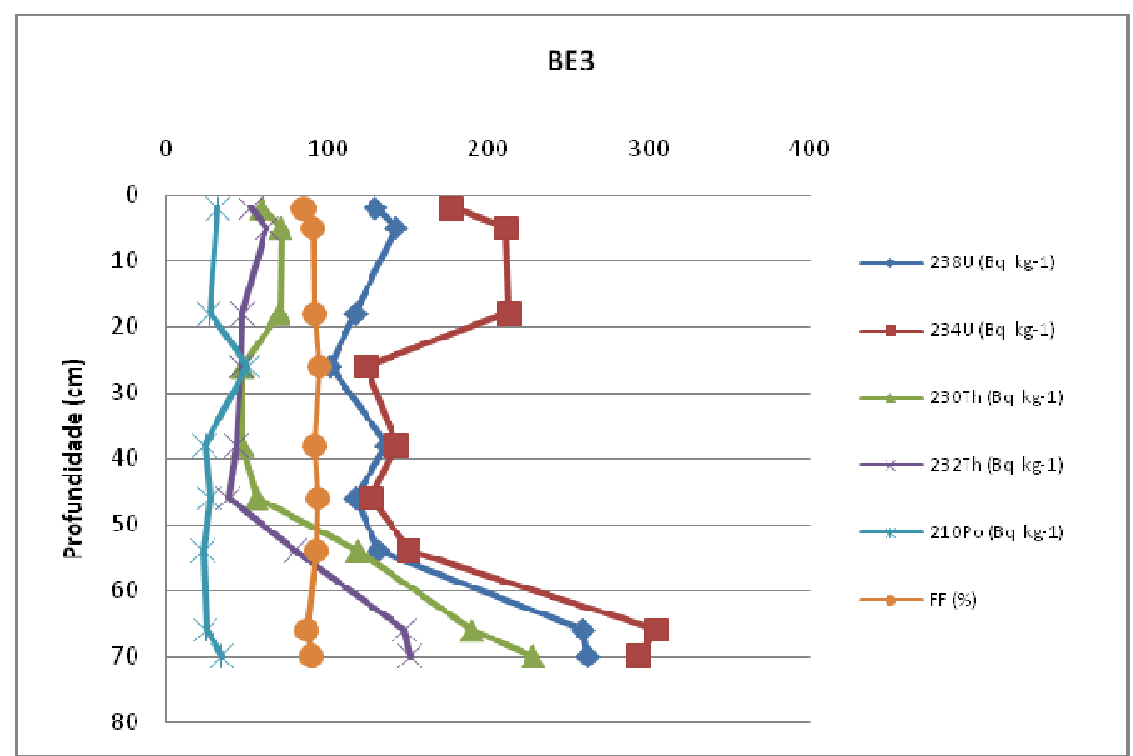

FIGURA 4.3: Concentrações de atividade dos radionuclídeos $\left(\mathrm{Bq} \mathrm{kg}^{-1}\right)$ e fração fina no testemunho BE3 coletado na região de Bertioga 
BERTIOGA

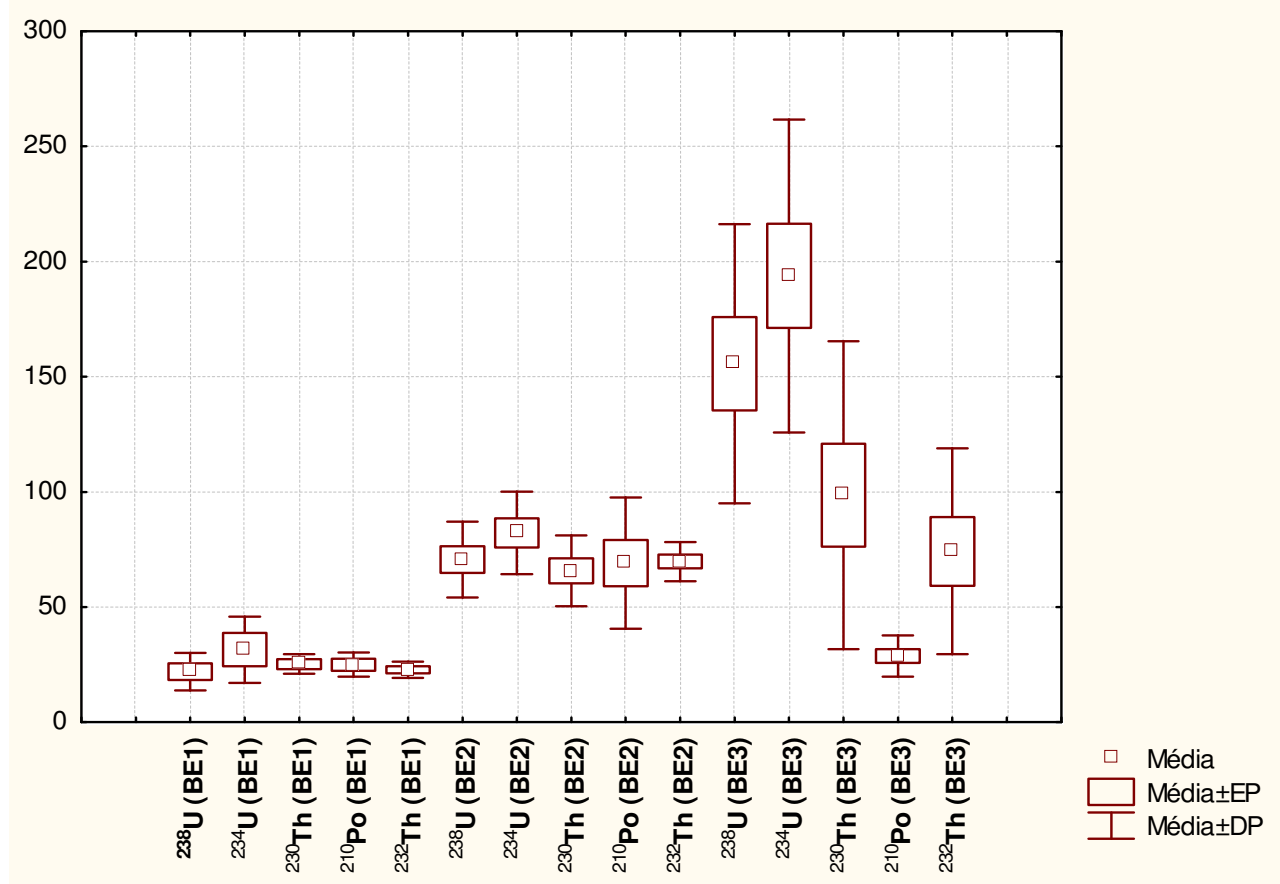

FIGURA 4.4: Box plot com as concetrações de atividade média dos radionuclídeos estudados nos testemunhos coletados na região de Bertioga (BE1, BE2 e BE3), mostrando erro padrão (EP) e desvio padrão (DP)

O testemunho BE2, que apresentou concentrações de atividade intermediárias em relação aos outros dois testemunhos de Bertioga, também apresenta quantidades intermediárias da fração fina.

Como dito anteriormente, os valores de concentração de atividade para o testemunho BE3 foram os maiores medidos na região (exceto para polônio), o que é coerente coma alta a porcentagem de fração fina, praticamente $100 \%$ em toda a sua extensão (FIGURA 4.3).

Considerando-se os valores médios de concentração de atividade obtidos e os seus respectivos desvios padrão, pode-se observar que os radionuclídeos da série do ${ }^{238} \mathrm{U}$ encontram-se muito próximos ao equilíbrio radioativo secular nos testemunhos $\mathrm{BE} 1$ e BE2, com um pequeno enriquecimento do ${ }^{234} \mathrm{U}$ em relação ao ${ }^{238} \mathrm{U}$.

No testemunho BE3 observa-se que ${ }^{230} \mathrm{Th}$ e ${ }^{210} \mathrm{Po}$ estão em desequilíbrio em relação aos isótopos de urânio. Para o polônio, pode-se afirmar que os dados encontrados representam os valores de referência da região. 
Os isótopos de ${ }^{234} \mathrm{U}$ e ${ }^{238} \mathrm{U}$ encontram-se em equilíbrio radioativo em sistemas fechados muito antigos, porém os processos de interação entre o sedimento e a água produzem razões isotópicas diferentes da unidade (Cherdyntesev, 1971; Osmond \& Cowart, 1976) em virtude de processos como deslocamento do ${ }^{234} \mathrm{U}$ do retículo cristalino provocado pelo recuo durante $\mathrm{O}$ decaimento alfa do ${ }^{238} \mathrm{U}$ (Dooley et al, 1966), enfraquecimento da ligação do ${ }^{234} U$ nos retículos cristalinos e oxidação preferencial para o estado hexavelente, que é mais solúvel. Se estes processos ocorrem na fonte do sedimento, $0{ }^{234} \mathrm{U}$ será preferencialmente lixiviado e poderá se tornar enriquecido nos locais onde ocorrer a sua deposição (reincorporação ao sedimento).

Os isótopos de tório, embora pertencentes a séries de decaimento diferentes, apresentam concentrações de atividade muito semelhantes em todos os testemunhos e isto, provavelmente, é devido ao fato de apresentarem o mesmo comportamento químico, uma vez que se trata do mesmo elemento, e apresentarem uma baixa solubilidade e, portanto, baixa mobilidade. O tório é transportado, em muitos materiais terrestres, na forma coloidal ou com o material particulado, e exposição à água resulta em precipitação devido ao produto de solubilidade de aproximadamente $10^{-35} \mathrm{do} \mathrm{Th}(\mathrm{OH})_{4}$. Este processo é tão eficiente que mesmo $0^{230} \mathrm{Th}$, formado pelo decaimento do ${ }^{238} \mathrm{U}$, será removido da solução e incorporado ao sedimento na maioria das condições (Molinari \& Snodgrass, 1990).

\subsection{Cubatão}

Os resultados das concentrações de atividade para os radionuclídeos estudados nos testemunhos de Cubatão são apresentados nas TABELAS $4.4 \mathrm{e}$ 4.5. A distribuição das concentrações de atividade e da granulometria em função da profundidade são mostrados nas FIGURAS 4.5 e 4.6 .

O radionuclídeo que apresentou a maior concentração média de atividade, por perfil, foi $\circ{ }^{234} \mathrm{U}\left(118 \mathrm{~Bq} \mathrm{~kg}{ }^{-1}\right)$, já $0{ }^{210} \mathrm{Po}$ foi o que apresentou a menor concentração média, $18 \mathrm{~Bq} \mathrm{~kg}^{-1}$. 
TABELA 4.4: Concentrações de atividade dos radionuclídeos $\left(\mathrm{Bq} \mathrm{kg}{ }^{-1}\right)$ no testemunho CB1 em Cubatão

\begin{tabular}{|c|c|c|c|c|c|c|c|c|}
\hline Prof. (cm) & ${ }^{238} \mathrm{U}$ & 234 & & ${ }^{234} \mathrm{U}$ & ${ }^{230} \mathrm{Th}$ & ${ }^{232} \mathrm{Th}$ & ${ }^{210} \mathrm{Po}$ & $F F(\%)$ \\
\hline 2 & $74 \pm 3$ & 91 & 3 & $91 \pm 3$ & $103 \pm 3$ & $70 \pm 2$ & $32 \pm 2$ & 96 \\
\hline 14 & $57 \pm 2$ & 70 & 3 & $70 \pm 3$ & $83 \pm 2$ & $59 \pm 2$ & $45 \pm 2$ & 94 \\
\hline 26 & $79 \pm 2$ & 97 & 3 & $97 \pm 3$ & $68 \pm 2$ & $69 \pm 2$ & $12 \pm 1$ & 95 \\
\hline 34 & $94 \pm 3$ & 114 & 4 & $114 \pm 4$ & $114 \pm 3$ & $74 \pm 2$ & $12 \pm 1$ & 82 \\
\hline 38 & $94 \pm 3$ & 114 & 4 & $114 \pm 4$ & $116 \pm 3$ & $71 \pm 2$ & $13 \pm 1$ & 67 \\
\hline 42 & $110 \pm 3$ & 135 & 4 & $135 \pm 4$ & $128 \pm 3$ & $81 \pm 2$ & $16 \pm 1$ & 88 \\
\hline 50 & $96 \pm 3$ & 117 & 4 & $117 \pm 4$ & $108 \pm 3$ & $69 \pm 2$ & $36 \pm 2$ & 75 \\
\hline 58 & $120 \pm 3$ & 147 & 4 & $147 \pm 4$ & $114 \pm 3$ & $74 \pm 2$ & $15 \pm 2$ & 81 \\
\hline 70 & $102 \pm 4$ & 125 & 3 & $125 \pm 3$ & $104 \pm 3$ & $74 \pm 2$ & $41 \pm 2$ & 84 \\
\hline 74 & $141 \pm 4$ & 171 & 5 & $171 \pm 5$ & $75 \pm 3$ & $78 \pm 2$ & $52 \pm 5$ & 75 \\
\hline média* & $97 \pm 24$ & 118 & \pm 29 & $118 \pm 29$ & $101 \pm 20$ & $72 \pm 6$ & $27 \pm 16$ & $84 \pm 16$ \\
\hline$d p r^{* *}$ & 25 & & & 24 & 19 & 8 & 57 & 11 \\
\hline intervalo & 57 a 141 & & & 70 a 171 & 68 a 128 & 59 a 81 & 12 a 36 & 67 a 96 \\
\hline
\end{tabular}

* representa média e desvio padrão

${ }^{* *}$ desvio padrão relativo

TABELA 4.5: Concentrações de atividade dos radionuclídeos ( $\left.\mathrm{Bq} \mathrm{kg}{ }^{-1}\right)$ no testemunho CB2 em Cubatão

\begin{tabular}{|c|c|c|c|c|c|c|}
\hline Prof. (cm) & ${ }^{238} \mathrm{U}$ & ${ }^{234} \mathrm{U}$ & ${ }^{230} \mathrm{Th}$ & ${ }^{232} \mathrm{Th}$ & ${ }^{210} \mathrm{Po}$ & FF(\%) \\
\hline 3 & $141 \pm 4$ & $91 \pm 3$ & $180 \pm 5$ & $129 \pm 3$ & $21 \pm 1$ & 61 \\
\hline 15 & $119 \pm 3$ & $70 \pm 3$ & $78 \pm 3$ & $92 \pm 2$ & $14 \pm 1$ & 88 \\
\hline 27 & $113 \pm 4$ & $97 \pm 3$ & $62 \pm 2$ & $82 \pm 2$ & $27 \pm 2$ & 78 \\
\hline 38 & $137 \pm 3$ & $114 \pm 4$ & $59 \pm 2$ & $91 \pm 2$ & $13 \pm 1$ & 87 \\
\hline 51 & $107 \pm 3$ & $117 \pm 4$ & $93 \pm 3$ & $68 \pm 1$ & $24 \pm 1$ & 88 \\
\hline 55 & $82 \pm 2$ & $147 \pm 4$ & $67 \pm 2$ & $64 \pm 1$ & $10 \pm 1$ & 91 \\
\hline 59 & $87 \pm 3$ & $150 \pm 4$ & $63 \pm 2$ & $60 \pm 1$ & ND & 91 \\
\hline média* & $112 \pm 23$ & $112 \pm 29$ & $86 \pm 43$ & $84 \pm 24$ & $18 \pm 7$ & $83 \pm 11$ \\
\hline$d p r^{* *}$ & 20 & 26 & 50 & 28 & 37 & 13 \\
\hline intervalo & 82 a 141 & 70 a 150 & 59 a 180 & 60 a 129 & 10 a 27 & 61 a 91 \\
\hline
\end{tabular}

ND = não determinado

* representa média e desvio padrão

** representa o desvio padrão relativo

A análise dos testemunhos na região de Cubatão apresentou concentrações para os isótopos de urânio e tório semelhantes, já o polônio apresentou concentrações menores (média de $18 \mathrm{~Bq} \mathrm{~kg}^{-1}$ em CB2 e $27 \mathrm{~Bq} \mathrm{~kg}^{-1} \mathrm{em}^{-}$ CB1). 
No caso do ${ }^{238} \mathrm{U}$ e ${ }^{232} \mathrm{Th}$ a variação encontra-se dentro do esperado para a região de acordo com dados da literatura que apresentam uma variação de 89 a 154Bq kg-1 e 66 a 98 Bq kg-1 para estes nuclídeos, respectivamente (Silva, 2004).

A composição granulométrica em CB1 varia de 67 a 96\% de silte + argila, sendo que, como pode ser visualizado a partir da FIGURA 4.5, há uma ligeira queda na proporção de finos com a profundidade. Porém em CB2, apesar da variação ser muito semelhante (61 a 91\% de fração fina) o inverso ocorre, ou seja, há um aumento da composição de finos com a profundidade. Nos dois casos não foi verificada uma relação entre a variação da granulometria e a concentração dos radionuclídeos.

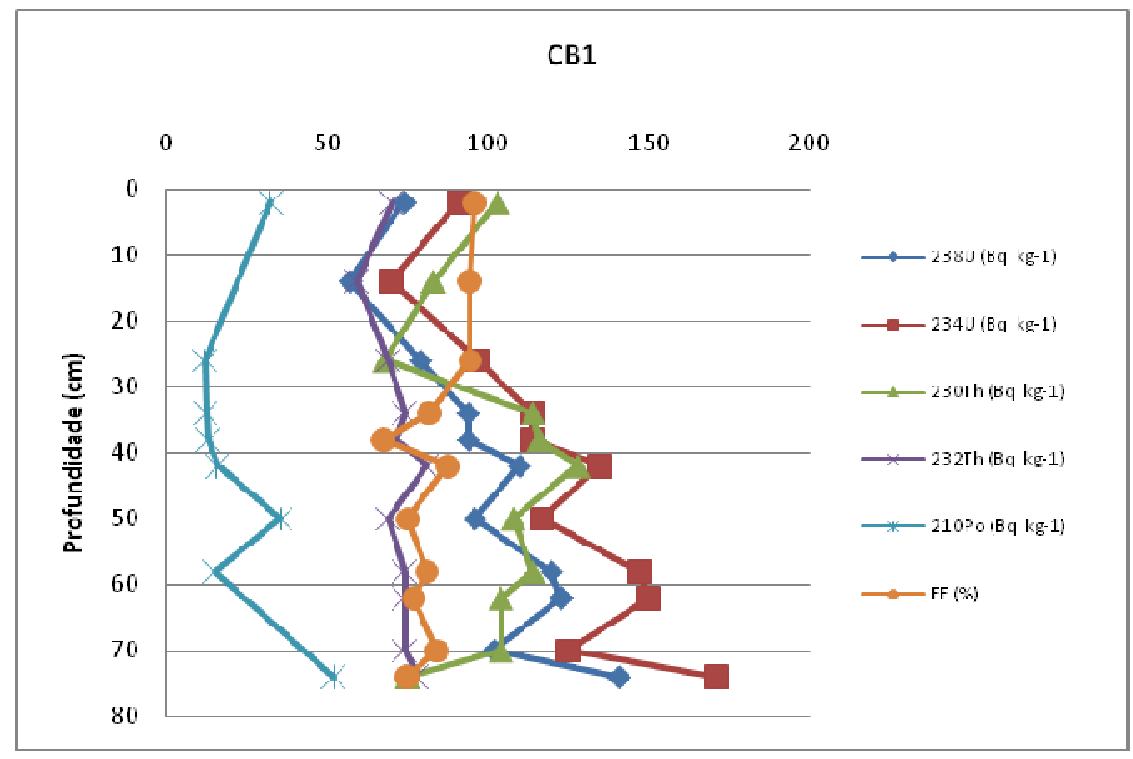

FIGURA 4.5: Concentrações de atividade dos radionuclídeos (Bq kg $\left.{ }^{-1}\right)$ e fração fina no testemunho CB1 coletado na região de Cubatão

O perfil CB1 apresentou uma tendência ao aumento das concentrações de atividade com a profundidade, o que não pode ser explicado pela variação na fração fina já que como dito anteriormente, esta decresce nas fatias mais profundas. Este aumento deve estar relacionado, como no caso de perfil BE3 de Bertioga, a um evento de contaminação ocorrido no passado. 


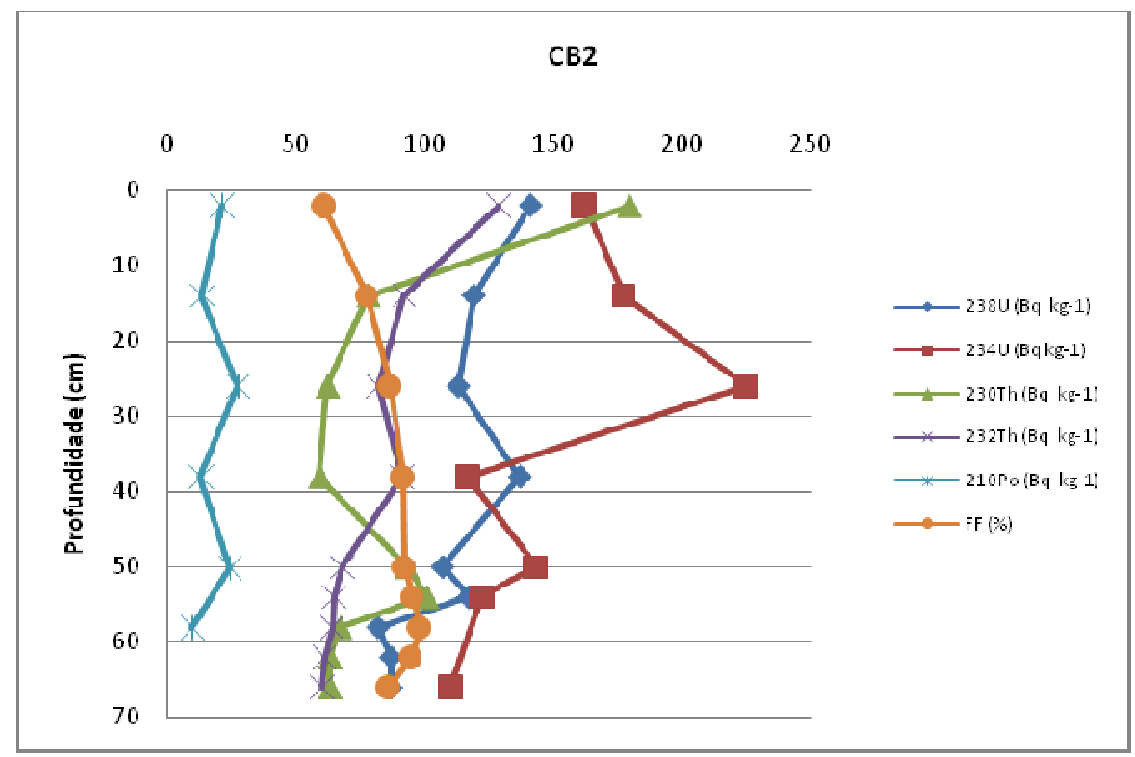

FIGURA 4.6: Concentrações de atividade dos radionuclídeos $\left(\mathrm{Bq}^{-1}\right)$ e fração fina no testemunho CB2 coletado na região de Cubatão

No testemunho CB2 a concentração dos radionuclídeos nos últimos $20 \mathrm{~cm}$ foi praticamente constante e pode ser considerada como uma indicação da linha de base da concentração destes elementos nos sedimentos desta região.

Na FIGURA 4.7 é mostrado o box plot contendo as médias das atividades dos radionuclídeos analisados, o erro padrão e o desvio padrão para os testemunhos CB1 e CB2. 


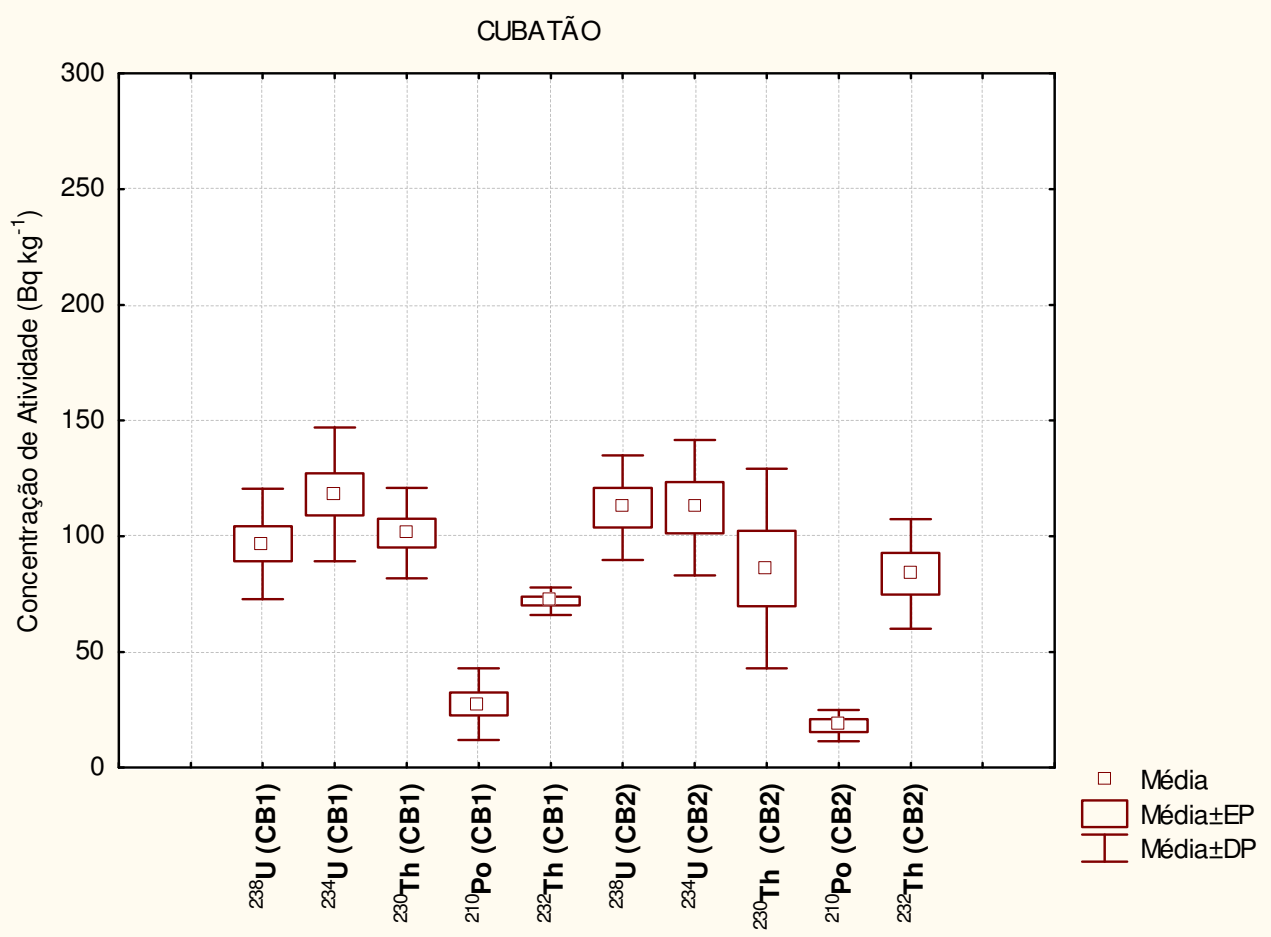

FIGURA 4.7:Box plotcom as concetrações de atividade média dos radionuclídeos estudados nos testemunhos coletados na região de Cubatão (CB1 e CB2), mostrando erro padrão (EP) e desvio padrão (DP)

Considerando-se os valores médios de concentração de atividade obtidos e os seus respectivos desvios padrão, pode-se observar que os radionuclídeos da série do ${ }^{238} \mathrm{U}$ encontram-se muito próximos ao equilíbrio radioativo secular nos testemunhos $\mathrm{CB} 1$ e $\mathrm{CB} 2$, com um pequeno enriquecimento do ${ }^{234} \mathrm{U}$ em relação ao ${ }^{238} \mathrm{U}$ no perfil CB1.

Nos perfis de Cubatão percebe-se alguma influência antrópica, nas concentrações de $\mathrm{U}$ e Th, provavelmente devido à proximidade com o pólo industrial de Cubatão. A concentração do ${ }^{210} \mathrm{Po}$ nos dois perfis é da mesma ordem de grandeza dos outros dois perfis de Bertioga e, portanto, pode ser considerada como valor de referência. 


\subsection{São Vicente}

Os resultados para as concentrações de atividade dos radionuclídeos determinados nos testemunhos da região de São Vicente são apresentados nas TABELAS 4.6, 4.7, e 4.8 e as concentrações de atividade e porcentagem de fração fina são apresentadas nas FIGURAS 4.8, 4.9 e 4.10.

TABELA 4.6: Concentrações de atividade dos radionuclídeos $\left(\mathrm{Bq} \mathrm{kg}^{-1}\right)$ no testemunho SV1 em São Vicente.

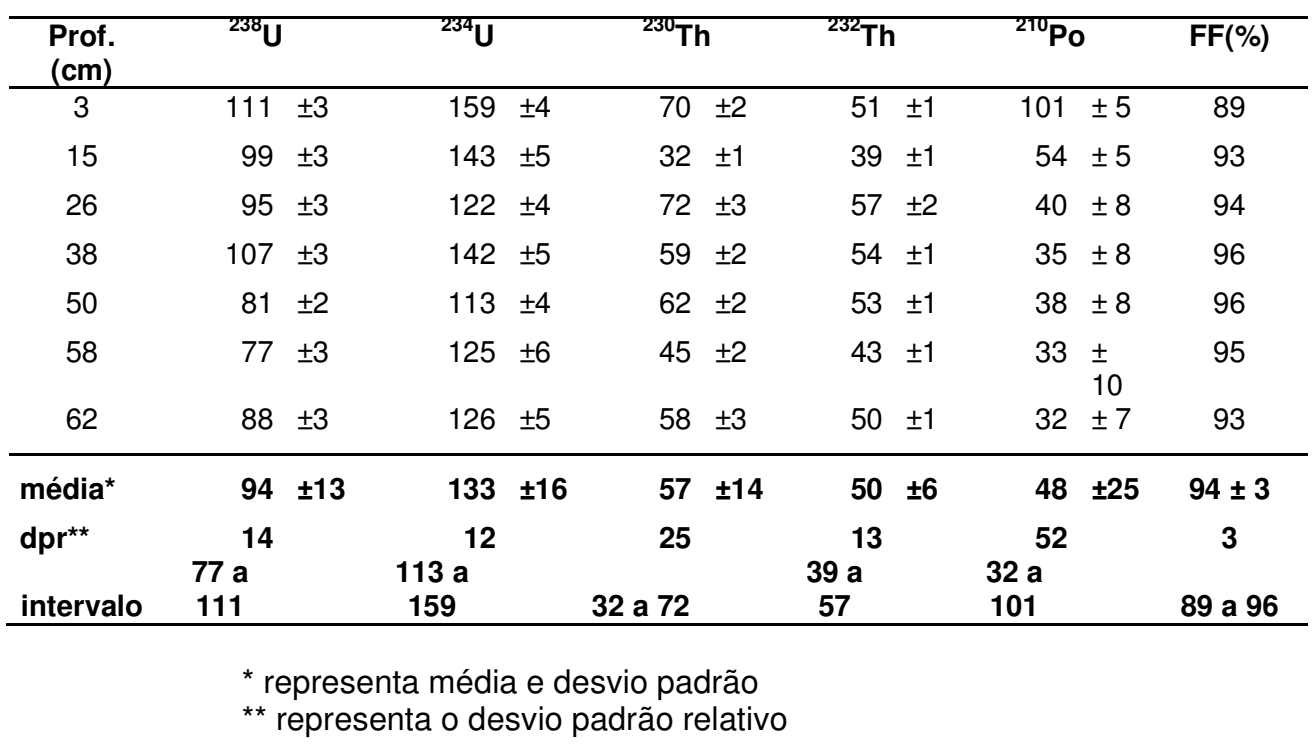

TABELA 4.7: Concentrações de atividade dos radionuclídeos $\left(\mathrm{Bq} \mathrm{kg}^{-1}\right)$ no testemunho SV2 em São Vicente

\begin{tabular}{|c|c|c|c|c|c|c|c|}
\hline \multirow{2}{*}{$\begin{array}{c}\text { Prof. (cm) } \\
14\end{array}$} & \multicolumn{2}{|c|}{${ }^{238} \mathrm{U}$} & ${ }^{234} U$ & ${ }^{230} \mathrm{Th}$ & ${ }^{232} \mathrm{Th}$ & ${ }^{210} \mathrm{Po}$ & \multirow{2}{*}{$\begin{array}{c}\mathrm{FF}(\%) \\
73\end{array}$} \\
\hline & 129 & \pm 3 & $214 \pm 4$ & $71 \pm 3$ & $46 \pm 2$ & $29 \pm 10$ & \\
\hline 38 & 49 & \pm 2 & $62 \pm 3$ & 45 & $39 \pm 2$ & $28 \pm 6$ & 73 \\
\hline 50 & 41 & \pm 2 & $64 \pm 2$ & $79 \pm 2$ & $39 \pm 2$ & $53 \pm 8$ & 48 \\
\hline 74 & 121 & \pm 2 & $207 \pm 4$ & $77 \pm 3$ & $51 \pm 2$ & $27 \pm 6$ & 51 \\
\hline 94 & 15 & \pm 2 & $24 \pm 1$ & $43 \pm 1$ & $25 \pm 1$ & $30 \pm 7$ & 42 \\
\hline 98 & 28 & \pm 2 & $46 \pm 1$ & $32 \pm 1$ & $23 \pm 1$ & $22 \pm 9$ & 44 \\
\hline média* & 64 & \pm 49 & $103 \pm 85$ & $58 \pm 20$ & $37 \pm 11$ & $32 \pm 11$ & $55 \pm 14$ \\
\hline$d p r^{\star \star}$ & 77 & & 82 & 35 & 30 & 35 & 26 \\
\hline intervalo & 15 a 129 & & 24 a 214 & 32 a 79 & 23 a 51 & 22 a 53 & 42 a 73 \\
\hline
\end{tabular}

* representa média e desvio padrão

** representa o desvio padrão relativo 
TABELA 4.8: Concentrações de atividade dos radionuclídeos $\left(\mathrm{Bq} \mathrm{kg}^{-1}\right)$ no testemunho SV3 em São Vicente

\begin{tabular}{|c|c|c|c|c|c|c|}
\hline $\begin{array}{l}\text { Prof. } \\
\text { (cm) }\end{array}$ & ${ }^{238} \mathrm{U}$ & ${ }^{234} U$ & ${ }^{230} \mathrm{Th}$ & ${ }^{232} \mathrm{Th}$ & ${ }^{210} \mathrm{Po}$ & FF(\%) \\
\hline 2 & $55 \pm 2$ & $77 \pm 3$ & $46 \pm 2$ & $27 \pm 2$ & $26 \pm 2$ & 6 \\
\hline 10 & $58 \pm 2$ & $64 \pm 3$ & $28 \pm 2$ & $28 \pm 2$ & ND & 8 \\
\hline 22 & $41 \pm 2$ & $41 \pm 3$ & $51 \pm 3$ & $23 \pm 2$ & ND & 1 \\
\hline 34 & $33 \pm 1$ & $35 \pm 2$ & ND & $16 \pm 1$ & $18 \pm 1$ & 3 \\
\hline 70 & $63 \pm 2$ & $72 \pm 3$ & $55 \pm 3$ & $23 \pm 2$ & ND & 6 \\
\hline 74 & $48 \pm 2$ & $43 \pm 2$ & $60 \pm 3$ & $17 \pm 1$ & ND & 5 \\
\hline média* & $50 \pm 11$ & $55 \pm 18$ & $48 \pm 12$ & $22 \pm 5$ & $22 \pm 6$ & $5 \pm 3$ \\
\hline$d p r^{\star *}$ & 23 & 32 & 26 & 22 & 26 & 53 \\
\hline intervalo & 33 a 63 & 35 a 77 & 28 a 60 & 16 a 28 & 24 a 99 & 1 a 8 \\
\hline
\end{tabular}

$\mathrm{ND}=$ não determinado

* representa média e desvio padrão

** representa o desvio padrão relativo

No testemunho SV1 os isótopos do tório e o polônio apresentam concentrações de atividade semelhantes (valores médios variando de 48 a $57 \mathrm{~Bq}$ $\mathrm{kg}^{-1}$ ). Já os isótopos do urânio foram medidos em concentrações maiores (valores médios variando de 94 e $133 \mathrm{~Bq} \mathrm{~kg}^{-1}$, para estes nuclídeos, respectivamente).

Nos testemunhos SV2 e SV3, os valores de concentração de atividade foram semelhantes, exceto para as concentrações do ${ }^{232} \mathrm{Th}$ em SV3 que foram menores que nos demais pontos de coleta (media igual a $22 \mathrm{~Bq} \mathrm{~kg}^{-1}$ ).

Em São Vicente foram encontradas concentrações de atividade para ${ }^{238} \mathrm{U}$ variando de 50 a $94 \mathrm{~Bq} \mathrm{~kg}{ }^{-1}$ em média, e as atividades do ${ }^{232} \mathrm{Th}$ variaram de 22 a $50 \mathrm{~Bq} \mathrm{~kg}{ }^{-1}$. Estes valores foram maiores do que os obtidos por Silva (2004), que apresentou resultados variando de 16 a $46 \mathrm{~Bq} \mathrm{~kg}^{-1}$ para o ${ }^{238} \mathrm{U}$ e de 7 a $11 \mathrm{~Bq} \mathrm{~kg}^{-1}$ para o ${ }^{232} \mathrm{Th}$.

Os testemunhos SV1 e SV2 são os que apresentaram maior proporção de silte e argila (89 a 96\% e 42 a 73\%, respectivamente), sendo o testemunho SV1 praticamente constante quanto à composição granulométrica (desvio padrão relativo igual a 3). Já o testemunho SV3 é composto em maior parte por areia (1 a $8 \%$ de silte + argila). 


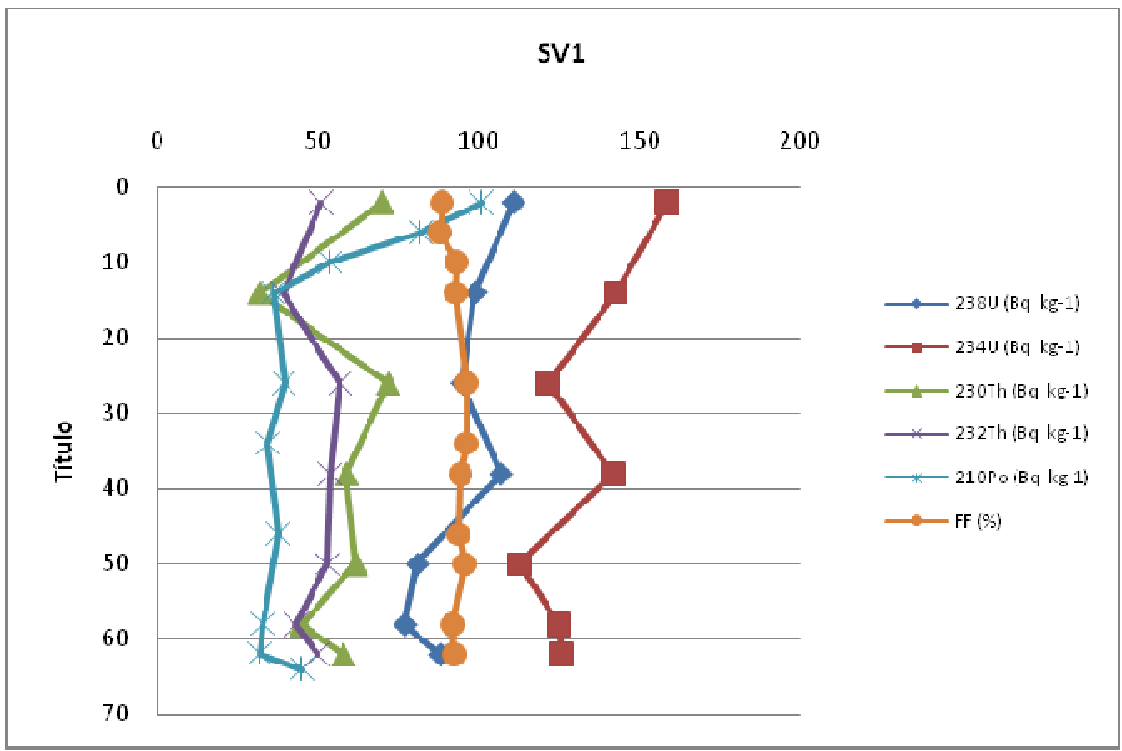

FIGURA 4.8: Concentrações de atividade dos radionuclídeos $\left(\mathrm{Bq} \mathrm{kg}^{-1}\right)$ e fração fina no testemunho SV1 coletado na região de São Vicente, SP.

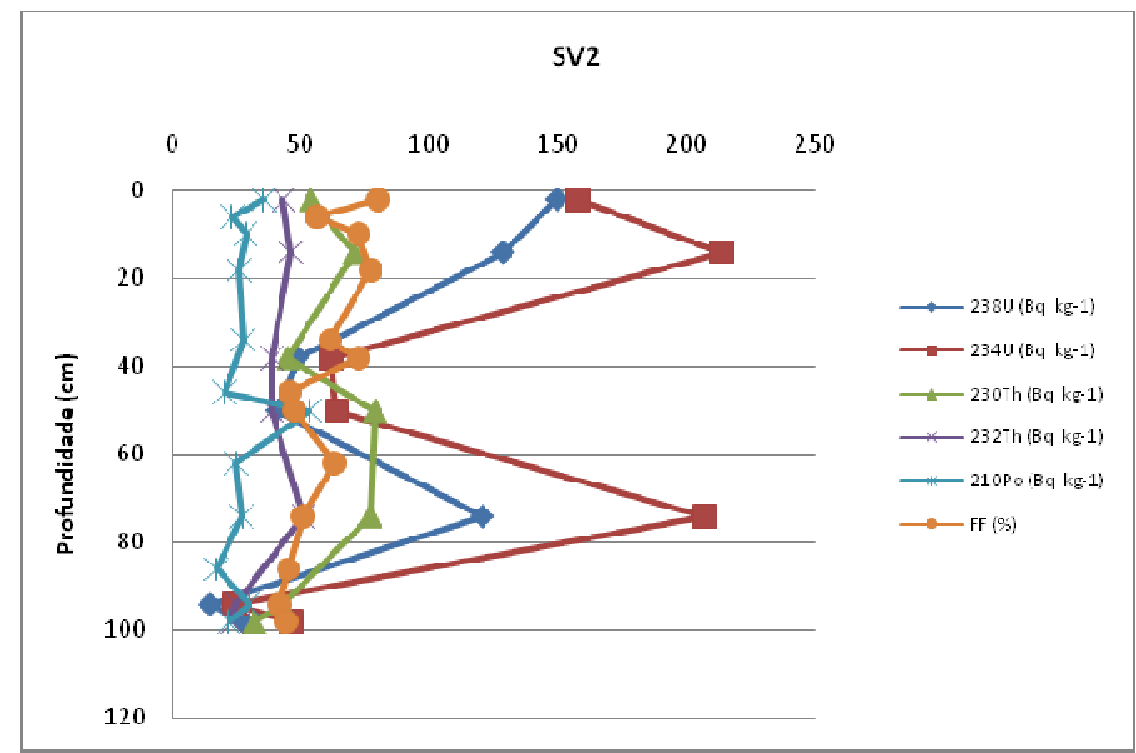

FIGURA 4.9: Concentrações de atividade dos radionuclídeos $\left(\mathrm{Bq} \mathrm{kg}^{-1}\right)$ e fração fina no testemunho SV2 coletado na região de São Vicente, SP. 


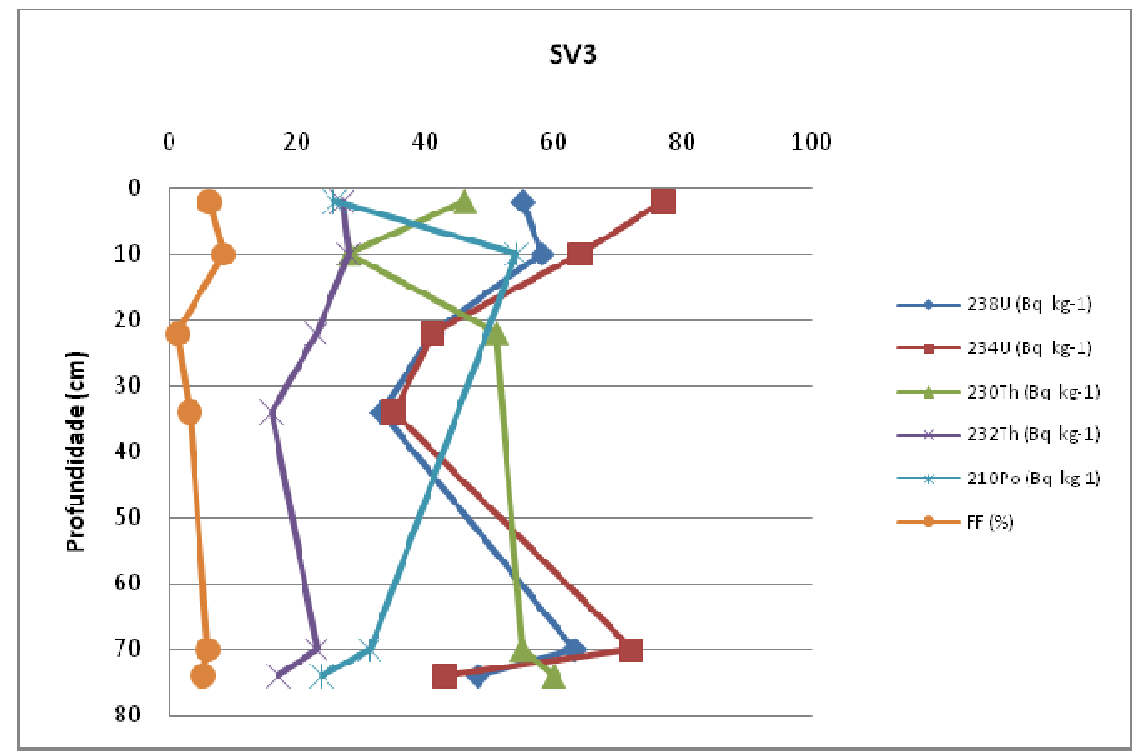

FIGURA 4.10: Concentrações de atividade dos radionuclídeos $\left(\mathrm{Bq}^{\mathrm{kg}}{ }^{-1}\right)$ e fração fina no testemunho SV3 coletado na região de São Vicente, SP.

Nas fatias mais profundas de SV2 (entre 80 e $100 \mathrm{~cm}$ ) nota-se que as concentrações de atividade diminuem e os valores dos radionuclídeos da série do ${ }^{238} \mathrm{U}$ aproximam-se entre si, indicando uma possível linha de base para estes elementos na região.

Na FIGURA 4.11, na qual é mostrado o box plot com as médias das concentrações de atividade (e os respectivos desvios padrão), pode-se verificar que os testemunhos com maior teor de finos (SV1 e SV2) apresentaram concentrações ligeiramente maiores, especialmente no caso dos isótopos de urânio. 


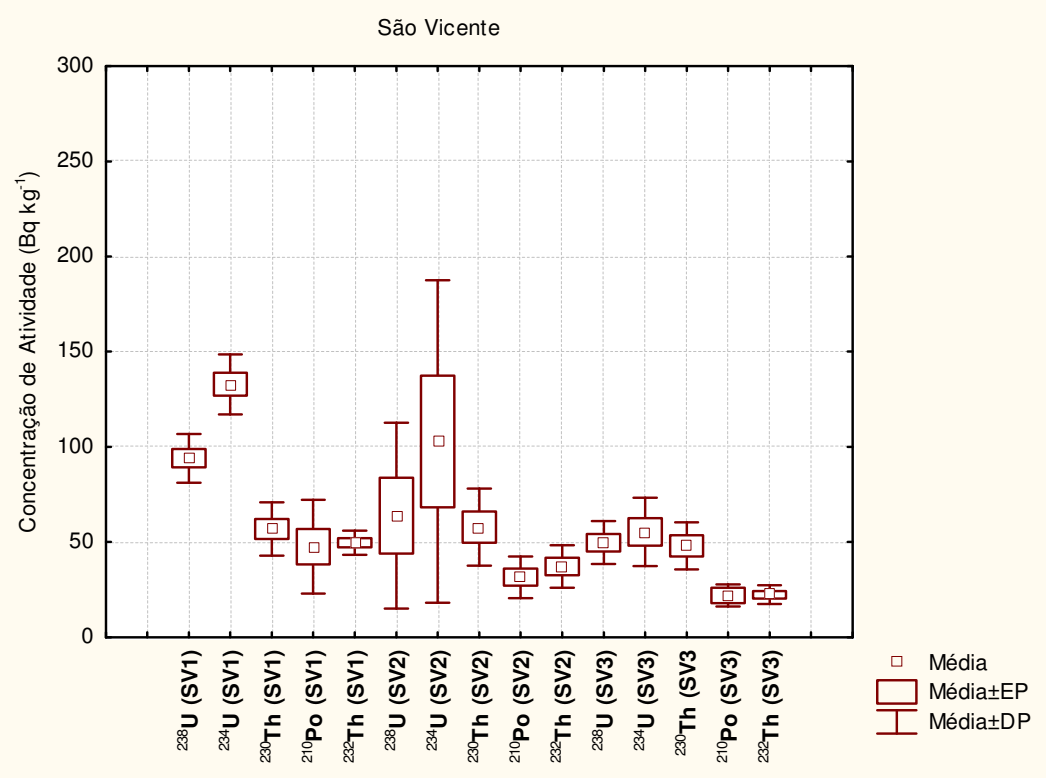

FIGURA 4.11 Box plot do testemunho SV1 coletado na região de São Vicente, SP, mostrando as médias, erro padrão (EP) e desvio padrão (DP) para os radionuclídeos estudados.

Novamente é possível verificar a partir da observação do gráfico que há um enriquecimento do ${ }^{234} \mathrm{U}$ em relação ao ${ }^{238} \mathrm{U}$ especialmente em SV1 e SV2. Especificamente em SV1 pode-se notar um desequilíbrio entre os isótopos de urânio e destes em relação aos isótopos de tório.

Em São Vicente, os perfis SV1, SV2 e SV3 apresentam concentrações de atividade médias próximas, exceção feita aos isótopos de $U$ que apresentam alguma influência antrópica no perfil SV1 e SV2. Estes valores podem ser considerados como valores de referência para a região, o mesmo pode ser dito para as fatias mais profundas de SV2.

As concentrações de polônio nos testemunhos coletados em São Vicente, como nos demais pontos de amostragem já discutidos, podem ser consideradas como valores de referência para a região visto que os valores obtidos são uniformes ao longo de todos os perfis. 


\subsection{Santos}

Os resultados das concentrações de atividade dos radionuclídeos (incluindo média, desvio padrão e intervalo) para a região de Santos são apresentados nas TABELAS 4.9 e 4.10 e as concentrações de atividade e porcentagem de fração fina são apresentadas nas FIGURAS 4.12 e 4.13.

O ponto de coleta localizado próximo ao emissário submarino (SA1) apresentou valores de concentração de atividade menores quando comparado ao testemunho SA2 (próximo à ilha das Palmas). O padrão percebido no testemunho SA1 é diferente dos outros, já que desta vez $0{ }^{230}$ Th apresentou atividades mais altas do que as dos isótopos de urânio.

Os valores médios de concentração de atividade para o ${ }^{238} \mathrm{U}$ e ${ }^{232} \mathrm{Th}$ foram de $24 \mathrm{~Bq} \mathrm{~kg}{ }^{-1}(\mathrm{SA} 1)$ e $48 \mathrm{~Bq} \mathrm{~kg}{ }^{-1}(\mathrm{SA} 2)$ e $33 \mathrm{~Bq} \mathrm{~kg}^{-1}$ (SA1) e $44 \mathrm{~Bq} \mathrm{~kg}^{-1}$ (SA2), respectivamente. Silva (2004) encontrou valores semelhantes, os valores obtidos variaram de 14 a $74 \mathrm{~Bq} \mathrm{~kg}^{-1}$ para o ${ }^{238} \mathrm{U}$ e 10 a $41 \mathrm{~Bq} \mathrm{~kg}^{-1}$ para o ${ }^{232} \mathrm{Th}$.

TABELA 4.9: Concentrações de atividade dos radionuclídeos $\left(\mathrm{Bq} \mathrm{kg}^{-1}\right)$ no testemunho SA 1 em Santos

\begin{tabular}{|c|c|c|c|c|c|c|}
\hline Prof. (cm) & ${ }^{238} \mathrm{U}$ & ${ }^{234} \mathrm{U}$ & ${ }^{230} \mathrm{Th}$ & ${ }^{232} \mathrm{Th}$ & ${ }^{210} \mathrm{Po}$ & FF \\
\hline 3 & $28 \pm 1$ & $26 \pm 1$ & $50 \pm 6$ & $40 \pm 3$ & $13 \pm 2$ & 65 \\
\hline 7 & $29 \pm 1$ & $32 \pm 2$ & $55 \pm 3$ & $36 \pm 3$ & $54 \pm 3$ & 56 \\
\hline 11 & $26 \pm 1$ & $29 \pm 2$ & $44 \pm 5$ & $29 \pm 2$ & $58 \pm 2$ & 37 \\
\hline 19 & $27 \pm 1$ & $29 \pm 2$ & $38 \pm 4$ & $28 \pm 2$ & $22 \pm 1$ & 49 \\
\hline 25 & $22 \pm 1$ & $29 \pm 3$ & $28 \pm 3$ & $29 \pm 2$ & $38 \pm 3$ & 44 \\
\hline 39 & $25 \pm 1$ & $31 \pm 1$ & $93 \pm 8$ & $40 \pm 3$ & 13 & 61 \\
\hline 43 & $11 \pm 3$ & $14 \pm 1$ & $67 \pm 3$ & $30 \pm 2$ & 18 & 56 \\
\hline média* & $24 \pm 6$ & $27 \pm 6$ & $54 \pm 21$ & $33 \pm 5$ & $31 \pm 19$ & $53 \pm 10$ \\
\hline$d p r^{\star *}$ & 26 & 22 & 40 & 16 & 62 & 19 \\
\hline intervalo & 11 a 29 & 14 a 32 & 28 a 93 & 28 a 40 & 13 a 38 & 37 a 65 \\
\hline
\end{tabular}

* representa média e desvio padrão

** representa o desvio padrão relativo 
TABELA 4.10: Concentrações de atividade dos radionuclídeos $\left(\mathrm{Bq} \mathrm{kg}^{-1}\right)$ no testemunho SA 2 em Santos

\begin{tabular}{ccccrrrr}
\hline $\begin{array}{c}\text { Prof. } \\
(\mathbf{c m})\end{array}$ & ${ }^{238} \mathbf{U}$ & ${ }^{234} \mathbf{U}$ & ${ }^{230}$ Th & ${ }^{232}$ Th & ${ }^{210}$ Po & FF \\
\hline 3 & $40 \pm 3$ & $32 \pm 2$ & $44 \pm 3$ & $28 \pm 1$ & $20 \pm 1$ & 28 \\
7 & $42 \pm 3$ & $58 \pm 4$ & $45 \pm 2$ & $38 \pm 1$ & $20 \pm 2$ & 63 \\
11 & $48 \pm 3$ & $64 \pm 4$ & $76 \pm 4$ & $56 \pm 2$ & $81 \pm 4$ & 77 \\
13 & $44 \pm 3$ & $56 \pm 3$ & $67 \pm 4$ & $49 \pm 2$ & $38 \pm 2$ & 79 \\
19 & $57 \pm 3$ & $68 \pm 3$ & $59 \pm 3$ & $44 \pm 2$ & $110 \pm 2$ & 80 \\
23 & $54 \pm 3$ & $58 \pm 3$ & $72 \pm 3$ & $54 \pm 2$ & $67 \pm 3$ & $\mathbf{7 3}$ \\
25 & $53 \pm 3$ & $57 \pm 3$ & $60 \pm 2$ & $43 \pm 2$ & $31 \pm 1$ & 69 \\
29 & $39 \pm 3$ & $42 \pm 3$ & $62 \pm 2$ & $46 \pm 2$ & $18 \pm 1$ & 58 \\
33 & $55 \pm 4$ & $55 \pm 3$ & $57 \pm 3$ & $41 \pm 1$ & $22 \pm 1$ & 65 \\
\hline média & $\mathbf{4 8} \pm \mathbf{7}$ & $\mathbf{5 4} \pm \mathbf{1 1}$ & $\mathbf{6 0} \pm \mathbf{1 1}$ & $\mathbf{4 4} \pm \mathbf{8}$ & $\mathbf{4 5} \pm \mathbf{3 3}$ & $\mathbf{6 6} \pm \mathbf{1 6}$ \\
dpr & $\mathbf{1 5}$ & $\mathbf{2 0}$ & $\mathbf{1 8}$ & $\mathbf{1 9}$ & $\mathbf{7 3}$ & $\mathbf{2 4}$ \\
intervalo & $\mathbf{4 0}$ a $\mathbf{5 5}$ & $\mathbf{3 2}$ a $\mathbf{6 8}$ & $\mathbf{4 4}$ a 76 & $\mathbf{2 8}$ a 56 & $\mathbf{2 0}$ a 81 & $\mathbf{2 8}$ a 80 \\
\hline
\end{tabular}

* representa média e desvio padrão

** representa o desvio padrão relativo

O testemunho SA1 apresentou uma variação menor da fração fina com a profundidade (37 a $65 \%$ ), já em SA2 nota-se que esta variação é bem maior (28 a $80 \%$ ). Ambos os testemunhos apresentam aumento da concentração de atividade nas fatias com maior proporção de fração fina, particularmente em SA2 nota-se que a partir de $10 \mathrm{~cm}$ de profundidade há um aumento na proporção de finos acompanhado pelo aumento de concentração de atividade.

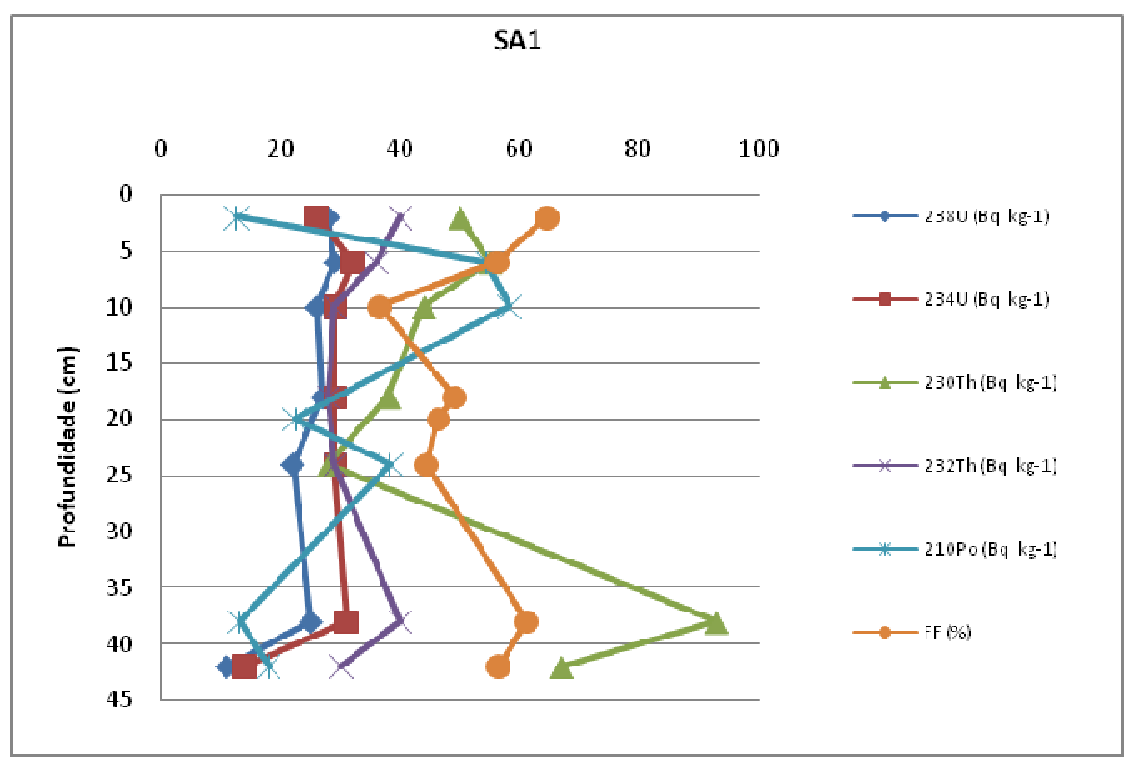

FIGURA 4.12: Concentrações de atividade dos radionuclídeos $\left(\mathrm{Bq} \mathrm{kg}^{-1}\right)$ e fração fina no testemunho SA1 coletado na região de Santos, SP. 


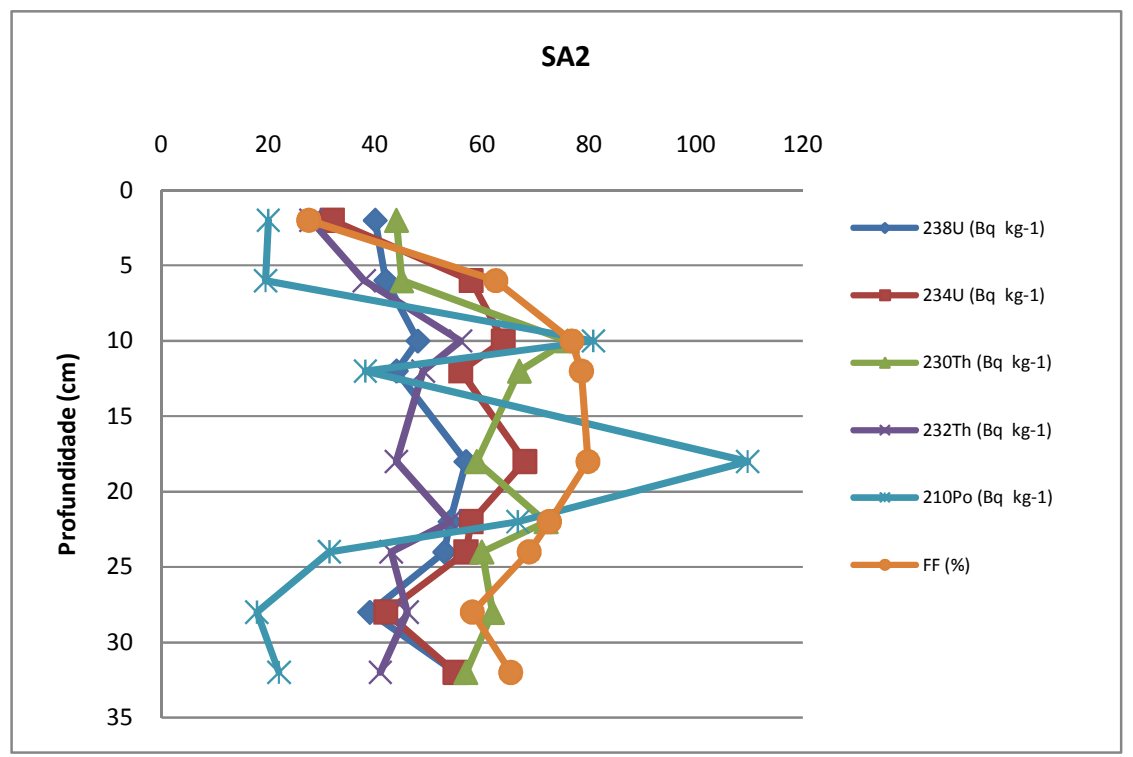

FIGURA 4.13: Concentrações de atividade dos radionuclídeos $\left(\mathrm{Bq} \mathrm{kg}^{-1}\right)$ e fração fina no testemunho SA2 coletado na região de Santos, SP.

Na FIGURA 4.14 são mostrados os box plots contendo as médias das atividades dos radionuclídeos analisados, o erro padrão e o desvio padrão para os testemunhos SA1 e SA2.

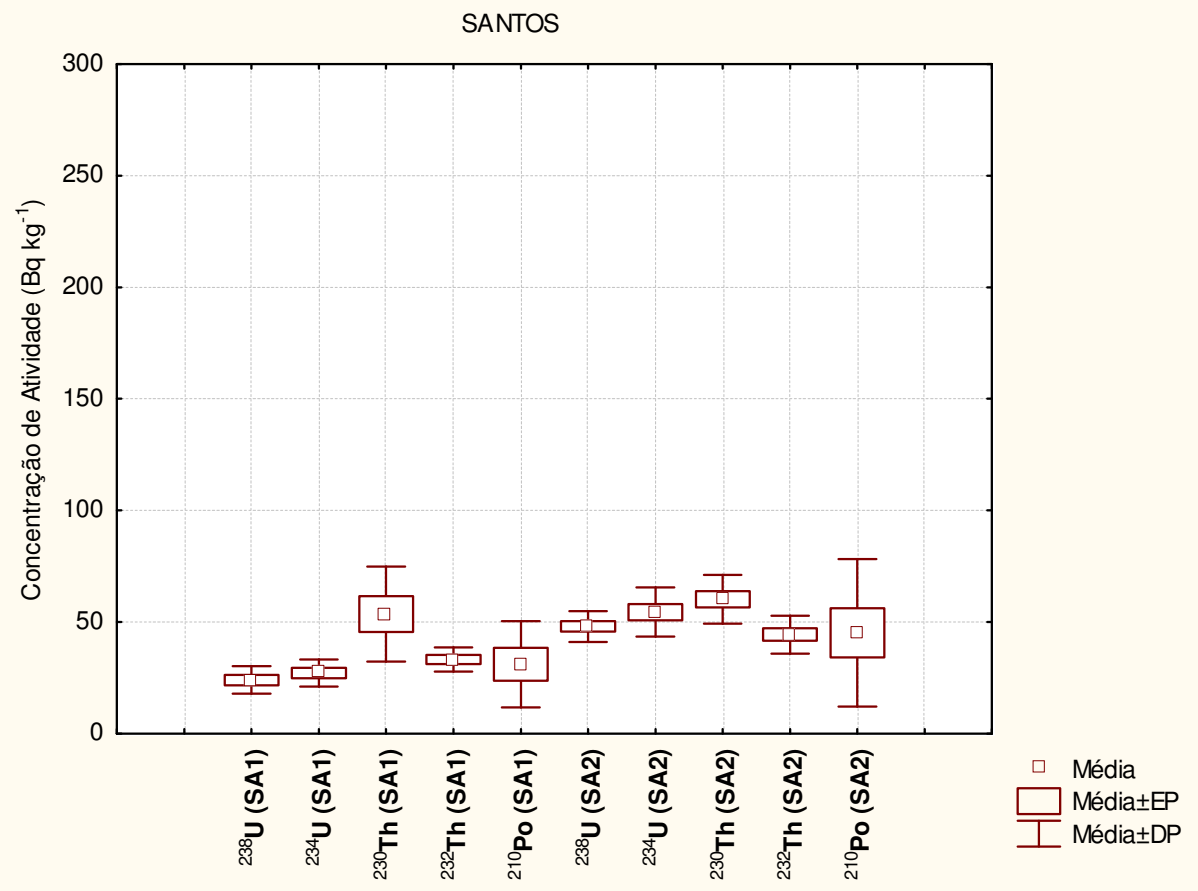

FIGURA 4.14: Box plot do testemunho SA1 coletado na região de Santos, SP, mostrando as médias, erro padrão (EP) e desvio padrão (DP) para os radionuclídeos estudados. 
Nos testemunhos coletados na Baia de Santos verificou-se que os sedimentos apresentam uma composição bem mais homogênea que nos demais perfis analisados. Nestes testemunhos pode observar que os radionuclídeos pertencentes à série do ${ }^{238} \mathrm{U}$ encontram-se em equilíbrio alem disso $0{ }^{232} \mathrm{Th}$ também apresentou concentrações de atividade da mesma ordem.

Todos os radionuclídeos determinados nos dois perfis da Baia de Santos foram encontrados em valores que podem ser considerados como valores de base para a região. 


\subsection{Considerações gerais}

Nas FIGURAS 4.15 a 4.19 são mostrados os box plots com as atividades médias, erro padrão e desvio padrão, por radionuclídeo, nos 10 perfis analisados.

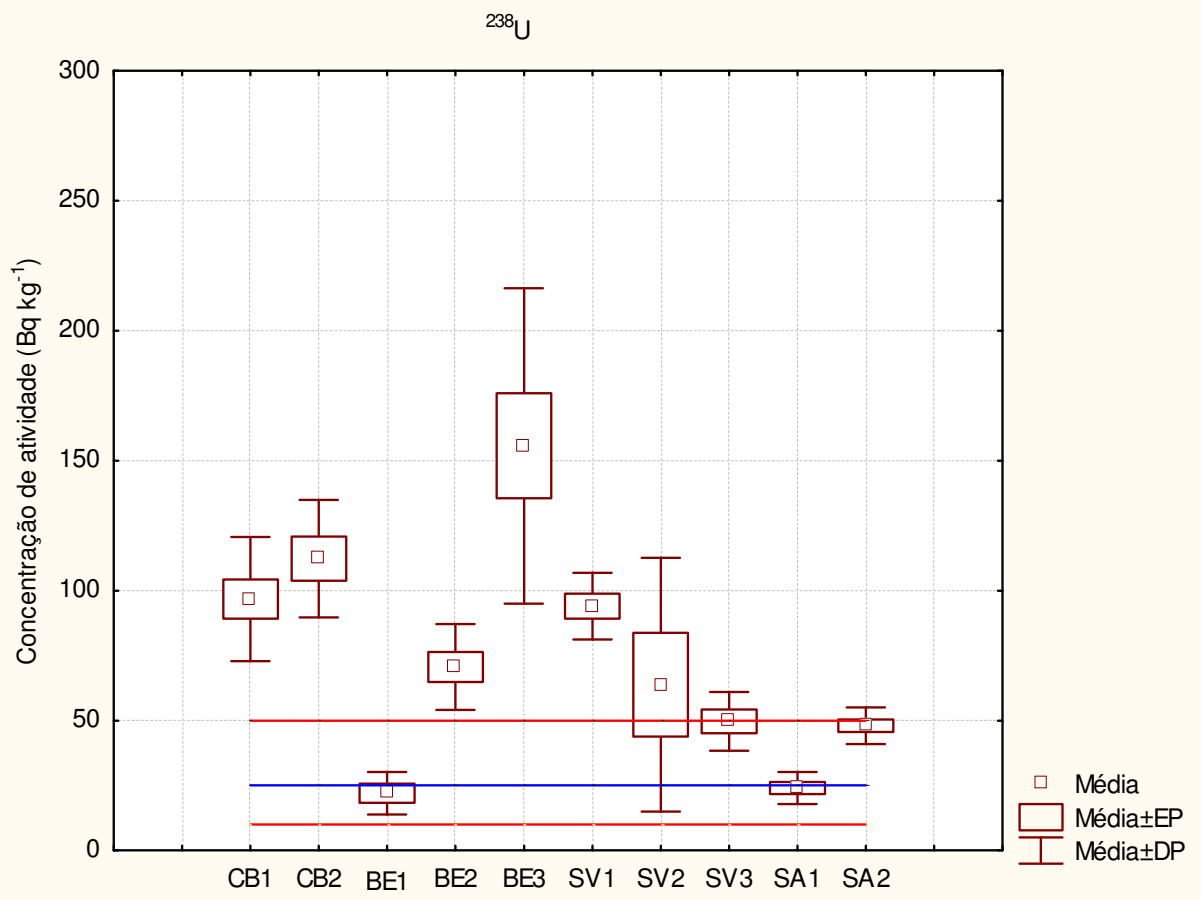

FIGURA 4.15: Box plot com as médias, erro padrão e desvio padrão das concentrações de atividade do ${ }^{238} \mathrm{U}$ nos dez testemunhos coletados, a linha azul representa o valor médio global para solos e as vermelhas a variação típica esperada (UNSCEAR, 1988). 


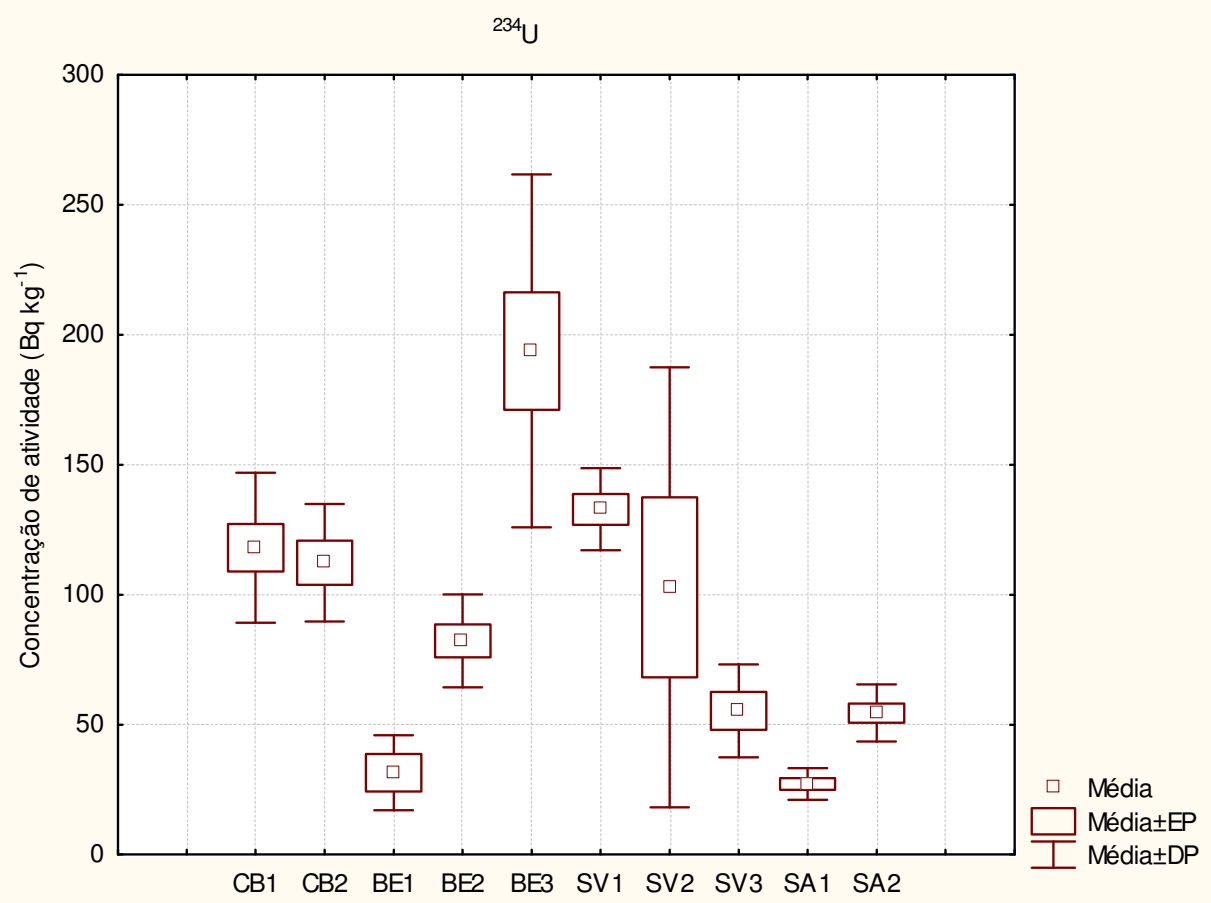

FIGURA 4.16: Box plot com as médias, erro padrão e desvio padrão das concentrações de atividade do ${ }^{234} \mathrm{U}$ nos dez testemunhos coletados.

Para $0{ }^{238} \mathrm{U}$ e ${ }^{232}$ Th são mostradas linhas indicando a média de concentração de atividade mundial para solos de acordo com dados do UNSCEAR (1988) bem como o intervalo esperado para estas concentrações de atividade. Considerando-se a distribuição do ${ }^{238} \mathrm{U}$, os perfis $\mathrm{BE} 1$ e $\mathrm{SA} 1$ apresentaram valores de concentração de atividade da mesma ordem de grandeza daqueles estabelecidos pelo UNSCEAR (1988) para este isótopo no solo.

Exemplos da variação das concentrações de atividade de ${ }^{238} \mathrm{U}$ e ${ }^{234} \mathrm{U}$ em diversas regiões, encontrados em literatura, são dados abaixo, para comparação com os valores obtidos neste trabalho.

Clulow et al. (1998) analisaram sedimentos lacustres, bem como amostras de água e peixes de lagos na região de Ontário Canadá. A região sofre a influência de um local de mineração e processamento de minério de urânio, que permaneceu com tratamento de água precário até 1961. Os valores da região de coleta, eleita como controle, variaram de 51 a $676 \mathrm{~Bq} \mathrm{~kg}^{-1}$. Já nos lagos em estudo os valores variaram de 303 a $557 \mathrm{~Bq} \mathrm{~kg}^{-1}$. 
Lozano et al. (2002) analisaram sedimentos de um rio na Espanha próximo a uma mina abandonada de urânio. No ponto considerado como branco para a região, foram obtidos valores médios iguais a $125 \mathrm{~Bq} \mathrm{~kg}^{-1}$ para ${ }^{238} \mathrm{U}$ e $124 \mathrm{~Bq} \mathrm{~kg}^{-1}$ para ${ }^{234} U$. Já nos pontos sob influência da mina, os valores de concentração de atividade foram, conforme esperado, várias ordens de grandeza maiores: $5025 \mathrm{e}$ $5055 \mathrm{~Bq} \mathrm{~kg}^{-1}$ para ${ }^{238} \mathrm{U} \mathrm{e}^{234} \mathrm{U}$, respectivamente.

Moon et al. (2003), analisando sedimentos marinhos na costa nordeste do oceano Pacífico, obtiveram concentrações de atividade variando de 10 a $43 \mathrm{~Bq}$ $\mathrm{kg}^{-1}$ para ${ }^{238} \mathrm{U}$ e 10 a $65 \mathrm{~Bq} \mathrm{~kg}^{-1}$ para ${ }^{234} \mathrm{U}$.

Ramasamy et al. (2010), analisando sedimentos em um rio da Índia, encontraram valores de concentração de atividade para ${ }^{238} \mathrm{U}$ variando de 1 a 90 $\mathrm{Bq} \mathrm{kg}^{-1}$, valores estes que os autores consideraram como naturais.

Frostick et al. (2010) analisaram testemunhos de sedimento de lagos próximos a uma região rica em minério de urânio e camadas superiores de rocha rica em urânio. O valor médio obtido para uma região localizada acima de uma empresa de mineração de urânio, considerada como branco, foi de $62 \mathrm{~Bq} \mathrm{~kg}^{-1}$. Os valores encontrados em camadas retiradas da cadeia de montanhas rica em urânio apresentaram valores variando de 17500 a $47200 \mathrm{~Bq} \mathrm{~kg}^{-1}$. Os testemunhos coletados rio abaixo em relação à mineração de urânio sofrem a influência tanto da fonte do minério de urânio quanto da empresa e apresentaram concentrações de atividade variando de 34 a $102 \mathrm{~Bq} \mathrm{~kg}^{-1}$. Segundo o autor não foi possível de determinar o grau de influência antrópica para a região.

Bolivar et al. (2002) avaliaram as concentrações de atividade de sedimentos próximos a uma indústria de fertilizantes fosfatados no sudoeste de Espanha. Neste estudo, determinaram que os sedimentos coletados próximos à pilha de fosfogesso apresentaram valores que variaram de 103 a $413 \mathrm{~Bq} \mathrm{~kg}^{-1} \mathrm{e}$ 106 a $394 \mathrm{~Bq} \mathrm{~kg}^{-1}$ para os isótopos de ${ }^{238} \mathrm{U} \mathrm{e}^{234} \mathrm{U}$, respectivamente.

Além dos valores de concentração de atividade relatados em literatura, um valor comumente utilizado para comparação de dados geoquímicos é o valor médio da crosta continental superior (CCS) (Taylor e McLennan, 1985), que 
apresenta para o $\cup \circ$ valor de 2,8 ppm. Convertendo-se este valor para concentração de atividade obtém-se um valor de $35 \mathrm{~Bq} \mathrm{~kg}^{-1}$.

Comparando-se os valores obtidos para ${ }^{238} \mathrm{U}$ neste trabalho (FIGURAS 4.15 e 4.16) com o valor médio de concentração de atividade para a crosta continental superior e com os dados encontrados em literatura pode-se concluir que os valores aqui obtidos estão próximos àqueles encontrados em regiões consideradas sem influência antrópica e próximos aos valores encontrados em solo (UNCEAR, 1988) e na crosta continental superior (UNCEAR, 2000). As exceções são os pontos que foram tidos como sob alguma influencia antrópica (CB1, CB2 e BE3) que apresentam valores semelhantes aos encontrados por Bolivar et al. (2002) que mediram TENORMs em concentrações de atividade semelhantes.

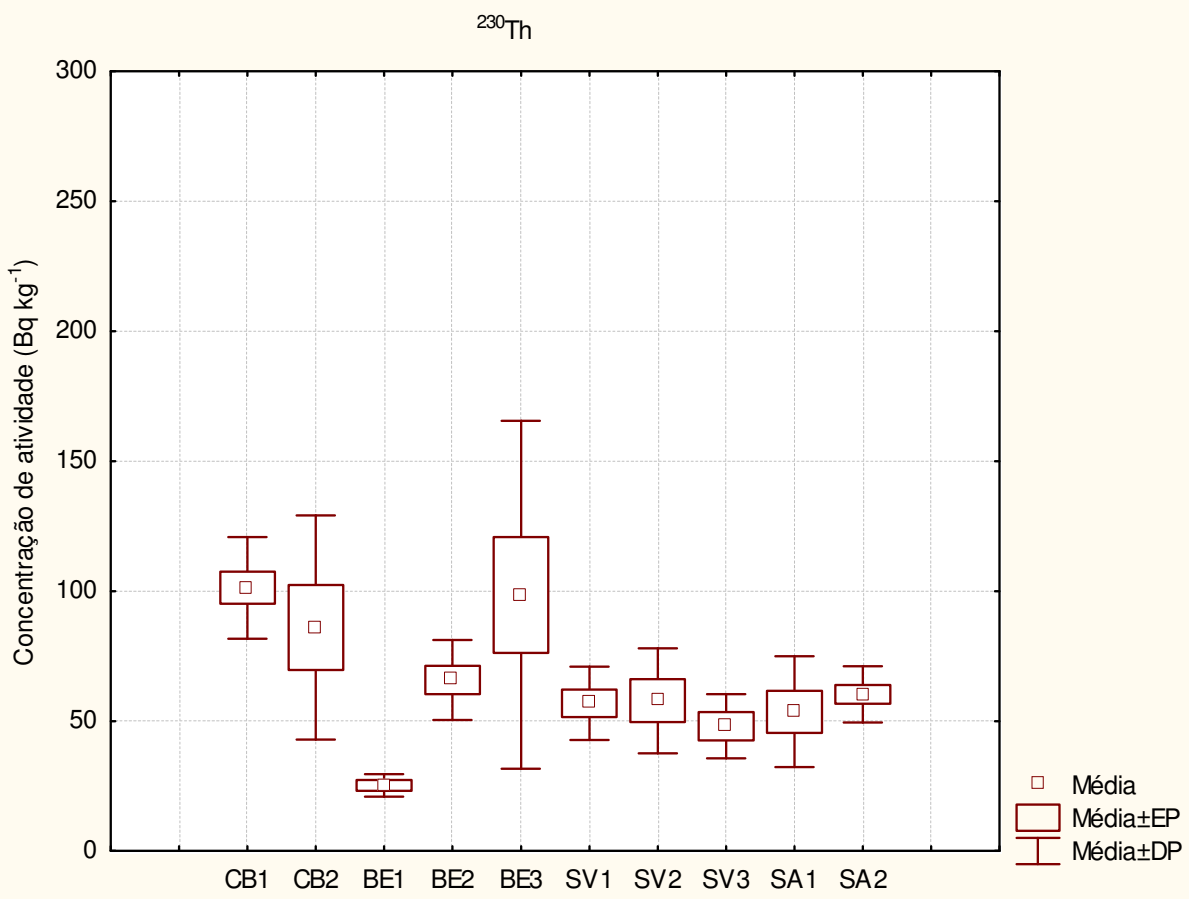

FIGURA 4.17: Box plot com as médias, erro padrão e desvio padrão das concentrações de atividade do ${ }^{230}$ Th nos dez testemunhos coletados. 


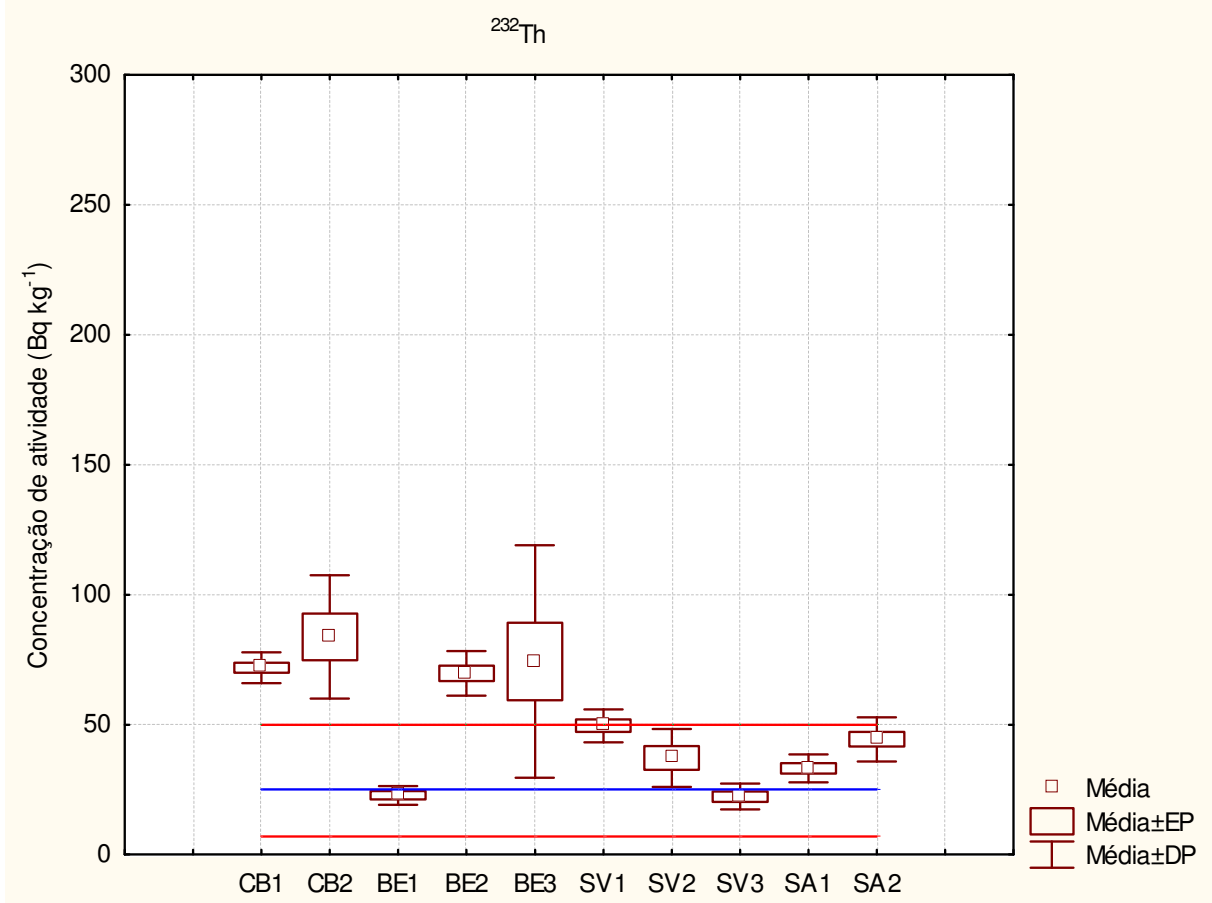

FIGURA 4.18: Box plot com as médias, erro padrão e desvio padrão das concentrações de atividade do ${ }^{232}$ Th nos dez testemunhos coletados, a linha azul representa o valor médio global para solos e as vermelhas a variação típica esperada (UNSCEAR, 1988)

Os isótopos de tório apresentaram concentrações de atividade menores do que os de urânio com valores muito semelhantes à variação esperada para a concentração média em solos no mundo que é de 7 a $50 \mathrm{~Bq} \mathrm{~kg}^{-1}$ (UNSCEAR, 1988).

Abaixo são apresentados dados da literatura para sedimentos para que seja possível a comparação com os valores obtidos no presente trabalho.

No trabalho de Bolívar et al. (2002), os valores para ${ }^{230} \mathrm{Th}$ e ${ }^{232} \mathrm{Th}$ variaram de 99 a $443 \mathrm{~Bq} \mathrm{~kg}^{-1}$ e 18 a $68 \mathrm{~Bq} \mathrm{~kg}^{-1}$ respectivamente. As concentrações obtidas pelos autores refletem a influência das fontes de ${ }^{238} \mathrm{U}$ (processamento de rocha fosfática e produção de fertilizantes) e seus radionuclídeos filhos nos sedimentos da região.

O estudo de radionuclídeos de ocorrência natural feito por Clulow et al. (1998) no Canadá, apresentou valores médios para ${ }^{230} \mathrm{Th}$ e ${ }^{232} \mathrm{Th}$ em sedimentos lacustres variando de 24 a $69 \mathrm{~Bq} \mathrm{~kg}^{-1}$ e 11 a $26 \mathrm{~Bq} \mathrm{~kg}^{-1}$ em dois lagos que foram considerados como controle ou branco da região, respectivamente. Já nos lagos 
estudados os resultados variaram de 70 a $163 \mathrm{~Bq} \mathrm{~kg}^{-1}$ e 24 a $42 \mathrm{~Bq} \mathrm{~kg}^{-1}$ para os isótopos de tório, ${ }^{230} \mathrm{Th}$ e ${ }^{232} \mathrm{Th}$, respectivamente.

Ramasamy et al. (2010), em trabalho já citado sobre sedimentos de rio na Índia, obtiveram valores médios para ${ }^{232} \mathrm{Th}$ variando de 53 a $59 \mathrm{~Bq} \mathrm{~kg}^{-1}$, o que o autor considerou com naturais.

Considerando-se o valor da concentração de tório da crosta continental superior (CCS) (Taylor e McLennan, 1985) de 10,7 ppm e convertendo-o para concentração de atividade obtém-se um valor de $43,5 \mathrm{~Bq} \mathrm{~kg}^{-1}$.

Comparando-se os valores obtidos para ${ }^{232}$ Th neste trabalho (FIGURAS 4.17 e 4.18) com o valor médio de concentração de atividade para a crosta continental superior e com os dados encontrados em literatura pôde-se concluir que os valores aqui obtidos estão próximos àqueles encontrados em regiões consideradas sem influência antrópica, aos valores encontrados em solo,de acordo com a UNSCEAR (1988) e na crosta continental superior. As exceções são os pontos que foram tidos como sob alguma influencia antrópica (CB1, CB2 e BE3) que apresentam valores semelhantes aos encontrados por Bolivar et al. (2002) que mediram TENORMs em concentrações de atividade semelhantes. 


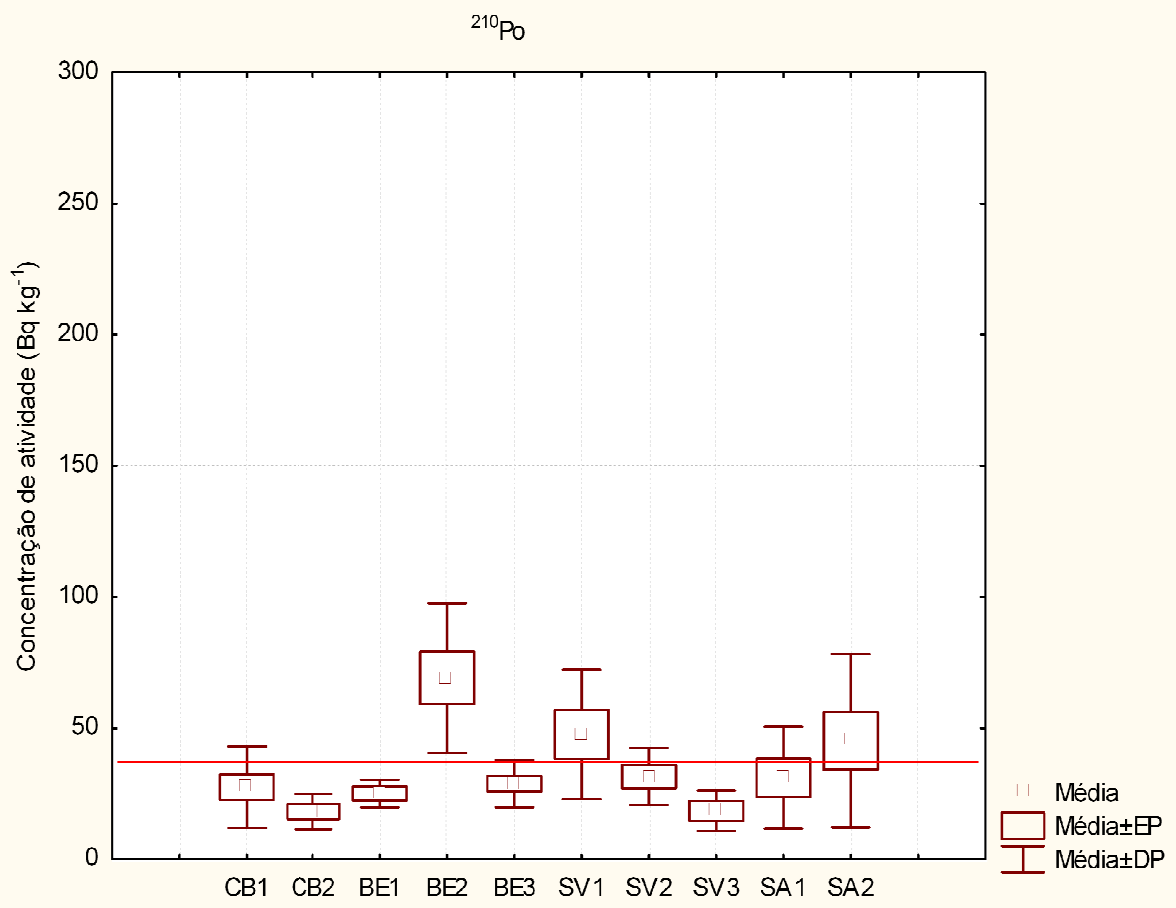

FIGURA 4.19: Box plot com as médias, erro padrão e desvio padrão das concentrações de atividade do ${ }^{210} \mathrm{Po}$ nos dez testemunhos coletados, a linha vermelha representa o valor médio para solos (Argonne, 2005)

Abaixo são apresentados dados da literatura para a concentração de atividade de polônio em sedimentos de maneira a estabelecer uma comparação com os valores obtidos no presente trabalho.

Suriyanarayanan et al. (2008) estudaram as concentrações de ${ }^{210} \mathrm{Po} e$ ${ }^{210} \mathrm{~Pb}$ em sedimentos marinhos e na biota na costa indiana para estabelecer a linha de base destes elementos na região. $\mathrm{O}$ valor obtido pelos autores para ${ }^{210} \mathrm{Po}$ foi $1,9 \mathrm{~Bq} \mathrm{~kg}^{-1}$, que o autor considerou como muito baixo quando comparado aos sedimentos de regiões próximas como a praia Manapam que apresentou valores variando de 32 a $35 \mathrm{~Bq} \mathrm{~kg}^{-1}$ (Somasundaram in Surianarayanan, 2008).

Houmani et al. (2001) mediram ${ }^{210} \mathrm{Po}$ em sedimentos de rio próximo a uma tubulação de óleo cru. Os valores obtidos foram considerados pelo autor como semelhantes aos de locais não poluídos (variando de 5 a $51 \mathrm{~Bq} \mathrm{~kg}^{-1}$ ).

Saito (1996) apresentou resultados para sedimentos marinhos da Antártica, os valores médios obtidos variaram de 8 a $60 \mathrm{~Bq} \mathrm{~kg}^{-1}$. 
Shaheed et al. (1996) encontraram valores de concentração de atividade em sedimentos de rios na Índia variando de 14,5 a $26,5 \mathrm{~Bq} \mathrm{~kg}^{-1}$

Noureddine e Bagoura (1997) encontraram valores para sedimentos marinhos, na região da costa norte da África (Algeria), variando de $52 \pm 1$ a $118 \pm$ $3 \mathrm{~Bq} \mathrm{~kg}$. Estes valores forma considerados pelos autores como sendo relativamente altos.

Martinez-Aguirre \& Garcia Leon (1997) mediram diversos radionuclídeos naturais em uma região pantanosa na Espanha próxima á uma indústria de produção de ácido fosfórico. Os valores obtidos pelos autores para ${ }^{210} \mathrm{Po}$ foram de 25 a $778 \mathrm{~Bq} \mathrm{~kg}^{-1}$.

O relatório do laboratório Argonne (2005) sobre toxicidade para elementos radioativos diz que a concentração de atividade média global para polônio em solos é de $1 \mathrm{pCi} \mathrm{g}^{-1}$, o que convertido para a unidade padrão é equivalente a 37 $\mathrm{Bq} \mathrm{kg}^{-1}$.

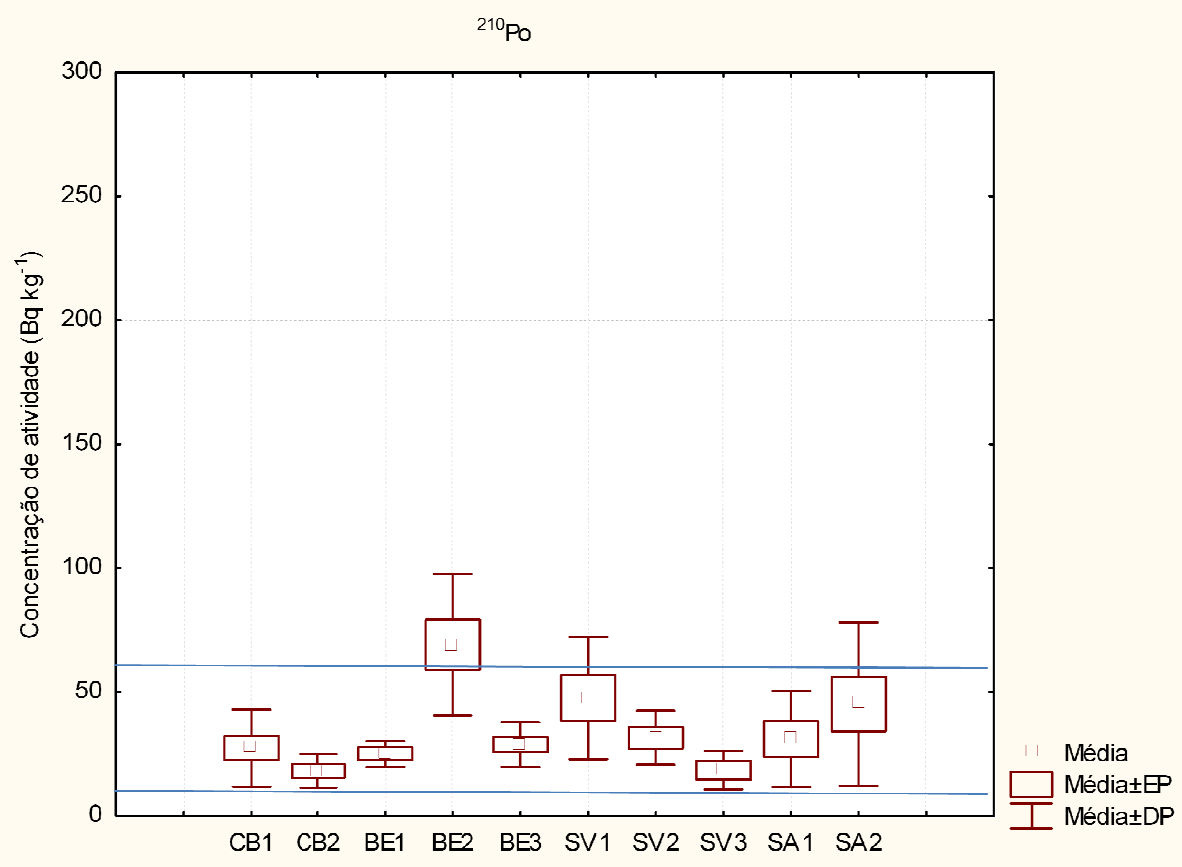

FIGURA 4.20: Box plot com as médias, erro padrão e desvio padrão das concentrações de atividade do ${ }^{210} \mathrm{Po}$ nos dez testemunhos coletados, as linhas azuis representam os valores máximos e mínimos para sedimentos marinhos da Antartica (Saito, 1996) 
Portanto, comparando-se os dados da literatura e o valor médio para o polônio em solos com os valores obtidos neste trabalho (FIGURAS 4.19) podemos afirmar que este elemento encontra-se em níveis que podem ser considerados basais para este elemento nos dez testemunhos analisados na Baixada Santista.

Num sistema fechado, sem interações com outros componentes ambientais, as séries radioativas são encontradas em equilíbrio, ou seja, as atividades de todos os radionuclídeos são iguais. Porém ambientes aquáticos não são sistemas fechados, ao contrário, permitem múltiplas interações entre os radionuclídeos e o ambiente.

Devido à maior solubilidade do $U$ em relação ao Th, este é preferencialmente transportado, por águas pluviais e fluviais, e ao atingir as regiões estuarinas deposita-se sendo reincorporado ao sedimento. Este fato justifica os valores observados neste estudo que mostram, em todos os testemunhos, concentrações da atividade de $U$ maiores que as de Th, exceto nos pontos SA1, saída do emissário submarino e BE2, em Bertioga. As maiores concentrações de ${ }^{238} \mathrm{U}$ e ${ }^{234} \mathrm{U}$ em relação ao ${ }^{230} \mathrm{Th}$ e ${ }^{232} \mathrm{Th}$ indicam, portanto, que a principal forma de entrada dos isótopos de $U$ nos ambientes estudados é por meio de transporte em suspensão e em solução destes isótopos, já os isótopos de Th são transportados para a região estuarina preferencialmente como material detrítico sendo esta a forma de maior contribuição para a composição dos sedimentos em relação a este elemento.

As baixas concentrações de atividade observadas para $0{ }^{210} \mathrm{Po}$, em relação aos demais radionuclídeos da série do $U$ que foram analisados deve-se, provavelmente à maior solubilidade do ${ }^{226} \mathrm{Ra}$, produto de decaimento do ${ }^{230} \mathrm{Th}$. Entretanto, a solubilidade do $\mathrm{U}$ aumenta quando aumenta a salinidade (Aguado et al., 2004) e desta forma nos testemunho SA1 e SA2, que foram coletados em região de tipicamente marinha, de alta salinidade, as concentrações de Po são da mesma ordem de grandeza que aquelas observadas para os isótopos de U. Por outro lado, altas concentrações de Po, como as observadas na superfície do testemunho SV1, estão provavelmente relacionadas à deposição atmosférica do ${ }^{210} \mathrm{~Pb}$. 
A concentração de radionuclídeos em sedimentos depende de uma série de fatores tais como parâmetros físico-químicos, quantidade de matéria orgânica, concentração destes radionuclídeos na matriz dos sedimentos, granulometria dos sedimentos, etc. Deve-se lembrar, portanto, que neste trabalho, as concentrações dos radionuclídeos foram determinadas na fração total e, embora tenha sido possível identificar que existe um aumento das concentrações de atividade quando aumenta a quantidade de fração fina nos testemunhos, algumas variações observadas nos valores obtidos podem também estar relacionadas aos demais parâmetros citados. 


\section{CONCLUSÃO}

Foram analisados dez testemunhos de sedimento na região da Baixada Santista, sendo dois coletados na região de Cubatão, dois na baia de Santos, três em Bertioga e três em São Vicente. A partir destas amostras foram medidas as concentrações de atividade dos seguintes radionuclídeos naturais, ${ }^{238} \mathrm{U},{ }^{234} \mathrm{U}$, ${ }^{230} \mathrm{Th},{ }^{232} \mathrm{Th}$ e ${ }^{210} \mathrm{Po}$.

O ${ }^{210} \mathrm{Po}$ apresentou concentrações de atividade e variações baixas e, portanto, pode-se considerar os resultados obtidos como valores de base para este elemento na área de estudo.

Já para os demais elementos, também apresentaram valores considerados como de referência para a região os testemunhos: BE1, BE2, SV2, SV3, SA1 e SA2 e SV1 só para tório e polônio.

Na maioria dos testemunhos analisados verificou-se um enriquecimento de ${ }^{234} \mathrm{U}$ em relação ao ${ }^{238} \mathrm{U}$.

Em Bertioga, o perfil BE3 foi o que apresentou os maiores valores de concentração de atividade para todos os radionuclídeos (exceto polônio), e este perfil apresenta um aumento nas concentrações de atividade nas camadas mais profundas, o que pode estar relacionado a um evento de contaminação ocorrido no passado. Para BE1 e BE2 as concentrações obtidas nos testemunhos podem ser consideradas como valores de referência para a região.

No perfil CB1, da região de Cubatão, observou-se a existência de influência antrópica nas concentrações de atividade, visto que existe um aumento da concentração de atividade com a profundidade, ou seja nas fatias mais antigas. No testemunho CB2 a concentração dos radionuclídeos nos últimos $20 \mathrm{~cm}$ foi praticamente constante e pode ser considerada como uma indicação da linha de base da concentração destes elementos nos sedimentos desta região. Nos perfis de Cubatão percebe-se alguma influência antrópica, nas concentrações de $\mathrm{U}$ e Th, provavelmente devido à proximidade com o pólo industrial de Cubatão

Em São Vicente, os perfis SV1, SV2 e SV3 apresentam concentrações de atividade próximas, exceção feita aos isótopos de $U$ que apresentam alguma influência antrópica nos perfis SV1 e SV2. Os valores obtidos podem ser 
considerados como valores de referência para a região, o mesmo pode ser dito para as fatias mais profundas de SV2.

Todos os radionuclídeos determinados nos dois perfis da Baia de Santos apresentaram valores que podem ser considerados como valores de base para a região.

Comparando os resultados obtidos para as concentrações de atividade dos radionuclídeos com dados encontrados na literatura pode-se concluir que estes são semelhantes aos de sedimentos marinhos em regiões não contaminadas, exceto para os isótopos do urânio e tório nos perfis CB1, CB2, SV1 e SV2 (somente para urânio) e BE3 nos quais foi possível identificar influência antrópica. 


\section{REFERÊNCIAS BIBLIOGRAFICAS}

Abessa, D.M.S., Carr, R.S., Rachid, B.R.F., Sousa, C.P.M., Hortelani, M.A., Sarkis, J. E. Influence of a Brazilian sewage outfall on the toxicity and contamination of adjacent sediments. Marine Pollution Bulletin, v. 50, p. $875-$ 885. 2005

Aguado, J.L., Bolivar, J.P., Garcia-Tenorio, R., Sequential extraction of ${ }^{226} \mathrm{Ra}$ in sediments from and estuary affected historically by anthropogenic inputs of natural radionuclides. Journal of Environmental Radioactivity. v. 74, p. 117126. 2004

Aloupi, M. \& Angelidis, M.O. Geochemistry of natural and anthropogenic metals in the coastal sediments of the island of Lesvos, Aegean Sea. Environmental Pollution, v. 113, p. $211-219,2001$.

Argonne Radiological Fact Sheet. Argonne National Laboratory. 2005. Disponível em:<http://www.evs.anl.gov/pub/doc/ANL_ContaminantFactSheets_All_070418.pd $f>$ Acesso em: 08/08/2010.

Baxter, M.S. Technologycally enhanced radioactivity: an overview. Journal of Environmental Radioactivity. v. 32, p. 3-17. 1996.

Belzunce, M.B.; Solaun, O.; Franco, J.; Valencia, V. \& Borja, A. Accumulation of organic matter, heavy metals and organic compounds in surface sediments along the Nérvion Estuary (Northern Spain). Marine Pollution Bulletin, v. 42(12), p.1407-1411, 2001.

Bolivar,J. P.; Garcia-Tenório; R.; Mas, J. L.; Vaca, F. Radioactive impact in sediments from an estuarine system affected by industrial waste releases. Environment International. v. 27, p. 639-645, 2002.

Cherdyntesev, V.V. Uranium-234. Israel Program for Scientific Translations. p144. 1971 
CETESB - Companhia de Tecnologia de Saneamento Ambiental. Governo do

Estado de São Paulo, Secretaria de Obras e do Meio Ambiente Relatório de balneabilidade das praias paulistas, São Paulo, 1997.

CETESB - Companhia de Tecnologia de Saneamento Ambiental. Governo do Estado de São Paulo, Secretaria de Obras e do Meio Ambiente. Poluição das águas no estuário e bala de Santos. v. 1. 1978.

Clulow, F.V., Dav, N.K , Lim, T.P., Avadhanula, R. Radionuclides (lead-210, polonium-210, thorium-230, and-232) and thorium and uranium in water, sediments, and fish from lakes near the city of Elliot Lake, Ontario, Canada" Environmental Pollution. v 99, p. 199-213. 1998.

Damatto, S.R. Radionuclídeos Naturais das Séries do ${ }^{238} U e^{232} T h$, elementos traço e maiores determinados em perfis de sedimento da Baixada Santista para avalialção de áreas impactadas. 2010. (tese). Instituto de Pesquisas Energéticas e Nucleares, São Paulo. 254 p.

Distrito Federal (Brasília). Ministério do Meio Ambiente (MMA). Áreas prioritárias para a conservação, uso sustentável e repartição dos benefícios da Biodiversidade brasileira: Atualização - Portaria MMA n ${ }^{\circ}, 23$ de janeiro de 2007.Disponível em.<http://www.mma.gov.br/estruturas/chm/_arquivos/biodiversidade31.pdf> Acesso em 20 de março 2009.

Dooley, J.R.; Granger, H.C. \& Rosholt, J.N. Uranium-234 fractionation in the sandstone-type uranium deposits of the Ambrosia Lake District, New Mexico. Economic Geology. V. 61, p. 1362-1382. 1966.

Emerson, H. S.; Young, A. K. Method development for the extraction of naturally occouring radionuclides in marine sediments. The science of total environment. v. $173 / 174$, p. 313-322. 1995.

Flynn, W.W. Determination of low levels of polonium-210 in envirounmental materials. Analytica Chimica Acta, v. 43, p. 221-227. 1968.

Frostick, A. Bollhöfer, A., Parry D. "A study of radionuclides, metals and stable lead isotope ratios in sediments and soils in the vicinity of natural U-mineralisation areas in the Northern Territory" Journal of Environmental Radioactivity p. 1e 8. 2010. doi:10.1016/j.jenvrad.2010.04.003 
Fukumoto, M. M. Determinação da história deposicional do Alto Estuário Santista, com base nos teores de metais e na susceptibilidade magnética dos sedimentos. 2007. Tese (Doutorado). Instituto de Pesquisas Energéticas e Nucleares (IPEN), São Paulo. 123p.

Fulfaro, V. J. \& Ponçano, W. L. Sedimentação atual do estuário e baia de Santos: um modelo geológico aplicado a projetos de expansão do porto da zona portuária. In Congresso Brasileiro de Geologia de Engenharia, 1. Anais. Rio de Janeiro, ABG. V. 2 p. 67-90, 1976.

Fuller, C.C.; van Geen, A.; Baskaran, M.; Anima, R. Sediment chronology in San Francisco Bay, California, defined by ${ }^{210} \mathrm{~Pb},{ }^{234} \mathrm{Th},{ }^{137} \mathrm{Cs}$ and ${ }^{239,240} \mathrm{Pu}$. Marine Chemistry, v. 64, p 7-27. 1999.

Fundação SEADE. Perfil regional. Região Metropolitana da Baixada Santista. Assessoria da Gestão Estratégica da Secretaria da Economia. Acessado em junho de 2010, www.planejamento.sp.gov.br/des/textos8/RMBS.pdf

Galindo, C., Mougin, L., Noureddin, A. An improved radiochemical separation of uranium and thorium in environmental samples involving peroxide fusion. Applied Radiation and Isotopes, v. 65, p. 9 - 16, 2007.

Hernandez, C. A.; Asencio, M.D. Caravaca, A. M.; Morell, E.S.; Moreno, R.A ${ }^{137}$ Cs and ${ }^{210} \mathrm{Po}$ dose assessment from marine food in Cienfuegos Bay (Cuba). Journal of environmental radioactivity, v. 61, p. 203-211, 2002.

Hou, X \& Roos, P; Critical Comparison of Radiometric and Mass Spectrometric Methodsfor the Determination of Radionuclides in Environmental, Biological and Nuclear Waste Samples. Riso DTU Technical University of Denmark. 2007. Disponível em: <www.risoe.dk/rispubl/art/2007 333.pdf> Acesso em: 29 de Nov 2009.

Houmani, Z. M.M., Bradley,D.A., Maahc, M. J., Ahmedd, Z. "Concentration of ${ }^{210} \mathrm{Po},{ }^{226} \mathrm{Ra}$ and ${ }^{228} \mathrm{Ac}$ in non-siliceous environmental materials". Radiation Physics and Chemistry. v.61, p. 665-668. 2001

IBGE Instituto Brasileiro de Geografia e Estatística. $<\mathrm{ftp}: / / \mathrm{ftp}$. ibge.gov.br/Contagem_da_Populacao_2007/>Acesso em: 22/01/2009.

Ivanovich, M. \& Harmon, R. S. Uranium-series disequilibrium: applications to Earth, Marine and Environmental Sciences, Claredon Press - Oxford. 1992 
Keller, C. Radioquímica Pernambuco, Recife: Editora Universitária, 1981.Tradução de: Radiochemie.

Ketcham, R. A. An improved method for determination of heat production with gamma-ray scintillation spectrometry. Geochemical Geology. v 130: p. 175-794. 1996.

Koide, M.; Bruland, K.W.; Goldberg, E.D. Th-228/Th-232 and Pb-210 geochronologies in marine and lake sediments. Geochimica Cosmochimica. Acta, v. 37: p. 1171-1187. 1973.

Kretschmer, S, Geibert, W. Michiel, Loeff, M. R.V. D., Mollenhauer, G. Grain size effects on 230Thxs inventories in opal-rich and carbonate-rich marine sediments, Earth and Planetary Science Letters, v. 294, p 131 142, 2010.

Kvasnicka, J., Radiation protection in the offshore petroleum industry. In: 9th WORLD CONGRESS OF THE INTERNATIONAL RADIATION PROTECTION ASSOCIATION, Vienna, Austria. Proceedings Vienna:14-19 April. p. 621-623. 1996.

Lauria, D. C.; Rochedo, E. R. R. The legacy of monazite processing in Brazil. Radiation Protection and Dosimetry. v. 114, n 4, p 546 - 550. 2005.

Martinez-Aguirre, A. Garcia-Leon, M. "Radioactive Impact of Phosphate Ore Processing in a Wet Marshland in Southwestern Spain" Journal of Environmental Radioactivity v.34, n.1, p. 45-57. 1997.

Matthews, K. M., Kim, C., Martin, P. Determination of ${ }^{210} \mathrm{Po}$ in environmental materials: A review of analytical methodology. Applied Radiation and Isotopes. v. 65, p 267-279, 2007.

Miranda, L. B.; Castro, B. M.; Kjerfve, B., Princípios de Oceanografia Física de Estuários. Edusp - Editora da Universidade de São Paulo. 2002. 
Mishra, U.C. Environmental radioactivity research - expectations in the new millennium. Journal of Environmental Radioactivity. v. 57 p. 1-5. 2001.

Molinari, J. \& Snodgrass, J.W. The chemistry and radiochemistry of radium and other elements of uranium and thorium natural decay series. IAEA, The Environmental behavior of radium. vol. 1, p. 11 - 56. 1990.

Moon,D. S, Hong, G., Young, K., Baskaran, M., Chung, C. S., Kim, S. H., Lee, H. J., Lee, $S$ H., Povinec, P.P. "Accumulation ofanthropogenic and natural radionuclides in bottom sediments of the Northwest Pacific Ocean" Deep-Sea Research II. v. 50, p. 2649-2673. 2003

Noureddine, A., Baggoura, B "Plutonium Isotopes, ${ }^{137} \mathrm{Cs},{ }^{90} \mathrm{Sr}$ - and Natural Radioactivity in Marine Sediments from Ghazaouet (Algeria)" Journal of Environmental Radioactivity,v. 34, p. 127-138. 1997

Nudat 2.5. Nudat database versão 2.5,

Acessível em <http://www.nndc.bnl.gov/nudat2/> acesso em fevereiro de 2009.

NCRP (1987) Exposure of the population in the USA and Canada from Natural background radiation. Rep. № 94 .

Osmond, J.K. \& Cowart, J.B. The theory and uses of natural uranium isotopic variations in hydrology. Atomic Energy Review.,v. 14 p. 621-679. 1976

Paschoa, A.S. \& Godoy, J.M. The areas of high natural radioactivity and TENORM wastes. International Congress Series. v 1225 p 3 - 8. 2002

Porto de Santos. Apresenta dados sobre a atividade portuária em Santos. Disponível em: www.portodesantos.com.br Acesso em 20/07/2010. 
Ramasamy, V., Suresh, G. Meenakshisundaram, V. Ponnusamy, V. "Horizontal and vertical characterization of radionuclides and minerals in river sediments" Applied Radiation and Isotopes. v 69 p. 184-195. 2011

Randle, K. \& Al-Jundi, J. Instrumental neutron activation analysis (INAA) of estuarine sediments. Journal of Radioanalytical and Nuclear Chemistry, v. 249 (2). p. $361-367.2001$.

Saito, R. T. Determinação de ${ }^{210} \mathrm{~Pb}$ e ${ }^{210} \mathrm{Po}$ em amostras marinhas e aerossóis. 1996. Dissertação (Mestrado) - Instituto de Pesquisas Energéticas e Nucleares, IPEN, São Paulo. 83p.

Salbu, B., Oughton, D.H. Processes affecting the uptake of radioactive species into the envirounment. Radiation Protection Dosimetry. v. 62 n. 1/2. p. 1-4. 1995.

Santos, R. N. Implantação da metodologia de espectrometria alfa para a determinação de isótopos de $U$ e Th em rochas ígneas: aplicação ao estudo do desequilíbrio radioativo na ilha da Trindade. (2001), Tese (Doutorado) Departamento de Geofísica do Instituto Astronômico e Geofísico da USP.

São Paulo (Estado). Secretaria de Economia e Planejamento. Região Metropolitana da Baixada Santista. Disponível em:

<http://www.ppa.sp.gov.br/perfis/PerfilRMBaixadaSantista.pdf> Acesso em 08/09/2010.

Schell, W. R. Concentrations, physico-chemical states and mean residence times of ${ }^{210} \mathrm{~Pb}$ and ${ }^{210} \mathrm{Po}$ in marine and estuarine waters. Geochimica Cosmochimica. Acta, v. 41: p. 1019 - 1031. 1977.

Shaheed, K., Somasundaram, S.S.N. Shehul Hameed, O. lyengar, M.A.R. A study of Polonium - 210 disctribution aspects in the riverine ecossistem of Kaveri, Tiruchirappalli, India. Environmental Pollution, v. 95, n. 3, p. 371-377. 1997. 
Silva, P.S.C. Caracterização química e radiológica dos sedimentos do estuário de Santos, São Vicente e baía de Santos. 2004, Tese (Doutorado) Instituto de Pesquisas Energéticas e Nucleares, São Paulo. 320p.

Silva, A.P. Relatório de avaliação de risco à saúde por exposição a resíduos perigosos em áreas se Itanhaem e São Vicente/SP. 2007.

Silva, P.S.C. Determinação de radionuclídeos pertencentes às series do $238 \mathrm{U}$ e 232Th nos fosfatos do arquipélago de Abrolhos, (BA). 1998, Dissertação (Mestrado) - Departamento de Geofísica do Instituto Astronômico e Geofísico, São Paulo. 83p.

Sirelkhatim, D.A., Sam, A.K., Hassona, R. K., Distribution of ${ }^{226} \mathrm{Ra}-{ }^{210} \mathrm{~Pb}-{ }^{210} \mathrm{Po}$ in marine biota and surface sediments of the Red Sea, Sudam, Journal of Environmental Radioativity., 2008, p. 1-4.

SMA - Secretaria do Meio Ambiente - Educação Ambiental em Unidade de Conservação. Governo do Estado de São Paulo. 1989.

Sombrito, E. Z.; Bulos, A. DM.; Sta. Maria, E. J.; Honrado, M. C. V. Sedimentation rates in Manila bay from ${ }^{210} \mathrm{~Pb}$ profiles. Philippines Nuclear Journal, v. 13 p. 110. 2001

Soto-Jiménez, M.; Páez_Osuna, F. \& Ruiz-Fernandez, A.C. Geochemical evidences of the anthropogenic alteration of trace metal composition of the sediments of Chiricahueto marsh (SE Gulf of California). Environmental. Pollution. 125: 423 - 432, 2007

Stewart, G., Cochram, J. K., Xue, J., Lee, C, Wakehan, S.G., Armstrong, R.A., Masqué, P., Miguel, J. C., Exploring the connection between ${ }^{210} \mathrm{Po}$ and organic matter in the northwestern Mediterranean. Deep-Sea Research. Issue I 54 415427, 2007. 
Suriyanarayanan, S., Brahmanandhan, G.M., Malathi, J., Kumar, S.R., Masilamani, V., Shahul Hameed, P., Selvasekarapandian, S. "Studies on the distribution of ${ }^{210} \mathrm{Po}$ and ${ }^{210} \mathrm{~Pb}$ in the ecosystem of Point Calimere Coast (Palk Strait), India" Journal of Environmental Radioactivity. v.99, p. 766 e 771. 2008

Taylor, S.R. \& McLennan, S.M. The continental crust: Its composition and evolution. An examination of the geochemical record preserved in sedimentary rocks. Blackwell. 1985

Theng, T. L.; Ahmad, Z.; Mohamed, C. A. R. Estimation of sedimentation rates using ${ }^{210} \mathrm{~Pb}$ and ${ }^{210} \mathrm{Po}$ at the coastal water of Sabah, Malaysia. Journal Radioactive Nuclear Chemistry. 256: 115-120. 2003.

Turner, A., Trace metal contamination in sediments from U.K. estuaries: An empirical evaluation of the role of hydrous iron and manganese oxides. Estuary. Coast. And Shelf Sci., v. 50: 355 - 371. 2000.

UNSCEAR: United Nations Scientific Committee on the effects of Atomic Radiation. Sources Effects and Risks of lonizing Radiation. v1, anex c Report to the general Assembly. United Nations, New York, NY. 1988.

UNSCEAR: United Nations Scientific Committee on the effects of Atomic Radiation. Sources Effects and Risks of Ionizing Radiation. Report to the general Assembly. United Nations, New York, NY. 2000.

Valette-Silver, N. J. The use of sediment cores to reconstruct historical trends in contamination of estuarine and coastal sediments. Estuaries. v. 16, $n^{\circ} 3 \mathrm{~B}$, p. $577-$ 588. 1993. 